ANTONIO CARLOS NOGUEIRA

\title{
Estudo das alterações da variabilidade da freqüência cardíaca e troponina no paciente séptico
}

Tese apresentada à Faculdade de Medicina da Universidade de São Paulo para obtenção do título de Doutor em Ciências

Área de concentração: Emergências Clínicas

Orientador: Prof. Dr. Paulo Andrade Lotufo

São Paulo 
Preparada pela Biblioteca da

Faculdade de Medicina da Universidade de São Paulo

(C) reprodução autorizada pelo autor

Nogueira, Antonio Carlos

Estudo das alterações da variabilidade da freqüência cardíaca e troponina no paciente séptico / Antonio Carlos Nogueira. -- São Paulo, 2005.

Tese(doutorado)--Faculdade de Medicina da Universidade de São Paulo.

Departamento de Clínica Médica.

Área de concentração: Emergências Clínicas.

Orientador: Paulo Andrade Lotufo.

Descritores: 1.SEPSE/complicações 2.TROPONINA I 3.FREQÜÊNCIA

CARDÍACA 4.CORAÇÃO/anatomia \& histologia 5.ELETROCARDIOGRAFIA

AMBULATORIAL 6.CHOQUE SÉPTICO

USP/FM/SBD-270/05 
"Mire e veja: o importante e bonito, do mundo, é isto: que as pessoas não estão sempre iguais, ainda não foram terminadas - mas que elas vão sempre mudando. Afinam ou desafinam. Verdade maior. É o que a vida me ensinou."

Riobaldo, personagem de Grande Sertão: Veredas, de Guimarães Rosa 


\section{DEDICATÓRIA}

Aos meus pais: Antenor e Maria

Pelo carinho, dedicação, compreensão e infinita bondade.

Aos meus irmãos: Ana, Angélica,

Humberto, Alessandra e Jair

Pelo apoio em todos os momentos.

\section{A você, "Larinha"}

Pela alegria e significado que você traz às nossas vidas.

Lembre-se de que a vida deve ser uma vitória...

E lembrar de ti, toda vez que a vida mandar olhar para o céu, meu pequeno grande amor

(Beto Guedes)

E a Deus, por todo o resto. 


\section{AGRADECIMENTOS}

Aos professores doutores Paulo Andrade Lotufo e Francisco Garcia Soriano

Pelo privilégio da orientação, amizade, incentivo e empenho para a realização deste trabalho.

Aos amigos: Cristhielaine Venzel, Daniel Luiz Gimenez, Edmir José Marin, Francisco Geraldo Guércio, Kátia Harada, Luiz Gonzaga Ribeiro, Marcelo Nicaretta Scramin, Marcelo Zaninoto, Márcia Pereira, Maria Cleire Teixeira, Marina Passianotto, Mário Lúcio Batista Filho, Marta Scramin, Milena Miranda, Rachel Diniz, Ricardo Harada, Rita Aparecida Gouvêa, Tércia Soares e Wladimir Bacetic Ban

Pela amizade e pela força em todos os momentos desta jornada.

Aos eternos mestres: Adriana Carone, Ailton Beraldo, Alexey Nicolai, Antonia Petrizzo, Antonio Jorge Bichara, Benedita Fieri (in memoriam), Carla Ramalho, Carlos Roberto Ramos, Cássia Bossi, Dieter Seinfield, Expedito E. Ribeiro, Fábio Baptista, Filomena Fieri, Georges Haddad, Hercília Santos, Iran Gonçalves, Jader Rabello, João Augusto Mattar (in memoriam), Jóber Bastos, José Kaoru Kanashiro, Júlio Moribe, Laio Silva, Lélio Alves Silva, Márcia Aparecida Nascimento, Maria Helena Garcia, Maria José Massei, Marília C. L. 
Varella, Mário Linhares Neto (in memoriam), Mário Lúcio Baptista Filho, Milton Linhares, Olavo Ribeiro Rodrigues, Patrícia Barinotti, Paulo Sartori, Renata Fialdini, Renato Chiavassa, Renato Sâmea, Ricardo Salvadori, Rita Aparecida Gouvêa, Ruy Pedroso, Tereza Teruko, Wilson R. Santana e Yara Pompermayer Pelos ensinamentos e estímulo de toda uma vida.

Aos colegas do Hospital Universitário da Universidade de São Paulo (HU-USP): Amaro Duarte, Carla Valeri, Danilo Noritomi, Eduardo Borges, Elton Estumano, Fábio Costa, Joana Barradas, Luiz Gonzaga Ribeiro, Marcelo Lins, Márcia Martins Bernik, Maurício Seckeler, Paolo Bisseli, Patrícia Branquinho, Sylas Cappi, Vitor Kawabata, Vivian Reze e Wagner Hoshino

Pelo apoio e intensa contribuição na realização deste trabalho.

Aos professores doutores Csaba Szabó e Min Chen

Pela realização da imunoistoquímica das lâminas com amostras de miocárdio.

À doutora Ana Cláudia Teixeira

Pela amizade e pela realização dos ecocardiogramas dos pacientes do estudo. 
À professora doutora Elia Garcia Caldini

Pela realização da microscopia eletrônica das lâminas com amostras de miocárdio.

A toda a Equipe da Anatomia Patológica do HU-USP

Pela colaboração na obtenção das lâminas com amostras do miocárdio.

Aos colegas do Hospital Nipo-Brasileiro: Adauto Carvalho, Adriana Dias,Adriana Tirone, Ana Cristina Inamine, Annibal Barros, Ariel Masseto, Carla Petrini, Carlos Azuma, Carlos Manuel de Castro, Carlos Sano, Carlos Yajima, César Brant, Masahiko Akamine, Cláudia Bernoche, Daniela Martins, Eduardo Marlieri (in memoriam), Eduardo Nakagomi, Elizabeth Takitani, Fábio Gazel, Fernando Nakandakare, Flávia Azevedo, Gelson Oshiro, Helena Soufen, Iraci Yoko, Jorge Nakauchi, José Fabri Jr., Júlio Y. Takada, Leonel Carlos, Manfredo Kenji, Márcia Kanegae, Márcio Taira, Mauro Sakyama, Noboru Yassuda, Osvaldo Beppu, Sandra Eguchi, Sandra Passoto, Takuji Okubo, Vera Nunes, Vitor Kareyama, Wlamir Morimitsu e Yu Pin

Obrigado pela oportunidade da convivência.

Aos enfermeiros, técnicos e auxiliares do Hospital Nipo-Brasileiro, do HU-USP e do Hospital São Luiz Morumbi.

Obrigado pela paciência e colaboração. 
Aos fisioterapeutas do Hospital Nipo-Brasileiro, do HU-USP e do Hospital São Luiz Morumbi.

Pelos ensinamentos e convivência nesses anos.

Aos amigos da Associação Escola Graduada de São Paulo: Carlos Salvador, Flávia Bicudo, Fledsneri Silva, Luciana Santiago, Marlene Bustani, Raquel Araújo, Tércia Soares (incansável revisora, tradutora e ouvidora), Willian Castanho, além de todos os professores e funcionários.

Ao ex-superintendente da Escola Graduada, David Tully (in memoriam), sua esposa Elizabeth e seus filhos Joashua, Samuel, Oliver, Dominic e Gedeon

Que Deus llumine seus caminhos e conserve sempre a paz em seus corações.

Aos meus primos, tios, afilhados e padrinhos.

\footnotetext{
A Andréa Dalto

"O tempo é a sua matéria, o tempo presente, as pessoas presentes, a
} vida presente". 


\section{SUMÁRIO}

Introdução

Dedicatória

Agradecimentos

Lista de Abreviaturas

Lista de Figuras

Lista de tabelas

Resumo

Summary

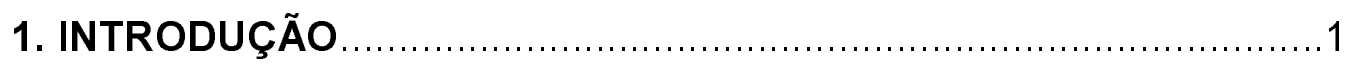

1.1. Sepse

1.2. Síndrome da resposta inflamatória sistêmica .......................

1.3. Hemodinâmica da sepse ...................................................

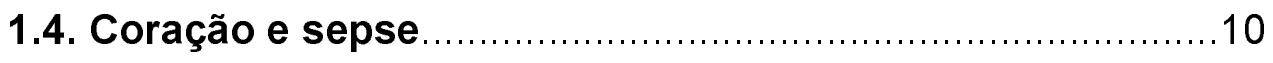

1.4.1. Disfunção cardíaca na sepse...............................12

1.4.2. Variabilidade da freqüência cardíaca.....................16

1.4.3. Variabilidade da freqüência cardíaca e síndrome da disfunção de múltiplos órgãos e sistemas.................18

1.5. Troponinas como marcadores séricos de lesão miocárdica.

1.6. Elevação da troponina na sepse e em pacientes

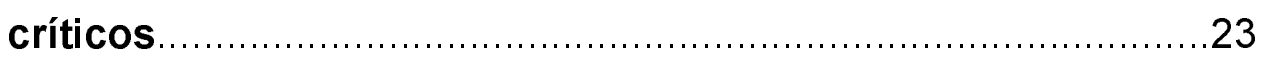

2. OBJETIVOS

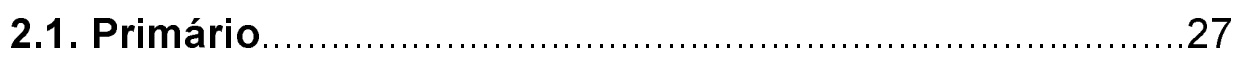

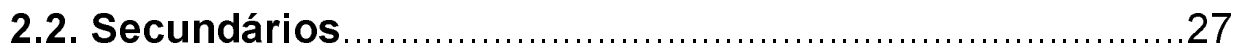


3.1. Desenho do estudo, critérios de inclusão e exclusão....28

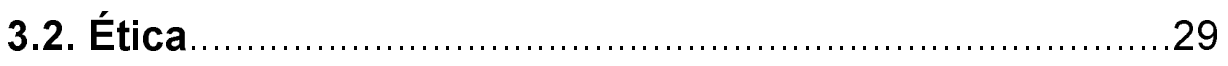

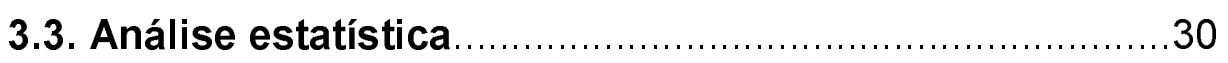

3.4. Avaliação clínica, laboratorial e anátomo-patológica.....30

3.4.1. Variabilidade da freqüência cardíaca e análise do sinal......

3.4.2. Determinação dos níveis séricos de troponina $I .33$

3.4.3. Determinação dos níveis séricos de creatinoquinase (CK).

3.4.4. Determinação dos níveis séricos de creatinoquinase-MB (CK-MB).

3.4.5. Determinação dos níveis séricos de proteina C-reativa.

3.4.6. Determinação dos níveis séricos de bilirrubinas total e frações 35

3.4.7. Determinação sérica da creatinina.........................36

3.4.8. Determinação do nível sérico de uréia...................37

3.4.9. Determinação do nível sérico de potássio.............37

3.4.10. Determinação do nível sérico de sódio. .38

3.4.11. Determinação gasimétrica do sangue arterial e venoso. 38

3.4.12. Hemograma. 39

3.4.13. Cultivo e isolamento de microorganismos. 39

3.4.14. Histologia e imunoistoquímica de fragmentos do miocárdio. .40

3.4.15. Deteç̧ão imunoistoquímica da poli(ADP-ribose) polimerase 40

3.4.16. Microscopia óptica. 41

3.4.17. Microscopia eletrônica. .42

3.4.18. Estudo morfométrico. 42 
4.1. Dados clínicos e demográficos .............................................

4.2. Pesquisa de lesão cardíaca (dados bioquímicos) .............50

4.3. Análise da função cardíaca .................................................

4.3.1. Ecocardiograma e medidas hemodinâmicas.........51

4.4. Análise da variabilidade da freqüência cardíaca..............59

4.4.1. Análise das bandas de freqüência..........................59

4.4.2. Análise do uso de medicamentos que podem alterar a variabilidade da freqüência cardíaca..................62

4.4.2.1. Drogas vasoativas............................................62

4.4.2.2. Doses de sedação recebidas.............................64

4.5. Análise da variabilidade da freqüência cardíaca................66

4.5.1. Correlação da troponina I com o índice de baixa freqüência normalizado.........................................66

4.5.2. Correlação da proteína C-reativa com o índice de baixa freqüência normalizado. 68

4.6. Correlação da poli(ADP-ribose) polimerase com a troponina I e com o trabalho sistólico do ventriculo esquerdo. 69

4.7. Lesões histológicas cardíacas .71

5. DISCUSSÃO

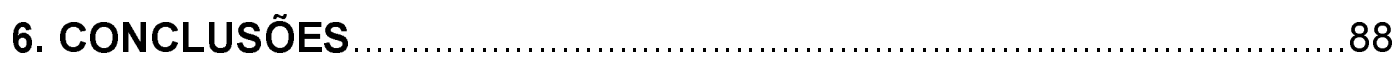

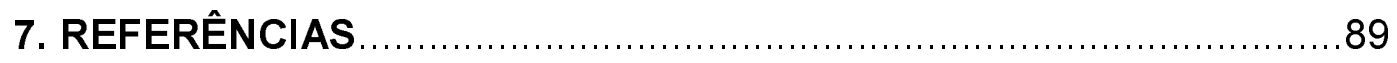

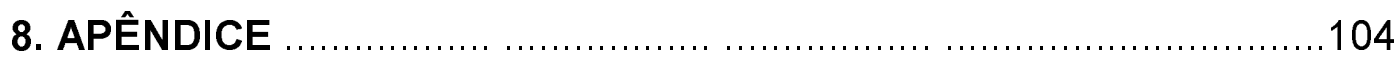


8.1. Cálculo da variabilidade da freqüência cardíaca e medidas e

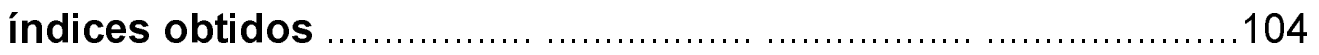

8.1.1. Métodos lineares …............................................. 105

8.1.2. Métodos não-lineares ………............................106

8.2. Análise da variabilidade da freqüência cardíaca no domínio do tempo por meio de índices geométricos.............................. 112

8.3. Análise no domínio da freqüência ……….....................114 


\section{Lista de abreviaturas}

$\begin{array}{ll}\text { AF/HF } & \text { alta freqüência/high frequency } \\ \text { APACHE } & \text { Acute Physiology and Chronic Health Evaluation } \\ \text { BF/LF } & \text { baixa freqüência/low frequency } \\ \text { BPM } & \text { batimentos por minuto } \\ \text { CLP } & \text { punção e ligadura do ceco } \\ \text { CPK } & \text { creatinofosfoquinase } \\ \text { CPK-MB } & \text { creatinofosfoquinase fração MB } \\ \text { DMOS } & \text { disfunção de múltiplos órgãos e sistemas } \\ \text { DPOC } & \text { doença pulmonar obstutiva crônica } \\ \text { G6PDH } & \text { glicose-6-fosfato desidrogenase } \\ \text { ICC } & \text { insuficiência cardíaca congestiva } \\ \text { IL } & \text { interleucina } \\ \text { Intervalo RR } & \text { intervalos entre duas ondas R do eletrocardiograma } \\ \text { ITSVE } & \text { índice do trabalho sistólico do ventrículo esquerdo } \\ \text { LPS } & \text { lipopolissacáride } \\ \text { MBF/NLF } & \text { muito baixa freqüência/very low frequency } \\ \text { Ms } & \text { milisegundos } \\ \text { NAC } & \text { N-acetilcisteína } \\ \text { NADP } & \text { nicotinamida adenina dinucleotídeo fosfato } \\ \text { NADPH } & \text { nicotinamida adenina dinucleotídeo fosfato reduzida } \\ \text { NO } & \text { óxido nítrico } \\ \text { NOS } & \text { óxido nítrico sintase } \\ \text { nu } & \text { normalizado(a) } \\ \text { PARP } & \text { poli(ADP)-ribose polimerase } \\ \text { pNN50 } & \text { porcentagem de intervalos RR adjacentes com } \\ & \text { diferença de duração superior a 50 milisegundos } \\ \text { rMSSD } & \text { raiz quadrada da média do quadrado das diferenças } \\ & \text { entre intervalos RR normais adjacentes } \\ \text { RPM } & \text { respirações por minuto } \\ \text { SDANN } & \text { desvio padrão das médias dos intervalos RR normais } \\ \text { SDNN index } & \text { a cada cinco minutos } \\ \text { SDNN } & \text { média dos desvios padrão dos intervalos RR, } \\ \text { Tn C } & \text { medidos em intervalos de cinco minutos } \\ \text { Tn I } & \text { desvio-padrão das médias dos intervalos RR normais } \\ \text { TNF-a } & \text { troponina C } \\ \text { UBF/ULF } & \text { troponina I } \\ \text { VFC } & \text { fator de necrose tumoral alfa } \\ & \text { ultra baixa freqüência/ultra low frequency } \\ \text { variabilidade da freqüência cardíaca }\end{array}$




\section{LISTA DE FIGURAS}

Figura 1 - Evolução temporal das concentrações plasmáticas de troponina sérica em pacientes sépticos internados em unidade de terapia intensiva, comparando os grupos sobreviventes (SV) e nãosobreviventes (NS). Os dados são representados como erro

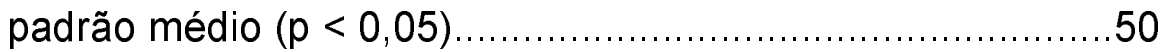

Figura 2 - Evolução temporal do índice de trabalho do ventrículo esquerdo por sístole, comparando os grupos sobreviventes (SV) e nãosobreviventes (NS), entre pacientes sépticos internados em unidade de terapia intensiva. Os dados são representados como erro padrão médio $(p<0,05)$ 57

Figura 3 - Diferença do volume diastólico final do ventrículo nos grupos de pacientes sobreviventes (SV) e não-sobreviventes (NS) internados em unidade de terapia intensiva com sepse. Os dados são representados como erro padrão médio $\left({ }^{*} \mathrm{p}<0,05\right)$

Figura 4A - Índices de baixa freqüência (BF) cardíaca, máxima e mínima, na análise da variabilidade de freqüência cardíaca de pacientes sépticos internados em unidade de terapia intensiva. Os dados foram representados como erro padrão médio $\left({ }^{*} \mathrm{p}<0,05\right)$ 60

Figura 4B - Dados de alta freqüência (AF) cardíaca, da análise da variabilidade da freqüência cardíaca de pacientes sépticos internados em unidade de terapia intensiva, representados como erro padrão médio $\left({ }^{*} p<0,05\right)$. 61

Figura 5 - Quantidade de catecolaminas recebidas pelo pacientes sépticos internados em unidade de terapia intensiva. Não houve diferença significativa entre os dois grupos, de sobreviventes (SV) e não-sobreviventes (NS) 63

Figura 6 - Quantidade de sedativos utilizadas pelo grupo de sobreviventes (SV) e não-sobreviventes (NS) internados em unidade de terapia intensiva. Os dados foram representados como erro padrão médio $\left({ }^{*} \mathrm{p}<0,05\right)$. 65

Figura 7 - Correlação da troponina I com a baixa freqüência normalizado (Bfnu) nos pacientes sobreviventes no primeiro dia de internação em unidade de terapia intensiva. 
Figura 8 - Correlação da troponina I com a baixa freqüência normalizado (Bfnu) nos pacientes sépticos não-sobreviventes no primeiro dia de internação em unidade de terapia intensiva.

Figura 9 - Correlação da proteína C-reativa com 0 índice de baixa freqüência cardíaca normalizado (BFnu) no grupo de pacientes sépticos sobreviventes no primeiro dia do estudo, realizado em unidades de terapia intensiva. 68

Figura 10 - Correlação da proteína C-reativa com o índice de baixa freqüência cardíaca normalizado (BFnu) no grupo de pacientes sépticos não-sobreviventes no primeiro dia do estudo, realizado em unidades de terapia intensiva. 69

Figura 11 - Correlação da poli(ADP-ribose) polimerase (PARP) com os níveis de troponina sérica em pacientes sépticos internados em unidade de terapia intensiva. .70

Figura 12 - Correlação da poli(ADP-ribose) polimerase (PARP) com o trabalho sistólico do ventrículo esquerdo (VE) em pacientes sépticos internados em unidade de terapia intensiva........70

Figura 13 - Microscopia óptica com coloração de hematoxilina-eosina de lâminas de miocárdio normal (aumento de $100 \mathrm{x}$ ). 72

Figura 14 - Microscopia óptica de miocárdio de paciente em sepse, demonstrando intenso infiltrado inflamatório (coloração por hematoxilina-eosina, aumento de $40 \mathrm{x}$ )...... 73

Figura 15 - Microscopia óptica de miocárdio de paciente em sepse, em maior aumento (100 x, coloração por hematoxilina-eosina), mostrando aumento no número de células inflamatórias no tecido cardíaco.

Figura 16 - Microscopia eletrônica do miocárdio (aumento de $16.800 \mathrm{~K}$, coloração por acetato e citrato de chumbo). A lâmina à esquerda demonstra distribuição normal das mitocôndrias em paciente com coração normal (não incluído neste estudo). A lâmina à direita, com amostra do miocárdio de um paciente séptico incluído, é exemplo do aumento importante do número de mitocôndrias e sua distribuição na sepse. 75

Figura 17 - Microscopia eletrônica do miocárdio de paciente em sepse demonstrando aumento do número e destruição de cristas mitocondriais. (aumento $28.000 \mathrm{~K}$, coloração por uranil acetato e citrato de chumbo) 76 
Figura 18 - Coloração red de Picrosirius demonstrando infiltração de colágeno no miocárdio em paciente do grupo de nãosobreviventes (aumento de $40 \mathrm{x}$ ). 77

Figura 19 - Análise imunoistoquímica do miocárdio evidenciando a ativação da poli(ADP-ribose) polimerase em paciente do grupo de não-sobreviventes (aumento de 40 x, coloração múltipla usada em imunoistoquímica) .78

\section{FIGURAS DO APÊNDICE}

Figura 1. SDNN: desvio-padrão da média de todos os intervalos RR normais, em gravação de 24 horas, expresso em milissegundos (ms). Neste exemplo simbólico e abreviado, a média equivale a $846 \mathrm{~ms}$ e o desviopadrão (ou SDNN) a $107 \mathrm{~ms}$. Em termos simples, desvio-padrão é um modo de representar a dispersão dos valores ao redor da média. Para distribuições Gaussianas, permite inferir que aproximadamente $68 \%$ dos valores situamse entre menos um e mais um desvios-padrão (entre 739 e $953 \mathrm{~s}$, no caso acima), $95 \%$ entre dois desvios-padrão e $99 \%$ entre três desvios-padrão.

Figura 2. SDANN: desvio-padrão das médias dos intervalos RR normais a cada cinco minutos, em gravação de 24 horas, expresso em milissegundos (ms). Neste exemplo, a média dos seis segmentos, de cinco minutos cada, equivale a $846 \mathrm{~ms}$, e o desvio-padrão dessas médias (ou SDANN), a 103 ms. Por se tratar de desvio-padrão de um valor médio obtido a partir de outras médias, seu valor é sempre inferior ao do SDNN em períodos longos de monitorização. 109

Figura 3. SDNN index: média dos desvios-padrão dos intervalos RR normais a cada cinco minutos, expressa em milissegundos (ms). Neste exemplo, equivale a $47 \mathrm{~ms}$. Seu valor geralmente é inferior ao do SDNN e SDANN.

Figura 4. pNN50: percentagem de intervalos RR adjacentes com diferença de duração maior que 50 milissegundos (ms). Neste exemplo equivale a $30 \%$, ou seja, dos 10 intervalos RR adjacentes, apenas três (o $2^{\circ}$, o $8^{\circ}$ e o $10^{\circ}$ ) apresentam diferença de duração superior a $50 \mathrm{~ms}$. 111

Figura 5. rMSSD: raiz quadrada da média do quadrado das diferenças entre intervalos RR normais adjacentes, expressa em milissegundos (ms). Neste exemplo simplificado, é calculada por meio desta fórmula específica ${ }^{1,2} \ldots . .111$

Figura 6. Análise da variabilidade da freqüência cardíaca (VFC) no domínio da freqüência: após a representação gráfica dos intervalos $R R$ em relação ao tempo (tacograma), o sinal eletrocardiográfico é decomposto em 
componentes de freqüência através da transformação rápida de Fourier ${ }^{3}$ (modelo autoregressivo).

Figura 7. Três ritmos distintos: alta freqüência, em verde (15 ciclos/minuto ou $0,25 \mathrm{~Hz}$ ); baixa freqüência, em laranja (6 ciclos/minuto ou $0,1 \mathrm{~Hz}$ ) e muito baixa freqüência, em vermelho ( 1 ciclo/minuto ou $0,016 \mathrm{~Hz}$ ). 116

Figura 8. Sinal complexo resultante da combinação dos três fenômenos ondulatórios representados na Figura 7 (equivalente ao tacograma de RR).

Figura 9. Resultado da análise espectral realizada no sinal representado na Figura 8, com identificação das três faixas de freqüência $(0,016,0,1 \mathrm{e}$ $0,25 \mathrm{~Hz}$ ) 116

Figura 10. Componentes espectrais do tacograma (bandas de freqüências, nervos eferentes e moduladores fisiológicos) 


\section{LISTA DE TABELAS}

Tabela 1 - Características dos pacientes com evolução a óbito em até seis horas da admissão em unidade de terapia intensiva e que foram excluídos do estudo. 44

Tabela 2 - Diagnóstico, realização de cirurgia ou não e tempo de sobrevida dos seis pacientes que evoluíram a óbito nas primeiras seis horas de admissão na unidade de terapia intensiva (todos do sexo masculino) e que foram excluídos do estudo... 45

Tabela 3 - Característica dos 25 pacientes sépticos internados em unidade de terapia intensiva e analisados neste estudo.

Tabela 4 - Origem da sepse e bactérias identificadas em 25 pacientes sépticos internados em unidade de terapia intensiva e incluídos neste estudo. 47

Tabela 5 - Idade, gênero, diagnóstico e tempo de sobrevida dos pacientes sépticos não-sobreviventes (óbito tardio) internados em unidade de terapia intensiva. .48

Tabela 6 - Idade, diagnóstico e realização de cirurgia no grupo de pacientes sépticos internados em unidade de terapia intensiva e sobreviventes. 49

Tabela 7 - Dados do ecocardiograma realizado no primeiro dia do estudo nos pacientes sépticos internados em unidade de terapia intensiva que evoluíram a óbito tardio. 52

Tabela 8 - Dados do ecocardiograma realizado no primeiro dia do estudo, à admissão em unidade de terapia intensiva, nos pacientes sépticos e que sobreviveram.

Tabela 9 - Dados do ecocardiograma realizado no primeiro dia do estudo, no grupo de pacientes sépticos que evoluíram a óbito em até seis horas da admissão em unidade de terapia intensiva. Em dois doentes, não houve tempo hábil para a realização do ecocardiograma. 54

Tabela 10 - Dados ecocardiográficos no sexto dia de internação em unidade de terapia intensiva dos pacientes sépticos que evoluíram a óbito. Dois doentes não aparecem na Tabela por terem evoluído a óbito no quinto dia. 
Tabela 11 - Dados ecocardiográficos no sexto dia de internação em unidade de terapia intensiva dos pacientes sépticos sobreviventes............................................................56

\section{TABELA DO APÊNDICE}

Tabela 1. Valores normais dos índices de variabilidade da freqüência cardíaca (VFC). 120 


\section{Resumo}

CONTEXTO: Estudos observacionais têm demonstrado alterações na variabilidade da freqüência cardíaca em pacientes em sepse, embora não exista publicação correlacionando lesão cardíaca causada pela inflamação sistêmica e redução da variabilidade da freqüência cardíaca. OBJETIVOS: Determinar, em pacientes em sepse, se a lesão cardíaca é causa das alterações da variabilidade da freqüência cardíaca e sua correlação com a mortalidade. Analisar também a associação entre evolução clínica e variabilidade da freqüência cardíaca, troponina, lesão celular à microscopia eletrônica e óptica e variáveis hemodinâmicas. MÉTODO: Estudo observacional, prospectivo, entre pacientes que desenvolveram sepse grave ou choque séptico, analisando sobrevida. Foram analisados: variabilidade da freqüência cardíca (alta e baixa freqüência, através da monitorização cardíaca contínua), dosagem dos níveis séricos de troponina, creatinofosfoquinase e creatinofosfoquinase fração MB, proteína C-reativa, alterações morfológicas e funcionais das células cardíacas por microscopia óptica e eletrônica e imunoistoquímica. Os dados hemodinâmicos foram obtidos por ecocardiograma e medida direta por cateter de artéria pulmonar. RESULTADOS: Dos 31 pacientes incluídos, 12 (38,7 \%) morreram durante 0 acompanhamento de 6 dias e 13 sobreviveram até o $28^{\circ}$ dia $(41,9 \%) ; 6$ pacientes $(19,4 \%)$ morreram nas primeiras 6 horas do estudo. $O$ índice APACHE, utilizado como marcador prognóstico, foi igual nos dois grupos (27 +/- 2,6 nos sobreviventes e 26 +/- 2 nos não sobreviventes). A troponina plasmática se mostrou marcador de disfunção miocárdica na sepse 
(sobreviventes: $0,53+/-0,13 \mathrm{mg} / \mathrm{ml}$, e não-sobreviventes: $2,31+/-1,01$ $\mathrm{mg} / \mathrm{ml}, \mathrm{p}<0,05)$, com informação prognostica, e se correlacionou com os piores dados hemodinâmicos do grupo de não-sobreviventes (índice de trabalho sistólico do ventrículo esquerdo no grupo de sobreviventes de 48,1 +/- 6,7 g.m/m $/ \mathrm{m}^{2}$ e no de não-sobreviventes de $34,0+/-6,7 \mathrm{~g} \cdot \mathrm{m} / \mathrm{m}^{2}, \mathrm{p}<0,05$ ). A variabilidade da freqüência cardíaca diminuída se correlacionou com pior prognóstico e a análise multivariada apontou a baixa freqüência cardíaca como uma variável independente para predizer alta da unidade de terapia intensiva $\left(280+/-25 \mathrm{~ms}^{2}\right.$ nos sobreviventes e $84+/-7,2 \mathrm{~ms}^{2}$ nos pacientes que evoluiram a óbito, freqüência mínima $129+/-19 \mathrm{~ms}^{2}$ e $65+/-9 \mathrm{~ms}^{2}$ na freqüência máxima, $p<0,05)$. A microscopia do coração evidenciou infiltrado inflamatório difuso e aumento do número de mitocôndrias e destruição destas organelas. CONCLUSÃO: Nossos resultados sugerem que a alteração da variabilidade da freqüência cardíaca está relacionada com a evolução para óbito, e correlaciona-se com a lesão cardíaca diagnosticada pela dosagem de troponina sérica e alteração do índice do trabalho sistólico do ventrículo esquerdo por sístole. A histologia do coração demonstrou importante lesão celular do coração, com destruição e aumento do número de mitocôndrias. 


\section{SUMMARY}

CONTEXT: Observational studies have shown alterations in the variability of heart rate in patients with sepsis, although there is not a published study showing correlation to cardiac lesion caused by systemic inflammation and reduction on the heart rate variability. OBJECTIVE: To determine, in patients in sepsis, if the cardiac lesion is caused by the alteration on the heart rate variability and access its correlation with mortality; and also, to analyze the association between clinical evolution and cardiac rate variability, plasmatic troponin, cellular lesion on electronic microscopy and optic and the patients' hemodynamic data. METHOD: Observational study among patients that developed sepsis or septic shock, analyzing the survivors' rate. The heart rate variability was analyzed (high and low rate through continuous cardiac monitorization), as well as plasma levels of troponin, $\mathrm{CK}, \mathrm{CK}-\mathrm{MB}, \mathrm{C}$-reactive protein, the morphologic alterations and of cardiac cells' function, through electronic and optic microscopy and through immunohistochemistry. The hemodynamics' data were analyzed though echocardiogram and pulmonary artery catheter. RESULTS: Among 31 patients included, 12 (38.7\%) of them

died during the course of 6 days and $13(41.9 \%)$ survived until the $28^{\text {th }}$ day, 6 (19.4\%) died within the first 6 hours of the study. The APACHE index, used as a prognostic marker, was the same in both groups $(27+/-2.6$ in the survivor group and $26+/-2.0$ in the non-survivors group). The plasmatic troponin became a marker in the myocardial dysfunction in sepsis (survivors 
$0.53+/-0.13 \mathrm{mg} / \mathrm{ml}$ and non-survivors $2.31+/-1.01 \mathrm{mg} / \mathrm{ml}, p<0.05$ ), with prognostic information, and it correlated with the worst hemodynamic parameters among non-survivor's group (left ventricle systolic index was 48.1 $+/-6.7 \mathrm{~g} \cdot \mathrm{m} / \mathrm{m}^{2}$ in survivors and $34.0+/-6.7 \mathrm{~g} \cdot \mathrm{m} / \mathrm{m}^{2}$ in non survivors group, $\mathrm{p}<$ 0.05). The decrease on the heart rate variability was correlated with the worst prognoses and analyses pointed to a low rate as an independent variable to predict the patient's discharge from the intensive care unit $\left(280+/-25 \mathrm{~ms}^{2}\right.$ among survivors and $84+/-7.2 \mathrm{~ms}^{2}$ among non-survivors). The heart microscopy showed diffused inflammatory infiltration and increase in the number of mitochondrias and lesions in these organelles. CONCLUSION: Our results suggest that the alteration of the variability on the heart rate is related with the evolution to death, and correlated to cardiac lesion, evidenced through the dosage of troponin, and to alteration of the systolic workload of the left ventricle by systole. The heart histology demonstrated important cellular lesion of the heart, with a raise in number of and damage to mitochondrias. 


\section{INTRODUÇÃO}

\subsection{Sepse}

A invasão da corrente sangüínea ou de tecidos por microorganismos, tais como bactérias Gram-negativas, Gram-positivas, fungos e vírus, pode levar ao quadro conhecido como sepse. Em 1992, a sepse foi definida pela Conferência da Sociedade de Terapia Intensiva Americana como uma resposta sistêmica à infecção, manifestada pela presença de dois ou mais sintomas: a) temperatura $>38^{\circ} \mathrm{C}$ ou $<36^{\circ} \mathrm{C}$; b) freqüência cardíaca $>90$ bpm; c) freqüência respiratória acima de $20 \mathrm{rpm}$ ou $\mathrm{PaCO}_{2}<32$ torr e contagem de leucócitos acima $12.000 / \mathrm{mm}^{3}$ ou $<4.000 / \mathrm{mm}^{3}$.

A sepse representa um subgrupo da síndrome da resposta inflamatória sistêmica (SIRS)]. ${ }^{2}$ As bactérias Gram-positivas e Gram-negativas são as responsáveis pela maioria dos casos da sepse $(36 \%$ e $35 \%$, respectivamente), no entanto, a progressão da doença não é influenciada pela natureza da bactéria causadora. Quando o choque séptico se instala, ocorre hipotensão arterial sistêmica e hipoperfusão tecidual e esse estado pode progredir para falência de múltiplos órgãos e sistemas. ${ }^{3,4}$ A SIRS pode ocorrer também em associação com grande variedade de eventos nãoinfecciosos, como por exemplo: politraumatismo, cirurgia, pancreatite e queimadura. $^{2}$ 
A relevância da sepse é evidenciada pelos seguintes dados: necessidade de internação dos pacientes acometidos em unidade de terapia intensiva (UTI), com altos custos monetários para o tratamento; aumento da incidência de sepse em pacientes internados em hospitais e UTIs nas últimas décadas; altas mortalidade e ocorrência de complicações e falências de órgãos. ${ }^{5,6}$

Dados dos Estados Unidos indicam que a sepse grave é responsável por mais de 250.000 mortes anuais a partir de uma população total de 750.000 pacientes, com taxa média de mortalidade de aproximadamente $29 \% .{ }^{7}$ O Estudo SOAP (Sepsis Ocurrence in Acutely III Patients), em vias de publicação) encontrou que $37,4 \%$ dos pacientes admitidos em UTI cursaram com sepse e $24,7 \%$ deles apresentavam sepse na admissão; o trabalho demonstrou forte correlação entre presença de sepse e mortalidade. ${ }^{8}$

No Brasil, o Estudo BASES (Brazilian Sepsis Epidemiological Study) ${ }^{9}$ mostrou que a letalidade na sepse é de $33,9 \%$ e, no choque séptico, $52,2 \%$. Esses são dados compatíveis com a literatura mundial, em que sepse grave e choque séptico estão associados a taxas de mortalidade de 30 a $60 \%$ das admissões em UTI. ${ }^{10}$

A mortalidade por sepse permanece alta, similar à que ocorre por infarto agudo do miocárdio e acidente vascular cerebral, não se modificando apesar do desenvolvimento de novos antibióticos e do aprimoramento de medidas de tratamento intensivo..$^{5,6,11,12} \mathrm{O}$ tratamento atual permanece de suporte e direcionado para o controle da infecção e correção de distúrbios hemodinâmicos. ${ }^{3,4}$ Novas estratégias para o tratamento da sepse foram 
focadas em inibidores da endotoxina (anticorpos anti-endotoxina), em inibidores de citocinas (como o fator de necrose tumoral, TNF) e em bloqueadores de produção de substâncias vasoativas (óxido nítrico), ${ }^{13}$ no uso de corticosteróides em doses baixas, ${ }^{14}$ no controle intensivo da glicemia $^{15-18}$ e na otimização hemodinâmica dos pacientes sépticos na sala de emergência. ${ }^{19}$

\subsection{Síndrome da resposta inflamatória sistêmica}

A síndrome da resposta inflamatória sistêmica (SIRS) é um processo contínuo caracterizado por uma resposta anormal generalizada do hospedeiro atingindo órgãos remotos à agressão. A resposta de citocinas é regulada por uma intrincada rede de mediadores, que mantêm a resposta inflamatória inicial sob controle, com redução da produção e contrabalanço dos efeitos de citocinas pró-inflamatórias já produzidas. Em alguns pacientes, não se restabelece a homeostasia e, nesse estágio, o controle é perdido, ocorrendo uma intensa reação inflamatória. ${ }^{20,21}$

A SIRS é mediada por citocinas produzidas nos macrófagos, que estimulam receptores de órgãos-alvo em resposta à infecção. As citocinas são mediadores primários ou secundários. Os mediadores primários são o fator de necrose tumoral- $\alpha$ (TNF- $\alpha$ ), as interleucinas 1,6 e 8 (IL-1, IL-6 e IL8). ${ }^{22,23}$ Esses estimulam a liberação de mediadores secundários, tais como outras citocinas, derivados do ácido araquidônico (prostaglandina E2, ou 
$\mathrm{PGE}_{2}$, e tromboxano 2, ou $\mathrm{TXA}_{2}$ ), o fator ativador de plaquetas (PAF), peptídeos vasoativos, tais como bradicinina, angiotensina e peptídeo intestinal vasoativo, aminas, tais como histamina e serotonina, e uma variedade de produtos derivados do complemento. ${ }^{10}$

Há trabalhos da literatura propondo que a sepse é caracterizada por curto período da "síndrome de resposta inflamatória sistêmica" (SIRS) seguido por um sustentado período de imunossupressão e antiinflamação chamado de "síndrome da resposta antiinflamatória compensatória" (CARS). Outros propõem que a SIRS evolui pela liberação de citocinas próinflamatórias, tais como TNF- $\alpha$, IL-1 $\beta$ etc., concomitantemente à CARS. A CARS é caracterizada por defeito em apresentação de antígeno, "paralisia" de macrófagos, anergia de células $\mathrm{T}$, supressão de proliferação de células $\mathrm{T}$, diminuição da proliferação de células Th1 e aumento de apoptose das células B e T. Muitos dos efeitos da fase CARS são mediados pela IL-10. ${ }^{24}$

A resposta a imunológica é realizada pela sucessão dos mecanismos inatos e adaptativos, ou seja, nas fases iniciais da infecção, há predomínio das respostas inatas e, nas fases mais tardias, os linfócitos passam a gerar respostas imunológicas adaptativas. ${ }^{25} \mathrm{~A}$ principal diferença entre estes dois tipos de resposta é que a resposta imunológica adaptativa é altamente específica e é memorizada. A expansão clonal dos linfócitos em resposta a um agente infeccioso é absolutamente necessária para geração de uma resposta imunológica eficiente. O desenvolvimento de clones diferenciados em células efetoras leva de três a cinco dias. Esse período de tempo é o 
bastante para que as bactérias produzam danos sérios ou a morte do hospedeiro. $^{25}$

Os linfócitos "memorizam" a estrutura do agente agressor e passam a responder mais rápida e eficientemente no caso de haver reinfecção pelo mesmo patógeno. Por outro lado, os mecanismos efetores da imunidade inata (peptídeos antimicrobianos, fagócitos e via alternativa do complemento) são ativados imediatamente após a invasão. A resposta imunológica inata utiliza sistemas de reconhecimento primitivos e inespecíficos, que permitem sua ligação a muitos produtos microbianos. ${ }^{25}$ Essas estruturas são chamadas de "padrões moleculares associados a patogéno" (PAMPs) (por exemplo, peptidoglicanos, ácidos lipoteicóicos, DNA das bactérias etc.), e os receptores do sistema da imunidade inata que estão envolvidos no reconhecimento dos PAMPs são chamados receptores de reconhecimento do padrão (PRR). Eles estão expressos em muitas células efetoras do sistema inato, tais como neutrófilos polimorfonucleares, macrófagos, células dendríticas e células B - as células "profissionais" de apresentação de antígeno. ${ }^{20}$

O lipopolissacáride (LPS) da membrana externa de várias famílias microbianas gram-negativas é constituído de duas partes: 1) O lipídio A, que consiste em unidades dissacarídicas de glicosamina fosforilada, as quais estão ligadas a alguns ácidos graxos de cadeia longa. $\mathrm{O}$ ácido betahidroximirístico (C14) está sempre presente e é próprio deste lipídio. Os outros variam com a espécie bacteriana. O lipídio A constitui a endotoxina das bactérias Gram-negativas. 2) O denominado antígeno $\mathrm{O}$, um 
polissacarídio que se projeta até a superfície da bactéria e representa o mais importante antígeno de superfície destes microorganismos. Nesse polissacarídio, distinguem-se: a) um cerne (comum a todos os Gramnegativos) e formado por uma cadeia ramificada de 10 açúcares, que se une ao lipídio $A ;$ b) uma série terminal de unidades glicosídicas repetitivas (por exemplo, -manose-ramnose-galactose-, repetida 25 vezes, em uma Salmonella). ${ }^{26} \mathrm{O}$ antigeno $\mathrm{O}$ é característico e único para cada sorotipo bacteriano, tornando-se, então, um importante fator identificador. O LA representa o princípio endotóxico do LPS. De acordo com o conhecimento presente, é o LA bioativo, de característica anfofílica, que em meio aquoso forma micelas e em condições fisiológicas apresenta-se exclusivamente em estrutura não-laminar, mas cúbica ou hexagonal. Entretanto, a atividade endotóxica é mediada pelas moléculas singulares com conformação peculiar. $^{27}$

Os LPS-PRRs reconhecem LPS, encontrado exclusivamente em bactérias Gram-negativas, e "alertam" o sistema imunológico sobre a presença das bactérias. ${ }^{20} \mathrm{O}$ reconhecimento de microorganismos invasores pelo sistema imunológica inato leva à produção de sinais que controlam a ativação da resposta imunológica adaptativa. O sistema imunológico adaptativo responde de forma eficiente ao patógeno somente depois que este é reconhecido e os seus antígenos são apresentados pelo sistema imunológica inato aos linfócitos $B .^{20}$

Depois da entrada do LPS na corrente sangüínea, pelo menos duas proteínas, LBP (lipopolysaccharide-binding protein) e CD14, competem para 
a ligação com esta macromolécula tóxica, com conseqüências contrastantes para o hospedeiro. A ligação do LPS à LBP sérica facilita a transferência de LPS para CD14, HDL e proteínas séricas (lipoproteínas, lipoproteínas ricas em triglicerídeos), aumentando a atividade de LPS e lipídeo $A^{28,29}$ Por outro lado, quando LPS é transferido para lipoproteínas, o seu efeito tóxico é neutralizado e a resposta inflamatória no hospedeiro é efetivamente interrompida. Depois da associação com fatores séricos, LPS interage com receptores expressos pelas células-alvo da endotoxina, tais como granulócitos, linfócitos, células endoteliais e, em particular, monócitos/macrófagos. ${ }^{28,29}$

O CD14 é uma proteína superficial de monócitos que facilita a ativação celular induzida pelo LPS. O CD14 participa na apresentação de LPS para o receptor similar ao toll (toll-like receptor) tipo 4 (TLR4); este receptor ativa os leucócitos para a secreção de citocinas e inicia a resposta inflamatória aguda. Outra proteína, MD-2, é necessária para reconhecimento de LPS via TLR4. ${ }^{30,31}$ Os receptores como TLRs induzem CD80 ou CD86 a aparecerem em células apresentadoras de antígeno. A célula $\mathrm{T}$ recebe sinais para ativação apenas se o seu receptor se ligar ao PAMP/LPS (sinal de coestimulação) e se um outro receptor de antígeno reconhecer LPS em forma de uma molécula ligada ao complexo principal de histocompatibilidade do próprio organismo (MHC) de classe II. Reconhecimento de LPS na ausência de moléculas CD80, CD40 ou CD86 resulta em permanente inativação, apoptose ou tolerância de células $\mathrm{T}^{32,33}$ Assim, esse mecanismo assegura 
que, normalmente, somente células $\mathrm{T}$ específicas para determinado patógeno sejam ativadas.

Além disso, o ambiente das citocinas (IL-12) secretadas pelas células apresentadoras de antígenos determina a subpopulação de células $\mathrm{T}$ a ser produzida a partir das células Th0. Depois da ativação, as células T auxiliares tipo 1 (Th1, possivelmente, também tipo 3) controlam outras unidades de imunidade adaptativa, tais como as células $\mathrm{T}$ citotóxicas, células $\mathrm{B}$ e macrófagos. ${ }^{34} \mathrm{~A}$ resposta resultante integra a defesa do hospedeiro.

O evento central na cascata fisiopatológica da sepse é uma liberação sistêmica excessiva de citocinas pro-inflamatórias, tais como, TNF $\alpha$, interleucinas (IL)-1, IL-6, IL-12, IL-18, e interferon- $\gamma(\mathrm{INF} \gamma)$ em resposta ao LPS. Essas citocinas ativam sistemas celulares (fagócitos e endotélio) e humoral (vias de coagulação e ativação de complemento, mediadores de baixo peso molecular), os quais são primariamente orientados para eliminação de bactérias invasoras, mas ocasionalmente se tornam inflamação generalizada, auto-destrutiva, e conseqüente falência de múltiplos órgãos. Mecanismos de disfunção de órgãos na sepse dependem do evento fisiopatológico inicial e das condições clínicas do paciente. ${ }^{35,36}$ 


\subsection{Hemodinâmica da sepse}

A alteração da resistência vascular periférica é o fato que determina o padrão hemodinâmico encontrado no quadro séptico. A vasodilatação, que não é uniforme no leito vascular, não ocorre simplesmente devido a um aumento do calibre basal dos vasos ou perda da vasoconstrição, mas também devido à abertura de shunt comunicando o lado arterial ao venoso sem passar pelos capilares. ${ }^{37}$

O aumento na síntese da enzima óxido nítrico sintetase induzível, em células tais como macrófagos, endotélio e musculares lisas do vaso, cria o meio para uma produção continuada e elevada de óxido nítrico. A óxido nítrico sintetase induzível é expressa após estímulo com citocinas próinflamatórias como o TNF- $\alpha$, interleucinas (IL-1,IL-2,IL-6) e interferon-gama, que são todos parte do gatilho da cascata inflamatória, ativados pela endotoxina. $^{38}$

O óxido nítrico produz vasodilatação e reduzida resposta a drogas vasoconstritoras, ${ }^{39,40}$ podendo ainda estar associado a depressão miocárdica devido à alteração no metabolismo oxidativo das mitocôndrias. ${ }^{41}$ As ações fisiológicas compensatórias à vasodilatação desencadeadas são: descarga adrenérgica, aumento da freqüência cardíaca e aumento do débito cardíaco. $^{39,40}$ A hipotensão no choque séptico tem sido revertida usando-se análogos da L-arginina, como a NG-mono-metil-L-arginina (L-NMMA) e a 
NG-nitro-L-arginina-metil-éster (L-NAME), como bloqueadores competitivos da óxido nítrico sintase, em estudos animais e na sepse humana. ${ }^{41}$ Esses estudos mostraram aumento na pressão arterial e diminuição de necessidades do uso de drogas vasoativas; entretanto, os estudos clínicos da fase 3 do uso da L-NMMA no choque séptico foram suspensos devido ao aumento da mortalidade no grupo que recebeu o tratamento, possivelmente devido à inibição não somente da produção excessiva do óxido nítrico, mas também da produção basal, resultando em excessiva vasoconstrição e uma redução no débito cardíaco, talvez combinada com depressão miocárdica. ${ }^{42}$

\subsection{Coração e sepse}

Apesar de os efeitos da sepse sobre a função cardíaca terem sido objeto de muitas investigações, eles permanecem não completamente esclarecidos. Estudos experimentais em animais têm mostrado que a disfunção cardíaca se relaciona com a dose de LPS e com a bactéria. Contudo, em humanos, a disfunção cardíaca é independente do agente bacteriano. $^{43,44}$

A análise da participação do coração nas alterações hemodinâmicas apresenta inúmeras restrições técnicas, pois há alterações vasculares periféricas que influenciam o desempenho cardíaco, alterando pré e póscarga. Adicione-se a isso o fato de que, na fase inicial da sepse, o sistema 
simpático-adrenal está ativado, estimulando o inotropismo e cronotropismo cardíaco, que podem mascarar a depressão cardíaca presente. ${ }^{45,46}$

Por muito tempo tem-se considerado que o coração é um dos últimos órgãos a ser afetado pela sepse e, quando acometido, leva à morte. Entre os primeiros dados de disfunção cardíaca na sepse humana, a queda no débito cardíaco de pacientes que evoluíram para óbito foi a primeira a ser descrita. ${ }^{45}$ Porém, o que é encontrado rotineiramente durante a evolução da sepse é a presença de alto débito cardíaco. Desta forma, se faz necessária a procura de outros índices que avaliem a função cardíaca durante o estado de alto débito. Entre os possíveis a serem utilizados à beira do leito há a determinação da contratilidade cardíaca através do índice de trabalho por sístole, que está freqüentemente reduzido. Muitos estudos mostraram que as curvas de desempenho cardíaco (trabalho sistólico versus pressão de oclusão capilar pulmonar) nos pacientes em sepse estão deslocadas para a direita e para baixo. Os pacientes que sobrevivem apresentam retorno da curva para o normal; por outro lado, os que não sobrevivem mantêm a curva baixa mesmo na presença de drogas vasoativas. ${ }^{45,47,48}$

A redução da função cardíaca pode ser decorrente de alterações na perfusão coronariana. Os estudos analisando esse aspecto mostraram que o paciente em sepse apresenta fluxo coronariano elevado em relação ao de pessoas normais. Contudo, a diferença seio coronário-arterial de conteúdo de oxigênio e extração miocárdica de oxigênio mostrou-se reduzida em outros estudos. Esse cenário parece representar o quadro de alterações hemodinâmicas que ocorre no organismo durante a sepse, podendo haver 
desregulação metabólica ou alteração na distribuição da perfusão miocárdica, com áreas hipoperfundidas e outras com hiperperfusão. O metabolismo do miocárdio está alterado, alterando a capacidade de extração de oxigênio, ácidos graxos livres, glicose e lactato. ${ }^{43,49,50}$

A sensibilidade a catecolaminas endógenas ou exógenas tem se mostrado reduzida. A reposta cardíaca a catecolaminas mostrou reduzido trabalho cardíaco, freqüência cardíaca e captação de oxigênio em animais sépticos..$^{51,52}$

A troponina, um marcador de lesão celular miocárdica, foi estudada em pacientes sépticos. Os resultados dos estudos mostraram que há correlação entre níveis elevados de troponina e disfunção ventricular esquerda. Demonstrou-se que os pacientes que sobrevivem a um episódio de sepse apresentam níveis de troponina inferiores aos que morrem. Foi também interessante a observação de correlação positiva entre troponina e necessidade de uso de drogas vasoativas, e a correlação negativa com o índice de trabalho sistólico esquerdo. ${ }^{53,54}$

\subsubsection{Disfunção cardíaca na sepse}

Os sinais cardiovasculares clássicos vistos na sepse grave devidos à bacteremia por Gram-negativos foram descritos por Waisbren em $1951 .^{55} \mathrm{O}$ autor descreveu um estado hiperdinâmico com pulsos cheios, rubor, febre, oligúria e hipotensão; descreveu também um segundo grupo de pacientes 
que estavam pálidos e frios, com grave hipotensão e pulsos finos, e que pareciam piores. Em 1940, Wiggers foi provavelmente o primeiro autor a descrever a depressão miocárdica no choque, a disfunção miocárdica reversível pode ocorrer em aproximadamente $40 \%$ dos casos de sepse apud 56. Poucos anos mais tarde, Weil et al. ${ }^{57}$ relataram que a administração intravenosa de endotoxinas causa hipotensão secundária à diminuição do retorno venoso em um modelo canino. Em 1965 Weisben et al., ${ }^{\text {apud }} 58$ demonstraram que pacientes com choque séptico habitualmente cursavam com um estado hiperdinâmico.

Em 1975, Heyndrickx e colaboradores ${ }^{59}$ descreveram o fenômeno da reversão da disfunção ventricular esquerda, na oportunidade induzida por isquemia miocárdica. Braunwald e Kloner, ${ }^{60}$ em 1982, descreveram o fenômeno do "miocárdio atordoado", observando que, após um período de isquemia sem necrose da musculatura cardíaca instalada, ocorria um fenômeno auto-limitado de disfunção miocárdica associado com a redução da complacência ventricular. Na mesma linha, descreveram o fenômeno do "miocárdio hibernado", termo usado para apontar a disfunção miocárdica decorrente da isquemia crônica do miocárdio. ${ }^{60}$

Após a descrição da reversão da disfunção miocárdica nos pacientes com doença de artéria coronária, surgiu grande interesse no estudo da capacidade de reversão da disfunção miocárdica em doenças de origem não-coronariana como a sepse, alterando o curso clínico desses pacientes. Desde então, a disfunção miocárdica na sepse tem sido muito estudada e tem-se verificado que pode ocupar papel central na gênese do choque. ${ }^{61}$ 
Nos dias atuais, essa disfunção pode ser detectada pela ecocardiografia ${ }^{62-64}$ pelo cateter de termodiluição e pela cineangiografia por radionuclídeos. ${ }^{48,65,66} \mathrm{O}$ estresse à ecocardiografia com dobutamina tem sido usado como indicador de prognóstico no choque séptico. ${ }^{62,67}$

Apesar de haver aumento no débito cardíaco durante a fase hiperdinâmica da sepse, os estudos indicam que o miocárdio apresenta disfunção. Ambos os ventrículos podem dilatar; a função contrátil e a complacência ventricular diminuem. Trabalho de Parker e colaboradores ${ }^{48}$ demonstrou diminuição na fração de ejeção em alguns pacientes com sepse, apesar do débito cardíaco normal ou aumentado.

A disfunção miocárdica durante a sepse varia de moderada a grave. ${ }^{48,68,69}$ Apresenta-se como dilatação do ventrículo esquerdo ou como dilatação biventricular. ${ }^{70-72}$ Alterações segmentares globais da parede miocárdica podem ser encontradas ou distúrbios segmentares, particularmente no ápex cardíaco, podem ocorrer, ${ }^{72,73}$ geralmente acompanhados por achados eletrocardiográficos inespecíficos. ${ }^{74} \mathrm{~A}$ dilatação biventricular do coração parece ter efeito protetor, pois a disfunção é menor no grupo de pacientes que morrem, sugerindo que este é um fenômeno adaptativo. É possível que a habilidade de dilatar os ventrículos preserve um volume de ejeção apropriado, apesar da redução significante da fração de ejeção e da vasoplegia existente..$^{48,67}$ Vincent e colaboradores ${ }^{65}$ encontraram importante grau de disfunção ventricular direita associada com eventos fatais. 
Apesar de ser foco de inúmeros estudos, a etiologia da depressão miocárdica ainda não está esclarecida. A isquemia miocárdica não demonstrou relevância na gênese da depressão miocárdica, pois o fluxo sangüíneo coronário e os níveis de lactato no seio venoso coronário são normais nessa situação. ${ }^{64} \mathrm{Um}$ fator depressor do miocárdio também foi descrito, após a injeção de sangue ultrafiltrado de pacientes com sepse em cobaias com diminuição contração cardíaca. ${ }^{75}$ Um número diferente de proteínas, incluindo citocinas como o TNF- $\alpha$, de $17 \mathrm{kDa}$, foi identificado como uma potencial substância depressora do miocárdio. ${ }^{76} \mathrm{~A}$ infusão de TNF- $\alpha$ diminui a contratilidade do ventrículo esquerdo em torno de $23 \%$, após uma hora, e em torno de $52 \%$ após cinco horas. ${ }^{77}$ Uma outra proteína, a lisozima, foi identificada recentemente como substância depressora do miocárdio em cães em modelos de bacteremia por Escherichia coli. ${ }^{78-80}$

Uma outra hipótese afirma que a sepse leva a hipóxia citopática, ou seja, ao desacoplamento da fosforilação oxidativa e à interrupção da produção de fosfatos de alto teor energético. A literatura mostra discrepâncias na avaliação do ATP (adenosina trifosfato) disponível, entretanto muitos estudos demonstraram que os níveis de ATP estão preservados no miocárdio séptico disfuncionante ${ }^{78-80}$ por outro lado, níveis diminuídos de ATP foram relatados nos cardiomiócitos após ligação e punção do ceco, administração de endotoxina, ou várias manipulações em culturas de células. ${ }^{81-84}$ 


\subsubsection{Variabilidade da freqüência cardiaca}

Apesar de o ritmo cardíaco em indivíduos sadios ser percebido e descrito como normal, o coração humano saudável varia a sua freqüência de batimento a batimento. $^{85}$ Isso é conseqüência dos ajustes imediatos promovidos pelo sistema nervoso autônomo para manter o equilíbrio do sistema cardiovascular. Nos últimos anos, vários estudos têm tentado determinar o estado da ação autonômica em que se encontra o coração, com o estudo da variabilidade da freqüência cardíaca. ${ }^{86}$

A variabilidade da freqüência cardíaca, como outros fenômenos fisiológicos, reflete uma complexa interação entre células, tecidos e órgãos que são afetados por diversos fenômenos fisiológicos e patológicos. Alterações da variabilidade da freqüência cardíaca são encontradas não somente nas doenças cardíacas mas também em desordens fisiopatológicas caracterizadas pela alteração neuro-humoral. ${ }^{87} \mathrm{~A}$ disfunção cardíaca autonômica pode resultar em complicações como arritmias cardíacas malignas e morte súbita, sendo que os sistemas fisiológicos se alteram a cada momento para responder aos estímulos.

Os sistemas fisiológicos dos jovens sadios apresentam importante complexibilidade e variabilidade fisiológicas, ao passo que, com o aumento da idade ou na presença de doenças, o sistema mostra perda de variabilidade, diminuição da complexidade e aumento da regularidade. ${ }^{88} \mathrm{~A}$ 
perda ou a diminuição da variabilidade nos intervalos batimento-a-batimento foram encontradas em várias doenças. ${ }^{87-89}$ Postula-se que a diminuição da variabilidade da freqüência cardíaca é dinâmica e pode ocorrer em uma ampla série de doenças críticas e lesões, e parece ser intensamente correlacionada com a gravidade da doença e com boa evolução em pacientes adultos e pediátricos. ${ }^{87}$

Godin e Buchmam ${ }^{90}$ apresentaram a hipótese da patogênese da disfunção de múltiplos orgãos e sistemas em 1996, afirmando que os órgãos humanos funcionavam como osciladores biológicos acoplados um ao outro por uma rede de comunicação neural, humoral e por componentes das citocinas. A resposta inflamatória sistêmica não só teria impacto direto nas células dos órgãos individuais, mas também levaria ao enfraquecimento da comunicação interorgânica, que poderia romper e isolar os órgãos dos controles das alças de retroalimentação, levando rapidamente à falência. Esse desacoplamento dos osciladores biológicos pode ocorrer em diferentes níveis, desde uma célula até um órgão.

A hipótese ${ }^{91}$ derivada do trabalho de Pincus $^{92}$ demonstrou que o nãoacoplamento dos osciladores causa perda na variabilidade de cada oscilador. A variabilidade em cada oscilador reflete a "saúde das interconexões" com outros osciladores. Os autores ainda sugeriram que a redução na variabilidade da freqüência cardíaca era causada por resposta inflamatória exagerada.

O desacoplamento dos sistemas orgânicos foi considerado por Godin e Buchmam $^{90}$ como conseqüência da SIRS e causa da síndrome da disfunção 
de múltiplos órgãos e sistemas (DMOS). Essa teoria foi reafirmada por Godin e colaboradores, ${ }^{90,93}$ que demonstraram diminuição da variabilidade da freqüência cardíaca após a injeção intravenosa de endotoxina. Em humanos sadios, entretanto, eles repararam no fato de que, apesar de a endotoxina levar a diminuição da variabilidade da freqüência cardíaca, ela não foi suficiente para induzir disfunção de múltiplos órgãos e sistemas, não devendo então ser considerada, de maneira isolada, sua causa.

A disfunção autonômica é frequentemente encontrada em várias doenças que necessitam de admissão na UTI, como a síndrome da DMOS, sepse, ${ }^{86,94}$ traumas cranianos, lesões cerebrais, ${ }^{95,96}$ síndrome de GuillianBarré, ${ }^{97-99}$ infarto do miocárdio, ${ }^{100-103}$ insuficiência cardíaca congestiva ${ }^{87}$ e morte cerebral, ${ }^{89,104}$ arritmias cardíacas malignas e parada cardíaca, ${ }^{101,105,106}$ insuficiência cardíaca descompensada, ${ }^{101,107}$ insuficiência renal, ${ }^{108}$ cirrose hepática, ${ }^{109}$ eclâmpsia, ${ }^{110}$ tétano, ${ }^{111}$ hipertensão grave, ${ }^{112}$ cirurgia cardiovascular. $^{113-115}$

\subsubsection{Variabilidade da freqüência cardiaca e síndrome da disfunção de múltiplos órgãos e sistemas}

A síndrome da DMOS foi inicialmente descrita em 1969 por Skillman e colaboradores, ${ }^{116}$ que notaram um quadro de falência respiratória letal, hipotensão, sepse e icterícia. Mais tarde, em 1973, Tilney e colaboradores ${ }^{117}$ descreveram uma falência seqüencial de sistemas orgânicos após rotura de um aneurisma de aorta abdominal, referindo-se ao fato como um problema 
sem solução nos cuidados pós-operatórios. A DMOS é a causa mais comum de morte em pacientes com sepse, sendo caracterizada pela deteriorização aguda da função de dois ou mais órgãos, atingindo habitualmente pulmões, rins, coração (incluindo o sistema vascular), fígado, sistema nervoso (encefalopatia séptica) e coagulação. ${ }^{90}$

A falência orgânica seqüencial normalmente ocorre após dias a semanas de uma agressão fisiológica, em que se incluem pancreatite, trauma, queimadura, choque, infecção, broncoaspiração, transfusões sangüíneas múltiplas e contusão pulmonar. É caracterizada por uma ativação exacerbada da imunidade inata, resultando em um padrão de resposta que inclui distúrbios metabólicos, endócrinos e hemoendócrinos. A mortalidade correlaciona-se com o número de órgãos em falência, a idade, e o tempo de duração do processo, variando entre 30 a $100 \%$ dos casos. ${ }^{90}$

Seely e Christou ${ }^{118}$ estenderam o conceito de Godin e Buchman. ${ }^{90} \mathrm{Em}$ revisão de literatura, introduziram um novo paradigma na patogênese da DMOS, baseando-se na análise de sistemas não-lineares. Por meio desse método de estudo, analisaram as interações não-lineares múltiplas entre os sistemas nervoso, metabólico, endócrino, imune e inflamatório, demonstrando que o sistema imune e a resposta inflamatória respondem de modo não-linear. Em seu modelo, tentaram explicar a falência de terapias antimediadoras na DMOS e na sepse. Enfatizaram que a variabilidade da freqüência cardíaca representa alterações patológicas de várias doenças, como a DMOS. A avaliação da variabilidade e da conectividade dos componentes de um sistema não-linear complexo é uma condição crucial 
para se entenderem as reações oriundas do conceito de imunomodulação, e a resposta inflamatória sistêmica não pode ser entendida somente pelo estudo individual das partes de um sistema, sendo necessária a avaliação da interconexão das partes. Por meio da comparação dos achados de um sistema linear e um sistema não-linear complexo, descreveram ainda o comportamento não-linear dos mediadores de inflamação, como o TNF, sugerindo que os elementos críticos na inflamação não são mediadores próinflamatórios individuais e antiinflamatórios, mas a conseqüência de suas interações.

Toweill e colaboradores ${ }^{119}$ combinaram técnicas lineares e não-lineares para analisar os sinais hemodinâmicos durante a sepse e o choque séptico em pacientes pediátricos. Eles compuseram a hipótese de que um desacoplamento do sistema autonômico e cardiovascular ocorre durante a sepse e o choque séptico, e demonstraram atenuação na variabilidade da freqüência cardíaca na sepse versus choque séptico, concluindo que o desacoplamento do sistema cardiovascular e autonômico ocorreu na baixa e na alta freqüências durante a sepse.

Pontet e colaboradores ${ }^{120}$ estudaram a variabilidade da freqüência cardíaca como um marcador precoce da disfunção de múltiplos órgãos e sistemas em 46 pacientes com sepse, nas primeiras 24 horas de internação, sendo que 11 pacientes desenvolveram DMOS e 28, não ( 7 pacientes excluídos). Os autores concluiram que a redução da variabilidade da freqüência cardíaca, especialmente do índice baixa freqüência, pode ser usado como preditor de DMOS. 


\subsection{Troponinas como marcadores séricos de lesão miocárdica}

Os marcadores séricos cardíacos são definidos como macromoléculas intracelulares que atingem determinadas concentrações plasmáticas devido à perda da integridade da membrana do sarcolema. O dano em células cardíacas resulta no aumento das concentrações sangüíneas das proteínas que regulam a contração do coração, como a troponina I (TNI) e a troponina T. $^{121}$

A troponina é um complexo protéico que regula a contração do músculo estriado. O complexo troponina é localizado em intervalos regulares ao longo dos filamentos do músculo estriado e consiste de três proteínas, troponina I (uma subunidade inibidora), troponina C (uma subunidade ligadora do cálcio), e troponina $\mathrm{T}$ (uma subunidade que liga o complexo da tropomiosina ao filamento fino). ${ }^{121}$ Essas troponinas cardíacas são diferentes das troponinas presentes no músculo esquelético e, pelo fato de não serem encontradas na circulação, são marcadores altamente específicos de lesão de células miocárdicas.

A presença de troponina I ou troponina $T$ no sangue indica lesão miocárdica, e esses marcadores podem estar elevados mesmo na presença de concentrações normais de CK-MB (creatine-kinase-MB), um outro marcador de lesão cardíaca. ${ }^{122}$ As troponinas cardíacas livres T e I têm 37 e $24 \mathrm{kDa}$, respectivamente, sendo consideravelmente menores que a enzima 
CK-MB (86 kDa) e mais facilmente extravasam das membranas dos miócitos lesados. ${ }^{122}$ Postulou-se que o extravasamento persistente e irreversível dessas enzimas configurava a necrose irreversível da célula cardíaca. ${ }^{123,124}$ Já a troponina $C$ também serviria como marcador de lesão miocárdica, porém não estão disponíveis kits de laboratório viáveis para dosagem no dia-a-dia, fora do ambiente experimental.

Atualmente, os métodos laboratoriais imunoenzimáticos já permitem não apenas identificar a presença da troponina no soro, mas também quantificar a substância, o que facilita a ampliação dos estudos sobre a relação dosagem-morbidade. Tal desenvolvimento tecnológico possibilitou também aumentar a sensibilidade do exame e, conseqüentemente, identificar lesões miocárdicas clinicamente não-reconhecidas, definidas agora pela "elevação" das troponinas T (a mais facilmente dosada) e I, incrementando o diagnóstico. Troponinas $\mathrm{T}$ e I têm valor prognóstico nas síndromes coronarianas agudas. ${ }^{43,123,124}$

A elevação da troponina sérica pode estar presente no infarto agudo do miocárdio, na miocardite, ${ }^{125}$ em intervenções cardíacas percutâneas, em doenças infiltrativas do miocárdio (por exemplo: amiloidose e sarcoidose), no trauma cardíaco, na taquicardia, em insuficiência cardíaca congestiva, ${ }^{126,127}$ em complicações cardíacas pós-operatórias, na cardioversão elétrica e em portadores de cardioversores implantáveis, no pós-transplante cardíaco, na ablação por radiofreqüência e na pericardite. ${ }^{128,129}$ As doenças nãocardíacas e situações que podem cursar com aumento da troponina incluem sepse e choque séptico, hipotensão, insuficiência renal, ${ }^{130}$ toxicidade por 
drogas, hipotiroidismo, embolia pulmonar, ${ }^{131}$ ataque isquêmico transitório, acidente vascular cerebral, hemorragia subaracnóide, altas doses de quimioterapia, hipertensão pulmonar primária, envenenamento por picada de escorpião, exercícios extenuantes (tipo maratona) ${ }^{132,133}$ e exacerbação da doença pulmonar obstrutiva crônica. ${ }^{134}$

Os fatores que interferem com o método de detecção da troponina I sérica, levando a falsos positivos incluem anticorpos heterofílicos, ${ }^{135,136}$ fator reumatóide, ${ }^{135,137}$ coágulo de fibrina, ${ }^{137}$ micropartículas e mau funcionamento do equipamento analisador. ${ }^{136,138}$

\subsection{Elevação da troponina na sepse e em pacientes críticos}

Vários artigos foram publicados a respeito da elevação da troponina cardíaca na sepse e em doentes críticos. ${ }^{43,53,54,139}$ Os níveis da troponina I correlacionaram-se com o grau da hipotensão $0^{43}$ e com o escore APACHE (Acute Physiology and Chronic Health Evolution) II. ${ }^{53}$

Ammann e colaboradores avaliaram pacientes com sepse, sendo que $40 \%$ encontravam-se em choque séptico, ${ }^{54}$ dos quais $85 \%$ dos pacientes apresentavam elevação da troponina. ver Elst e colaboradores ${ }^{53}$ encontraram elevação da troponina I, em $50 \%$ dos seus pacientes com sepse. Em pacientes com sepse grave, choque séptico ou choque hipovolêmico, Arlati e colaboradores ${ }^{43}$ encontraram elevação da troponina I em $74 \%$ dos casos, sendo que a elevação da troponina ocorreu em $58 \%$ dos 
pacientes com sepse grave ou choque séptico, e todos os pacientes com choque hipovolêmico cursaram com aumento da troponina.

As causas da elevação da troponina em pacientes críticos não estão bem estudadas. Os estudos comentados aqui em geral tinham amostras pequenas e incluíram grupos heterogêneos de pacientes, alguns com doença coronariana prévia, sendo que o estresse induzindo infarto do miocárdio pode ter sido o responsável pelo aumento da troponina nesses grupos particularmente. Eventos coronarianos agudos puderam ser excluídos em alguns desses pacientes: por exemplo, Ammann e colaboradores $^{54}$ excluíram doença arterial coronariana em 10 dos 17 pacientes com troponina I positiva. Esses achados indicam que outros mecanismos estão envolvidos. ver Elst revelou que os pacientes com troponina elevada eram mais velhos e mais freqüentemente tinham hipertensão ou história prévia de infarto do miocárdio, sugerindo que a doença cardiovascular prévia poderia de algum modo contribuir para a elevação da troponina. ${ }^{53}$ Entretanto, esses achados não foram observados em um outro estudo. ${ }^{139}$

Não há dados de literatura que demonstrem claramente uma relação entre o tipo de patógeno e a elevação de troponina. No estudo de Ammann, a infecção pelo Streptococcus pneumoniae foi a causa da sepse em $41 \%$ dos pacientes com troponina positiva. ${ }^{54}$ Outro estudo mostrou que as bactérias Gram-negativas foram os patógenos responsáveis em $63 \%$ dos casos. $^{53}$ Spies e colaboradores ${ }^{139}$ não acharam diferenças em termos de 
bactérias causadoras de sepse em pacientes com e sem elevação da troponina.

A literatura tem discutido vários mecanismos potenciais para o aumento da troponina em pacientes sépticos. É bem conhecido que um número de mediadores circulantes e locais (exemplo: citocinas ou radicais livres), apresentam propriedades miocitotóxicas diretas. ${ }^{53} \mathrm{O}$ fator $\alpha$ de necrose tumoral (TNF- $\alpha$ ) e a interleucina 1 são depressoras cardíacas, ${ }^{140}$ o TNF- $\alpha$ aumenta a permeabilidade dos canais endoteliais para as macromoléculas e solutos de baixo peso molecular. ${ }^{141}$ Parece que a alteração da permeabilidade ocorre na membrana celular dos miócitos, levando ao extravasamento da troponina. A evidência experimental para essa hipótese foi estabelecida pela demonstração de bolhas membranosas reversíveis nos cardiomiócitos de ratos durante períodos limitados de hipóxia e aumento das enzimas miocárdicas. ${ }^{142}$ Ainda, de modo secundário, demonstrou-se lesão miocárdica pelas endotoxinas bacterianas das bactérias Gram-negativas. ${ }^{143}$ Por último, a disfunção da microcirculação foi descrita na sepse ${ }^{144}$ e pode ser advinda de trombose do leito vascular, levando a hipóxia miocárdica reversível e apoptose, associada a perda de proteínas para o soro.

A dosagem da troponina nos pacientes com sepse fornece informação prognóstica valiosa. ver Elst e colaboradores ${ }^{53}$ relataram que ambas troponina I e troponina $\mathrm{T}$ foram marcadores independentes de disfunção miocárdica em pacientes com sepse. Eles detectaram disfunção ventricular pelo ecocardiograma transesofágico em $78 \%$ e $9 \%$ dos pacientes com e sem a elevação da troponina I respectivamente. Alguns estudos mostraram 
correlação fraca entre a elevação da troponina e a mortalidade hospitalar. $^{139,145}$

A questão mais importante parece ainda ser se o aumento das troponinas representa lesão no miocárdio reversível ou irreversível, e como diferenciar necrose de lesão miocárdica reversível. Este ponto tem sido considerado nos últimos anos em vários estudos clínicos, pois a elevação das troponinas na sepse é um fator que indica aumento da mortalidade e prognóstico clinico pior, parecendo contribuir de modo importante para esse complexo quadro clinico. 


\section{OBJETIVOS}

\subsection{Primário}

2.1.1. Testar a hipótese de que a disfunção autonômica não é a única responsável pela alteração da variabilidade da freqüência cardíaca e evolução dos pacientes com disfunção de múltiplos órgãos e sistemas (DMOS).

\subsection{Secundários}

2.2.1. Pesquisar lesão cardíaca e inflamação nos pacientes sépticos por meio da monitorização hemodinâmica, análise da troponina, da proteína C reativa e da variabilidade da freqüência cardíaca.

2.2.2. Descrever as alterações histológicas do miocárdio nos pacientes que evoluíram a óbito. 


\section{MÉTODOS}

\subsection{Desenho do estudo, critérios de inclusão e exclusão}

O estudo foi observacional e prospectivo, envolvendo pacientes sépticos internados na Unidade de Terapia Intensiva do Hospital Universitário da Universidade de São Paulo entre novembro de 2002 e julho de 2004 , de qualquer raça ou gênero e com idade entre 18 e 70 anos. As observações internas da unidade mostravam que aproximadamente $40 \%$ das admissões cursam com sepse grave ou choque séptico.

Os critérios de exclusão foram: infarto do miocárdio agudo prévio (registrado na história clínica, por alterações eletrocardiográficas e alterações segmentares no ventrículo esquerdo no ecocardiograma da admissão), ritmo não-sinusal, porte de marcapasso permanente, insuficiência cardíaca congestiva (classe III ou IV da New York Heart Association ${ }^{146}$ síndrome de imunodificiência humana, neoplasia, insuficiência renal crônica e diabetes.

Os critérios de inclusão foram choque séptico com no máximo 24 horas de evolução ou sepse grave, como definida pela Sociedade de Terapia Intensiva Norte-Americana ${ }^{1}$, ou seja, a presença de dois ou mais dos seguintes sintomas: a) temperatura $>38^{\circ} \mathrm{C}$ ou $<36^{\circ} \mathrm{C}$; b) freqüência cardíaca $>90 \mathrm{bpm}$; c) freqüência respiratória acima de $20 \mathrm{rpm}$ ou $\mathrm{PaCO}_{2}<$ 
32 torr e contagem de leucócitos acima de $12.000 / \mathrm{mm}^{3}$ ou $<4.000 / \mathrm{mm}^{3}$. No início do estudo, informações clínicas foram obtidas, incluindo as informações necessárias para se tentar determinar o início do quadro infeccioso. Tentou-se de maneira rigorosa admitir pacientes com no máximo 24 horas de evolução do quadro de sepse.

A análise dos dados e a divisão dos grupos a serem estudados (sobreviventes e não sobreviventes) foi posterior (post hoc), após a definição de evolução clínica a óbito ou cura (após 28 dias).

\section{2. Ética}

O protocolo de pesquisa intitulado "Estudo das alterações da variabilidade da freqüência cardíaca e troponina no paciente séptico" e o termo de consentimento livre e esclarecido foram aprovados pela Comissão de Ética para a Análise de Projetos de Pesquisa do Hospital das Clínicas da Faculdade de Medicina da Universidade de São Paulo, sob número no 747/04, e pelo Comitê de Ética em Pesquisa do Hospital Universitário da Universidade de São Paulo sob número 392/02. Os pacientes foram incluídos no protocolo após assinatura do consentimento livre e esclarecidos pelos familiares. 


\subsection{Análise estatística}

Inicialmente os dados foram analisados de forma descritiva, para as variáveis contínuas (idade, diâmetros de câmaras cardíacas ao ecocardiograma), sendo calculados a média e o desvios-padrão. Para as variáveis classificatórias (sexo, idade, presença de cirurgia), foram calculadas freqüências absolutas e percentuais.

Posteriormente, foi utilizada a análise de variância (ANOVA), de repetição com pós-teste de Bonferroni. A correlação foi avaliada com 0 coeficiente de correlação de Pearson.

O nível de significância adotado foi de 0,05.

\subsection{Avaliação clínica, laboratorial e anátomo-patológica}

A gravidade do estado clínico à admissão foi calculada usando-se o escore APACHE (Acute Physiology and Chronic Health Evaluation) versão II: ${ }^{147}$ escores mais elevados indicam doença mais grave. Para o cálculo do APACHE, além de parâmetros clínicos, são utilizados os gases arteriais, hemograma e os níveis séricos de creatinina, bilirrubinas, sódio e potássio.

Foram coletadas amostras de sangue por cateter em artéria pulmonar nos dias 1, 3 e 6 de internação ou até a morte e mensurados os seguintes 
padrões hemodinâmicos: pressão capilar pulmonar, índice do trabalho sistólico do ventrículo esquerdo, índice cardíaco, pressão do átrio direito, pressão de artéria pulmonar, resistência vascular sistêmica e resistência vascular pulmonar. Nesses mesmos dias, e foi gravado o eletrocardiograma de 24 horas, com o método descrito com pormenores adiante.

Também nos dias 1, 3 e 6, uma vez ao dia, foram analisadas troponina I, creatinofosfoquinase $(\mathrm{CPK})$, creatinofosfoquinase fração $M B$ e proteína $C$ reativa $(P C R)$ séricas. Os métodos de determinação e valores de referência estão detalhados adiante.

O ecocardiograma transtorácico foi realizado à beira do leito nos dias 1 e 6 de internação, sendo mensurados a fração de ejeção, os diâmetros sistólico e diastólico do ventrículo esquerdo, o diâmetro do átrio esquerdo, a fração de encurtamento, o diâmetro do septo interventricular e a espessura da parede posterior do ventrículo esquerdo.

Os pacientes que evoluíram a óbito tiveram fragmentos do seu miocárdio analisados por microscopia óptica e microscopia eletrônica, sendo que os blocos foram ainda submetidos a imunoistoquímica para a determinação da ativação da poli(ADP-ribose) polimerase. Detalhes do método de análise anátomo-patológico são expostos a seguir.

Os pacientes que evoluíram em choque receberam cristalóides e, quando necessário, drogas vasoativas para a ressuscitação e manutenção da pressão arterial média em torno de $70 \mathrm{mmHg}$. Foram utilizadas dopamina, noradrenalina e dobutamina. A quantidade de substância vasoativa utilizada foi contabilizada em microgramas em 24 horas, e será 
demonstrada em Resultados. Os pacientes receberam suporte ventilatório e foram sedados com uso de midazolam e citrato de fentanil. As doses serão representadas em miligramas em 24 horas.

\subsubsection{Variabilidade da freqüência cardíaca e análise do sinal}

A gravação do ritmo cardíaco foi realizada nos dias 1,3 , e 6 de internação ou até a morte para o obtenção da variabilidade da freqüência cardíaca. Os pacientes foram monitorados por eletrocardiograma no leito, na posição supina, em horário determinado, durante uma hora. Já a gravação foi realizada com equipamento de três canais Dynamis 4000, da Empresa Cardio Sistemas Comercial e Industrial Ltda. (brasileira) e mantida por 24 horas, para observação de arritmias cardíacas. Durante a aquisição dos dados, era solicitada a não-manipulação dos pacientes pela equipe. Eram anotados os períodos em que ocorria variação na freqüência cardíaca.

A análise da gravação foi realizada com software da Holter CardioSmart Institutional CS 500, da Empresa Cardio Sistemas Comercial e Industrial Ltda., incluindo avaliação da variabilidade do intervalo RR no tempo e da freqüência cardíaca e análise de arritmias. 


\subsubsection{Determinação dos níveis séricos de troponina I}

Os níveis séricos da troponina I foram medidos de modo quantitativo por ensaio imunométrico quimioluminescente e auxílio do analisador IMMULITE $^{\circledR}$ (Diagnostic Products Corporation), considerando-se valores normais para infarto até $1,0 \mathrm{ng} / \mathrm{ml}$ e sensibilidade analítica de $0,20 \mathrm{ng} / \mathrm{ml}$ a $180,0 \mathrm{ng} / \mathrm{ml}$. O sistema utiliza pérolas de plástico recobertas por anticorpos (fase sólida/unidade-teste), reagente marcado com fosfatase alcalina e um substrato quimioluminescente por enzima. A unidade-teste serve como "vaso" reacional para a reação imune, processo de incubação, lavagem e desenvolvimento do sinal. A emissão de luz do substrato quimioluminescente, medida pelo luminômetro, reagindo com o conjugado enzimático ligado a pérola é proporcional à quantidade do analito presente na amostra.

\subsubsection{Determinação dos níveis séricos de creatinoquinase (CK)}

Os níveis séricos de creatinoquinase (CK) foram mensurados por método enzimático ( $\mathrm{N}$-acetilcisteína ativada segundo padronização do DGKC, German Societies for Clinical Chemistry), realizado no equipamento automatizado ADVIA $^{\circledR} 1650$ da Bayer $^{\circledR}$ ou Cobas Mira Plus ${ }^{\circledR}$ da Roche ${ }^{\circledR}$, 
considerando como valores normais para homens até $190 \mathrm{U} / \mathrm{l}$ e mulheres até $165 \mathrm{U} / \mathrm{l}$, e tendo como intervalo analítíco 0 a 1.300 U/l. A CK é ativada por Nacetilcisteína (NAC). Em uma primeira reação, a CK ativada catalisa a fosforilação da creatinofosfato. Em uma reação acoplada, catalisada pela hexoquinase, a glicose é fosforilada pelo ATP (adenosina trifosfato) formado na primeira reação, dando origem a D-glicose-6-fosfato. Finalmente, a glicose-6-fosfato desidrogenase (G6PDH) catalisa a oxidação de G6P pelo $\mathrm{NADP}^{+}$(nicotinamida adenina dinucleotídeo fosfato), dando origem a D-6fosfogliconato e NADPH (nicotinamida adenina dinucleotídeo fosfato reduzida). A taxa de formação de NADPH é diretamente proporcional à atividade catalítica da CK, determinada pelo aumento da absorbância a 340 $\mathrm{nm}$.

\subsubsection{Determinação dos níveis séricos de creatinoquinase-MB} (CK-MB)

Os níveis séricos de creatinoquinase-MB (CK-MB) foram mensurados por ensaio imunométrico quimiluminescente pelo equipamento IMMULITE ${ }^{\circledR}$ (Diagnostic Products Corporation, Los Angeles, USA), considerando como valores de referência: até $5 \mathrm{ng} / \mathrm{ml}$ para pacientes normais e superiores a 10 ng/ml para pacientes com lesão cardíaca. O intervalo analítico do teste é de $0,20 \mathrm{ng} / \mathrm{ml}$ a $500,0 \mathrm{ng} / \mathrm{ml}$. O ensaio é baseado em um anticorpo monoclonal anti CK-MB marcado por um ligante (ativador de $\mathrm{MB}$ ) e uma separação por 
fase sólida revestida de um anti-ligante (bloqueador de MM). O complexo CK-MB origina a liberação de fótons que são medidos pelo luminômetro sendo proporcional a concentração de ck-mb da amostra.

\subsubsection{Determinação dos níveis séricos de proteina C-reativa}

A dosagem sérica de proteína C-reativa foi realizada por método imunoquímico, realizado em equipamento automatizado nefelômetro BNII ${ }^{\circledR}$ (Dade Behring ${ }^{\circledR}$ ). Os valores de referência foram níveis inferiores a $5 \mathrm{mg} / \mathrm{l} \mathrm{e}$ o limite de detecção, de $0,175 \mathrm{mg} / \mathrm{l}$. As partículas de poliestireno revestidas com anticorpo monoclonal anti-proteína C-reativa se aglutinam quando misturadas com amostras que contenham proteína C-reativa. A intensidade de dispersão da luz é proporcional á concentração de proteína C-reativa da amostra, que é obtida por comparação com um padrão de concentração conhecida.

\subsubsection{Determinação dos níveis séricos de bilirrubinas total e frações}

Foi utilizado o método colorimétrico (Jendrassik e Grof) realizado no equipamento automatizado ADVIA ${ }^{\circledR} 1650$ da Bayer $^{\circledR}$ ou Cobas Mira Plus ${ }^{\circledR}$ da Roche ${ }^{\circledR}$ para determinação dos níveis séricos de bilirrubina total (BT) e 
frações $(\mathrm{BD}$ e $\mathrm{BI})$. Os valores de referência são: para $\mathrm{BT}$, até 1,5 $\mathrm{mg} / \mathrm{dl}$; para $\mathrm{BD}$, até $0,5 \mathrm{mg} / \mathrm{dl}$; e para $\mathrm{Bl}$, até $1,0 \mathrm{mg} / \mathrm{dl}$. A bilirrubina reage com o ácido diazossulfanílico em $\mathrm{pH}$ baixo para produzir azobilirrubina. A presença de cafeína permite reação rápida da bilirrubina, tanto a conjugada quanto a nãoconjugada (total/BT). Na ausência de cafeína, ocorre uma reação somente com bilirrubina conjugada (direta/BD). A intensidade da cor é diretamente proporcional à concentração de bilirrubina na amostra, e a absorbância do complexo azobilirrubina é medida a $545 \mathrm{~nm}$. O intervalo analítico é de 0 a $10,0 \mathrm{mg} / \mathrm{dl}$.

\subsubsection{Determinação sérica da creatinina}

Foi utilizado 0 método enzimático colorimétrico (Jaffé sem desproteinização), realizado no equipamento automatizado ADVIA $^{\circledR} 1650$ da Bayer $^{\circledR}$ ou Cobas Mira Plus ${ }^{\circledR}$ da Roche ${ }^{\circledR}$ para determinação da creatinina sérica. Os valores de referência são de 0,4 a 1,3 mg/dl.

A creatinina reage com ácido pícrico em meio alcalino para formar um complexo colorido, cuja taxa de formação é diretamente proporcional à concentração de creatinina na amostra. A absorbância é medida a $505 \mathrm{~nm}$. O intervalo analítico do soro é de 0 a $25 \mathrm{mg} / \mathrm{dl}$. 


\subsubsection{Determinação do nível sérico de uréia}

Para determinação do nível sérico de uréia, foi usado o método cinético (urease e glutamato desidrogenase), pelo equipamento automatizado ADVIA $^{\circledR} 1650$ da Bayer $^{\circledR}$ ou Cobas Mira Plus ${ }^{\circledR}$ da Roche ${ }^{\circledR}$. Os valores de referência são de 10 a $50 \mathrm{mg} / \mathrm{dl}$. A uréia é hidrolisada, na presença de água e urease, produzindo amônia e dióxido de carbono. A amônia reage com 2oxoglutarato na presença de glutarato desidrogenase e $\mathrm{NADH}$, dando origem a L-glutamato. A diminuição da concentração de NADH é diretamente proporcional à concentração de uréia na amostra, determinada medindo-se a absorbância a $340 \mathrm{~nm}$.

\subsubsection{Determinação do nível sérico de potássio}

Foi realizado o método de potenciometria com eletrodo seletivo de íon (ISE) para determinação do nível sérico de potassio, usando-se o equipamento automatizado ADVIA $^{\circledR} 1650$ da Bayer $^{\circledR}$. Os valores de referência são de 3,5 a 5,0 $\mathrm{mEq} / \mathrm{l}$. A amostra é misturada com tampão de eletrodo seletivo de íon (ISE), resultando, desse modo, em uma solução de pH e resistência iônica constantes. O potássio é medido potencimetricamente com auxílio de dois eletrodos: eletrodo de potássio e 
eletrodo de referência. As amostras são introduzidas através dos eletrodos e mudanças no potencial elétrico ocorrem. As diferenças de potencial são medidas contra o eletrodo de referência, obtendo-se a concentração de potássio da amostra. O intervalo analítico é de 1 a $10 \mathrm{mEq} / \mathrm{l}$.

\subsubsection{Determinação do nível sérico de sódio}

O nível sérico de sódio foi determinado pelo método de potenciometria com eletrodo seletivo de íon (ISE), com o equipamento automatizado ADVIA $^{\circledR} 1650$ da Bayer $^{\circledR}$. Os valores de referência são de 136 a 146 mEq/l. A amostra é misturada com tampão ISE, resultando, deste modo, em uma solução de $\mathrm{pH}$ e resistência iônica constantes. O sódio é medido potencimetricamente com auxílio de dois eletrodos: de sódio e de referência. As amostras são introduzidas através dos eletrodos e mudanças no potencial elétrico ocorrem. Essas diferenças de potencial são medidas contra o eletrodo de referência, obtendo-se a concentração de sódio da amostra. O intervalo analítico é de 100 a 200 mEq/l.

\subsubsection{Determinação gasimétrica do sangue arterial e venoso}

A determinação do gás em sangue arterial e venoso foi realizada pelos métodos potenciométrico, amperométrico e espectofotométrico, pelo 
equipamento OMNI C da Roche ${ }^{\circledR}$. Os parâmetros medidos foram os $\mathrm{pH}$ (nl: 6.0-8.0), $\mathrm{pO}_{2}(0-800 \mathrm{mmHg}), \mathrm{pCO}_{2}(4-200 \mathrm{mmHg}), \mathrm{SO}_{2}(50-100 \%)$.

\subsubsection{Hemograma}

O hemograma foi realizado utilizando-se o equipamento Cell Dyn $3700^{\circledR}$, que, por meio da impedância elétrica, realiza a contagem de leucócitos e a contagem e a avaliação do volume das hemácias e plaquetas. Através da citometria de fluxo, realiza a contagem de leucócitos e a análise de subpopulações de leucócitos, e, por colorimetria, a dosagem de hemoglobina. Valores normais considerados foram de 4,4 a 11,3 $\times 10^{3}$ para leucócitos, com 14,0 a 17,4\% para homens e 12,3 a 15,3\% para mulheres na dosagem de hemoglobina; no caso das plaquetas, 1,5 a 4,0 $\times 10^{3}$.

\subsubsection{Cultivo e isolamento de microorganismos}

A detecção da positividade para microorganismos foi realizada através do equipamento Bact/Alert ${ }^{\circledR}$ - BioMérieux ${ }^{\circledR}$. Isolamento e identificação de microorganismos foram realizados por técnicas manuais e automatizadas no equipamento Vitek - BioMérieux ${ }^{\circledR}$. 
3.4.14. Histologia e imunoistoquímica de fragmentos do miocárdio

Doze amostras do ventrículo esquerdo foram obtidas durante as necropsias para histologia e imunoistoquímica de fragmentos do miocárdio. Os cortes do miocárdio foram fixados por um dia em solução de paraformoldeído e outros cortes foram processados por técnicas de imunoistoquímica e coloração red de Picrosirius para a análise do colágeno.

3.4.15. Detecção imunoistoquímica da poli(ADP-ribose) polimerase

Os cortes de tecidos embebidos em parafina foram desparafinizados em xileno e reidratados em concentrações decrescentes $(100,95$ e $70 \%)$ de etanol, o que foi seguido por uma incubação de cinco minutos em solução tampão de fosfato (phosphate buffer saline, PBS). Para previnir o catabolismo dos polímeros pela poli(ADP-ribose) glicoridase, os cortes foram fixados em ácido tricloroacético a 10\%. Posteriormente, os blocos foram tratados com peróxido de hidrogênio a $0,3 \%$ por 15 minutos, para para bloquear a atividade da peroxidase endógena, e mergulhados rapidamente em solução tampão de fosfato (PBS). As pontes de ligação não específicas 
foram bloqueadas pela incubação das amostras por duas horas em uma solução de Triton/PBS contendo uma solução de soro de cabra a $2 \%$.

Para detectar a poli(ADP) ribose, uma rotina histoquímica foi aplicada como previamente já descrita, ${ }^{148}$ com pequenas modificações. Anticorpos policlonais produzidos em galinha anti-poli(ADP-ribose) pela Tulip Biolabs, e anticorpos isotípicos de controle foram aplicados em uma diluição de 1:300 durante a noite a $4^{\circ} \mathrm{C}$. Após extensa lavagem $(3 \times$ a 10 minutos com uma solução de Triton-PBS a 0,25\%, a imunorreatividade foi detectada com um anticorpo secundário produzido em cavalo e antigalinha e o complexo avidina-biotina peroxidase, ambos fornecidos pelo Vector Laboratories. A cor foi demonstrada usando o kit de substrato $\mathrm{Ni}_{2}-\mathrm{DAB}$ (da Vector Laboratories). Os cortes foram rapidamente lavados em solução salina/TRIS (ph 7,6) e incubadas em Tris/Cobalt $(\mathrm{pH} \mathrm{7,2)} \mathrm{por} \mathrm{dois} \mathrm{minutos.} \mathrm{Os} \mathrm{cortes} \mathrm{foram} \mathrm{então}$ contracorados com vermelho rápido nuclear, desidratados e montados. A coloração da Poly ADP ribose foi quantificada em uma escala entre "-" (não houve coloração das células) e "++++" (coloração forte em muitas células).

\subsubsection{Microscopia óptica}

Os tecidos foram fixados com paraformaldeído por seis horas a temperatura ambiente, desidratados em concentrações graduais de álcool, embebidos em parafina e seccionados a $5 \mu \mathrm{m}$ para posterior coloração e análise por microscopia óptica. 
Hematoxilina e eosina foram usadas na avaliação da arquitetura do miocárdio e de infiltração de células inflamatórias. A coloração de Picrosirius foi empregada na análise de colágeno. Esse método histológico se correlaciona com a medida bioquímica do colágeno. As secções foram coradas em sirius red a 0,1\% (F3B 200, Mobay Chemical Co.), dissolvidas em ácido pícrico saturado e contracoradas com hematoxilina Harris.

\subsubsection{Microscopia eletrônica}

Amostras de $1 \mathrm{~mm}$ do miocárdio foram fixadas em glutaraldeído a $2 \%$, dissolvido em 0,15 M de tampão fosfato no $\mathrm{pH}$ de 7,2 . Foi realizada então a pós-fixação com tetróxido de ósmio a 1\%, e a coloração em acetato uranil aquoso a $1 \%$. As amostras foram embebidas em uma resina de poliéster, cortadas com um aparelho Ultratome LKB, duplamente coradas por uranil acetato e citrato de chumbo, e examinadas com um microscópio eletrônico Jeol 1010, para a avaliação da estrutura das mitocôndrias.

\subsubsection{Estudo morfométrico}

As células inflamatórias polimorfonucleares e mononucleares presentes no miocárdio foram avaliadas pelo método de contagem manual em secções e coradas com hematoxilina-eosina. 
Imagens digitais da área total de secção foram realizadas. Cinco fotos randomizadas foram adquiridas de cada secção. A área de fração de colágeno intersticial foi determinada pela razão da área de Picrosirius pela da área de hematoxilina. O septo de colágeno e as fibras finas de colágeno compondo o septo foram claramente discerníveis pela coloração em vermelho de Picrosirius e foram selecionados pela imagem digital usando a ferramenta "Magic Wand" do programa Adobe Photoshop 8. A área total da imagem e a área da fração de colágeno foram calculadas usando o Image/J (um programa da análise de imagens gratuito desenvolvido pelo National Institutes of Health norte-americano). 


\section{RESULTADOS}

\subsection{Dados clínicos e demográficos}

Foram incluídos inicialmente 31 pacientes sépticos, dos quais seis (19\%) foram excluídos por terem evoluído ao óbito em seis horas, dificultando a análise seriada de exames e o seu acompanhamento ao longo do tempo. As Tabelas 1 e 2 demonstram as características desse grupo de seis pacientes que não sobreviveram e foram excluídos, todos do gênero masculino e com idade média de $48 \pm 5.7$ anos. $O$ índice de APACHE (Acute Physiology and Chronic Health Evaluation) entre esses seis doentes foi maior em relação aos outros pacientes analisados no estudo, o que configurou a maior gravidade.

Tabela 1 - Características dos pacientes com evolução a óbito em até seis horas da admissão em unidade de terapia intensiva e que foram excluídos do estudo

\section{Características}

Número

Gênero masculino - nº (\%)

Idade

APACHE II*

$$
(n=6)
$$

$$
6(100 \%)
$$

$48 \pm 5.7$

$30 \pm 2.5$

* Índice APACHE (Acute Physiology and Chronic Health Evaluation) versão II. 
Tabela 2 - Diagnóstico, realização de cirurgia ou não e tempo de sobrevida dos seis pacientes que evoluíram a óbito nas primeiras seis horas de admissão na unidade de terapia intensiva (todos do sexo masculino) e que foram excluídos do estudo

\begin{tabular}{|c|c|c|c|c|}
\hline Identificação & Idade & Diagnóstico & Cirurgia & Óbito \\
\hline RS & 20 & hantavirose & não & 5 horas \\
\hline $\mathrm{CA}$ & 57 & pancreatite aguda & não & 2 horas \\
\hline OS & 70 & $\begin{array}{l}\text { sepse abdominal } \\
\text { (perfuração) }\end{array}$ & não & 6 horas \\
\hline$A B$ & 29 & broncopneumonia & não & 4 horas \\
\hline PCS & 47 & pancreatite aguda & não & 5 horas \\
\hline \multirow[t]{2}{*}{ LA } & 64 & $\begin{array}{l}\text { sepse abdominal } \\
\text { (úlcera perfurada) }\end{array}$ & $\operatorname{sim}$ & 4 horas \\
\hline & & & \multicolumn{2}{|c|}{ Idade } \\
\hline & Média & & \multicolumn{2}{|c|}{47,83} \\
\hline & Mediana & & \multicolumn{2}{|c|}{52} \\
\hline \multicolumn{3}{|c|}{ Erro padrão médio } & \multicolumn{2}{|c|}{5,72} \\
\hline
\end{tabular}

Para facilitar a análise, os 25 pacientes restantes foram divididos no grupo de sobreviventes (após 28 dias da sepse) e grupo dos pacientes que evoluíram posteriormente a óbito. $\mathrm{Na}$ Tabela 3 estão demonstradas as características dos pacientes analisados no estudo, dentre os quais 17 (68\%) eram do gênero masculino e oito $(32 \%)$, do feminino. A idade média do grupo de sobreviventes (13 pacientes/52\%) foi de $48 \pm 5,1$ anos e a do grupo de não-sobreviventes (12 pacientes/48\%), de $54 \pm 4,6$ anos. O índice de APACHE foi de $27 \pm 2,6$ e $26 \pm 2,0$ respectivamente para sobreviventes e não-sobreviventes. 
Tabela 3 - Característica dos 25 pacientes sépticos internados em unidade de terapia intensiva e analisados neste estudo

\begin{tabular}{|c|c|c|}
\hline \multicolumn{1}{|c|}{ Características } & Sobreviventes & Não sobreviventes \\
\hline & $(n=13)$ & $(n=12)$ \\
Gênero masculino $-n^{\circ}(\%)$ & $8(61,5 \%)$ & $9(75 \%)$ \\
Idade & $48 \pm 5,1$ & $54 \pm 4,6$ \\
APACHE II* & $27 \pm 2,6$ & $26 \pm 2$ \\
\hline
\end{tabular}

*Indice APACHE (Acute Physiology and Chronic Health Evaluation) versão II: 0 índice mais elevado reflete doença crítica mais grave. $O$ índice real nas primeiras 24 horas foi diminuido artificialmente devido às intervenções para ressuscitação na unidade de terapia intensiva e pelo fato de termos assumido para o cálculo o nível de consciência dos pacientes como avaliado antes da sedação.

A origem principal da sepse foi pulmonar, seguida de sepse abdominal. A bactérias que foram isoladas em maior número nas hemoculturas foram os Gram-negativos, sendo que alguns pacientes apresentaram infecções polimicrobianas (Tabela 4). 
Tabela 4 - Origem da sepse e bactérias identificadas em 25 pacientes sépticos internados em unidade de terapia intensiva e incluídos neste estudo

\begin{tabular}{|c|c|c|}
\hline Características & Sobreviventes & Não sobreviventes \\
\hline \multicolumn{3}{|l|}{ Origem da sepse } \\
\hline Pneumonia & $7(54 \%)$ & $6(50 \%)$ \\
\hline Abdominal & $6(46 \%)$ & $3(25 \%)$ \\
\hline Osteomielite & & $1(8,5 \%)$ \\
\hline Endocardite & & $1(8,5 \%)$ \\
\hline Infecção de prótese de quadril & & $1(8,5 \%)$ \\
\hline \multicolumn{3}{|l|}{ Bactéria } \\
\hline Gram-negativa & $7(54 \%)$ & $8(67 \%)$ \\
\hline Gram-positiva & $4(31 \%)$ & $5(42 \%)$ \\
\hline Não-identificada & $3(24 \%)$ & $2(17 \%)$ \\
\hline
\end{tabular}

A Tabela 5 demonstra o diagnóstico, a presença de cirurgia, idade e o tempo de sobrevida dos pacientes incluídos que evoluíram a óbito (dois deles evoluíram a óbito no quinto dia do estudo, não sendo submetidos a análises laboratoriais e ecocardiograma no sexto dia do estudo). A Tabela 6 demonstra a idade, diagnóstico e presença de cirurgia no grupo de pacientes sobreviventes. 
Tabela 5 - Idade, gênero, diagnóstico e tempo de sobrevida dos pacientes sépticos não-sobreviventes (óbito tardio) internados em unidade de terapia intensiva

\begin{tabular}{|c|c|c|c|c|c|}
\hline Identificação & Sexo & Idade & Diagnóstico & Cirurgia & $\begin{array}{l}\text { Tempo de } \\
\text { sobrevida }\end{array}$ \\
\hline CAM & masculino & 65 & $\begin{array}{c}\text { sepse abdominal } \\
\text { (colangite/colecistite) }\end{array}$ & $\operatorname{sim}$ & 22 dias \\
\hline RCSF & masculino & 29 & $\begin{array}{c}\text { sepse abdominal } \\
\text { (perfuração intestinal) }\end{array}$ & $\operatorname{sim}$ & 28 dias \\
\hline$A G$ & masculino & 59 & endocardite & não & 6 dias \\
\hline $\mathrm{FN}$ & masculino & 67 & $\begin{array}{c}\text { sepse abdominal } \\
\text { (abdome agudo } \\
\text { obstrutivo) }\end{array}$ & $\operatorname{sim}$ & 20 dias \\
\hline JNBS & masculino & 37 & broncopneumonia & não & 20 dias \\
\hline MSS & feminino & 46 & broncopneumonia & não & 18 dias \\
\hline AJS & masculino & 69 & broncopneumonia & não & 5 dias \\
\hline JFB & feminino & 68 & broncopneumonia & não & 8 dias \\
\hline RSO & feminino & 68 & $\begin{array}{c}\text { infecção de prótese de } \\
\text { quadril }\end{array}$ & $\operatorname{sim}$ & 9 dias \\
\hline $\mathrm{FC}$ & masculino & 69 & broncopneumonia & não & 6 dias \\
\hline PLBR & masculino & 37 & osteomielite & $\operatorname{sim}$ & 5 dias \\
\hline$E G A$ & masculino & 33 & broncopneumonia & não & 9 dias \\
\hline & & & \multicolumn{3}{|c|}{ Idade } \\
\hline & Média & & \multicolumn{3}{|c|}{53,91} \\
\hline & Mediana & & \multicolumn{3}{|c|}{62} \\
\hline \multicolumn{3}{|c|}{ Erro padrão médio } & \multicolumn{3}{|c|}{4,65} \\
\hline
\end{tabular}




\begin{tabular}{|c|c|c|c|c|}
\hline Identificação & Sexo & Idade & Diagnóstico & Cirurgia \\
\hline JNA & masculino & & broncopneumonia & não \\
\hline $\mathrm{JCM}$ & masculino & 47 & broncopneumonia & não \\
\hline DRN & masculino & 19 & $\begin{array}{l}\text { sepse abdominal (peritonite } \\
\text { bacteriana espontânea) }\end{array}$ & $\operatorname{sim}$ \\
\hline MCG & feminino & 34 & broncopneumonia & não \\
\hline AFA & masculino & 63 & broncopneumonia & não \\
\hline BRM & masculino & 63 & broncopneumonia & não \\
\hline JRS & feminino & 49 & broncopneumonia & não \\
\hline FOB & feminino & 19 & $\begin{array}{l}\text { sepse abdominal } \\
\text { (apendicite) }\end{array}$ & $\operatorname{sim}$ \\
\hline KAPO & feminino & 32 & $\begin{array}{l}\text { sepse abdominal (aborto } \\
\text { infectado) }\end{array}$ & $\operatorname{sim}$ \\
\hline MAJ & masculino & 43 & $\begin{array}{c}\text { sepse abdominal (abdome } \\
\text { agudo perfurativo) }\end{array}$ & $\operatorname{sim}$ \\
\hline MML & masculino & 52 & pancreatite & $\operatorname{sim}$ \\
\hline TPS & feminino & 65 & $\begin{array}{l}\text { sepse abdominal } \\
\text { (diverticulite) }\end{array}$ & $\operatorname{sim}$ \\
\hline PF & masculino & 67 & broncopneumonia & não \\
\hline & & & \multicolumn{2}{|c|}{ Idade } \\
\hline \multicolumn{3}{|c|}{ Média } & \multicolumn{2}{|c|}{47,92} \\
\hline \multicolumn{3}{|c|}{ Mediana } & \multicolumn{2}{|c|}{49} \\
\hline \multicolumn{3}{|c|}{ Erro padrão médio } & \multicolumn{2}{|c|}{5,11} \\
\hline
\end{tabular}

Não pudemos obter amostras do miocárdio dos pacientes sobreviventes. 


\subsection{Pesquisa de lesão cardíaca (dados bioquímicos)}

Ocorreu aumento significativo da troponina sérica a partir do primeiro dia do estudo, e os níveis de troponina estiveram associados com aumento da mortalidade. No grupo de sobreviventes, os níveis séricos de troponina foram de $0,53 \pm 0,13 \mathrm{mg} / \mathrm{ml}$, e, no grupo de não-sobreviventes, de 2,31 \pm $1,01 \mathrm{mg} / \mathrm{ml}(\mathrm{p}<0,05)$ (Figura 1).

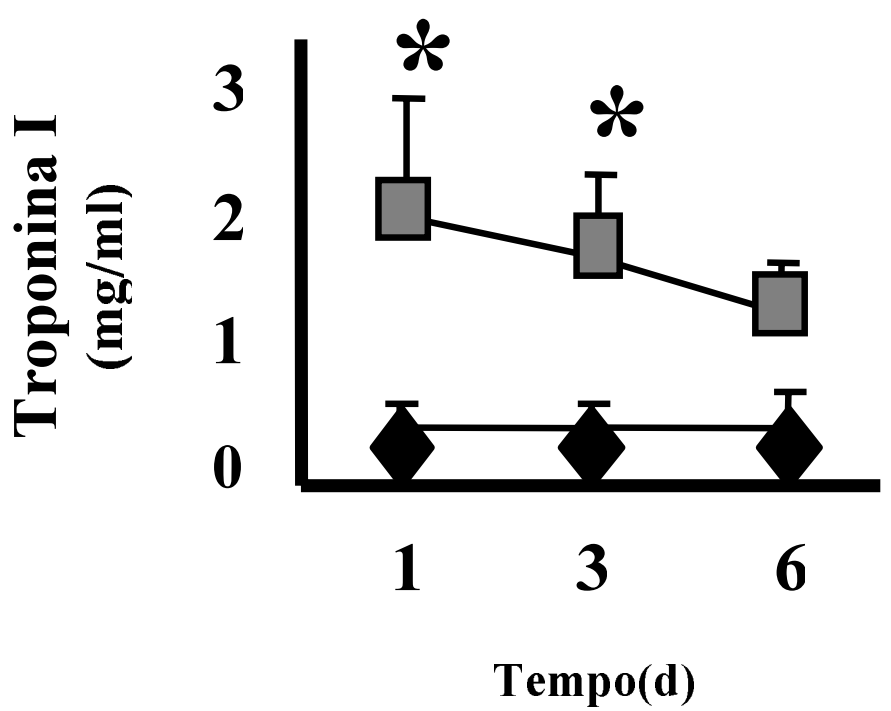

Figura 1 - Evolução temporal das concentrações plasmáticas de troponina sérica em pacientes sépticos internados em unidade de terapia intensiva, comparando os grupos sobreviventes (SV) e nãosobreviventes (NS). Os dados são representados como erro padrão médio $(p<0,05)$

Dois pacientes morreram antes do sexto dia da internação. No decorrer do estudo, a diferença dos níveis séricos de troponina, quando comparados 
sobreviventes e não-sobreviventes, se manteve nos dias 3 e 6 , apesar de dois pacientes terem morrido até o sexto dia. O grupo de não-sobreviventes manteve os níveis de troponina elevados durante os seis dias do estudo.

A dosagem de creatinofosfoquinase e creatinofosfoquinase fração MB não mostrou diferenças significativas entre os dois grupos.

\subsection{Análise da função cardíaca}

\subsubsection{Ecocardiograma e medidas hemodinâmicas}

A análise ecocardiográfica demonstrou tendência ao aumento do átrio esquerdo $(40 \pm 6 \mathrm{~mm})$ no grupo dos pacientes que evoluíram a óbito. $A$ diferença não foi significativa e o resultado parece estar relacionado ao aumento da incidência de arritmias supraventriculares, fenômeno semelhante ao de outras doenças cardíacas.

A Tabela 7 demonstra os dados do ecocardiograma obtidos no primeiro dia dos pacientes que evoluíram a óbito tardio. A Tabela 8 demonstra os dados dos pacientes sobreviventes na admissão; não encontramos diferenças significativas entre os dois grupos. A Tabela 9 demonstra os resultados dos pacientes que faleceram em até seis horas da admissão; em dois doentes não houve tempo hábil para a realização do exame. 
Tabela 7 - Dados do ecocardiograma realizado no primeiro dia do estudo nos pacientes sépticos internados em unidade de terapia intensiva que evoluíram a óbito tardio

\begin{tabular}{|c|c|c|c|c|c|c|c|c|c|c|}
\hline $\begin{array}{c}\text { Identif } \\
\text { icaçã } \\
\circ\end{array}$ & Sexo & Idade & $\begin{array}{l}\text { HAS } \\
\text { prévia }\end{array}$ & FE & Átrio $\mathrm{E}$ & DDVE & DSVE & DD & SIV & PP \\
\hline CAM & masculino & 65 & $\operatorname{sim}$ & 0,73 & 37 & 48 & 31 & 36 & 10 & 10 \\
\hline RCSF & masculino & 29 & não & 0,74 & 38 & 53 & 34 & 36 & 9 & 9 \\
\hline$A G$ & masculino & 59 & não & 0,73 & 40 & 49 & 33 & 32 & 9 & 9 \\
\hline $\mathrm{FN}$ & masculino & 67 & $\operatorname{sim}$ & 0,70 & 38 & 47 & 31 & 33 & 11 & 10 \\
\hline JNBS & masculino & 37 & não & 0,79 & 39 & 49 & 29 & 41 & 9 & 9 \\
\hline MSS & feminino & 46 & não & 0,75 & 36 & 51 & 33 & 42 & 10 & 10 \\
\hline AJS & masculino & 69 & $\operatorname{sim}$ & 0,69 & 39 & 52 & 35 & 32 & 11 & 11 \\
\hline JFB & feminino & 68 & $\operatorname{sim}$ & 0,65 & 34 & 53 & 34 & 30 & 10 & 10 \\
\hline RSO & feminino & 68 & $\operatorname{sim}$ & 0,66 & 40 & 52 & 32 & 33 & 9 & 10 \\
\hline FC & masculino & 69 & $\operatorname{sim}$ & 0,75 & 41 & 51 & 34 & 32 & 8 & 9 \\
\hline PLBR & masculino & 37 & não & 0,80 & 37 & 51 & 30 & 42 & 9 & 9 \\
\hline EGA & masculino & 33 & não & 0,72 & 39 & 49 & 32 & 31 & 9 & 10 \\
\hline & Idade & FE & Átrio & DDVE & DS & & DD & SIV & & PP \\
\hline média & 53,91 & 0,72 & 38,16 & 50,41 & 32 & & 35 & 9,5 & & 66 \\
\hline mediana & 62 & 0,73 & 38,5 & 51 & 32 & & 33 & 9 & & 10 \\
\hline $\begin{array}{l}\text { Erro } \\
\text { padrão } \\
\text { médio }\end{array}$ & 4,65 & 0,013 & 0,56 & 0,57 & 0, & & 1,27 & 0,26 & & 19 \\
\hline
\end{tabular}

HAS = hipertensão arterial sistêmica; FE = fração de ejeção; DDVE = diâmetro diastólico do ventrículo esquerdo $(\mathrm{em} \mathrm{mm})$; DSVE = diâmetro sistólico do ventrículo esquerdo $(\mathrm{em} \mathrm{mm}) ; \mathrm{DD}=$ diâmetro diastólico $(\mathrm{em}$ $\mathrm{mm}) ; \mathrm{SIV}=$ diâmetro do septo intraventricular (em mm); PP = diâmetro da parede posterior do ventrículo esquerdo (em $\mathrm{mm}$ ). 
Tabela 8 - Dados do ecocardiograma realizado no primeiro dia do estudo, à admissão em unidade de terapia intensiva, nos pacientes sépticos e que sobreviveram

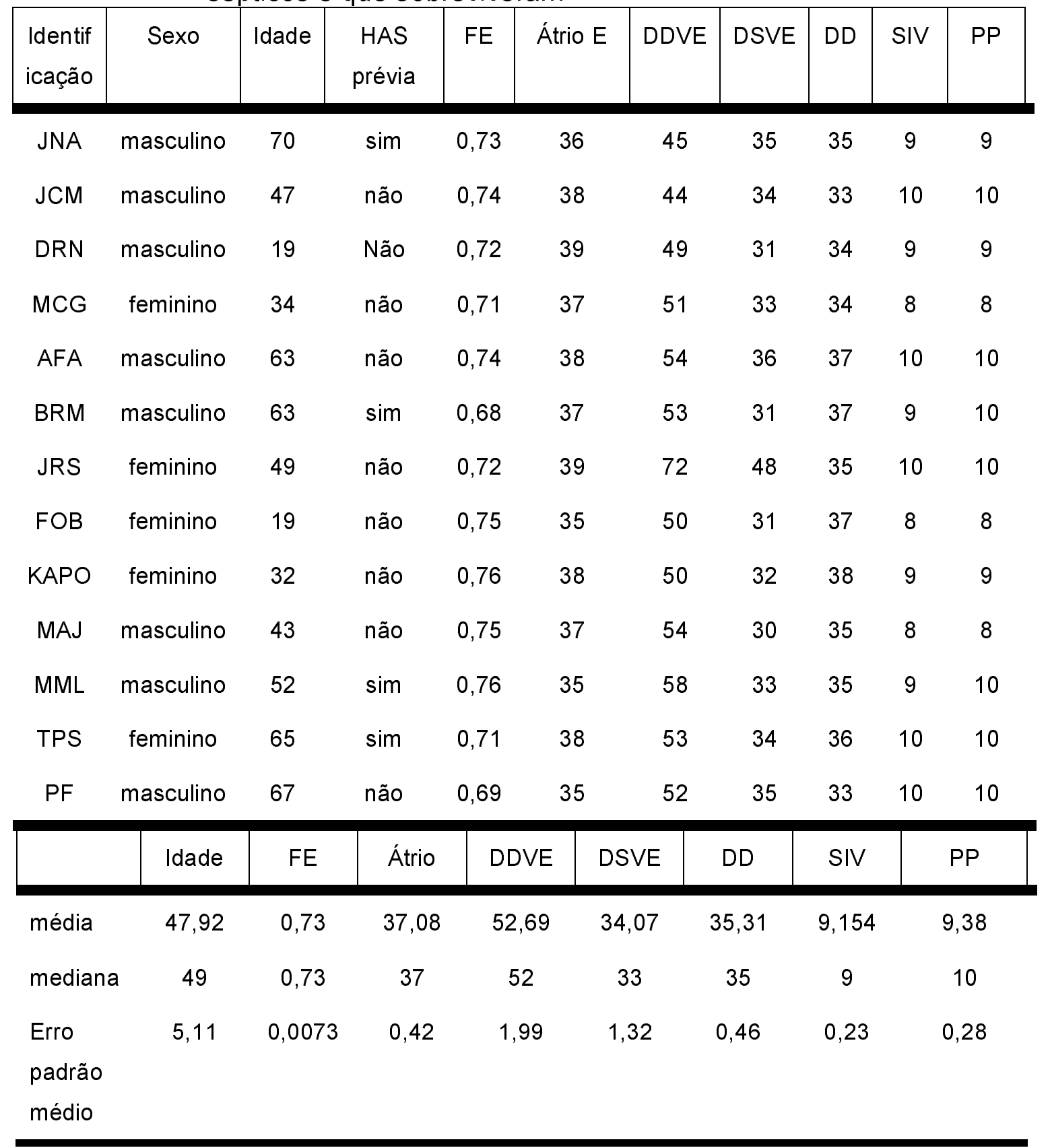

HAS = hipertensão arterial sistêmica; FE = fração de ejeção; DDVE = diâmetro diastólico do ventrículo esquerdo $(\mathrm{em} \mathrm{mm})$; DSVE = diâmetro sistólico do ventrículo esquerdo $(\mathrm{em} \mathrm{mm}) ; \mathrm{DD}=$ diâmetro diastólico (em $\mathrm{mm}) ; \mathrm{SIV}=$ diâmetro do septo intraventricular (em $\mathrm{mm}) ; \mathrm{PP}=$ diâmetro da parede posterior do ventrículo esquerdo (em $\mathrm{mm}$ ). 
Tabela 9 - Dados do ecocardiograma realizado no primeiro dia do estudo, no grupo de pacientes sépticos que evoluíram a óbito em até seis horas da admissão em unidade de terapia intensiva. Em dois doentes, não houve tempo hábil para a realização do ecocardiograma

\begin{tabular}{|c|c|c|c|c|c|c|c|c|c|c|}
\hline $\begin{array}{l}\text { Identific } \\
\text { ação }\end{array}$ & Sexo & Idade & $\begin{array}{l}\text { HAS } \\
\text { prévia }\end{array}$ & FE & Átrio $E$ & DDVE & DSVE & DD & SIV & PP \\
\hline RS & masculino & 20 & não & 0,70 & 42 & 64 & 33 & 30 & 9 & 9 \\
\hline CA & masculino & 57 & $\operatorname{sim}$ & --- & --- & --- & --- & --- & -- & --- \\
\hline OS & masculino & 74 & $\operatorname{sim}$ & 0,45 & 44 & 65 & 39 & 26 & 11 & 11 \\
\hline$A B$ & masculino & 29 & não & 0,50 & 43 & 62 & 32 & 29 & 8 & 8 \\
\hline PCS & masculino & 47 & não & 0,55 & 40 & 66 & 35 & 28 & 9 & 9 \\
\hline LA & masculino & 64 & $\operatorname{sim}$ & --- & & --- & & & & \\
\hline & Idade & FE & Átrio & DDVE & & & DD & SIV & & PP \\
\hline média & 45,4 & 0,55 & 42,25 & 64,25 & & & 28,25 & 9,25 & & 9,25 \\
\hline mediana & 47 & 0,525 & 42,5 & 64,5 & & & 28,5 & 9 & & 9 \\
\hline $\begin{array}{l}\text { Erro } \\
\text { padrão } \\
\text { médio }\end{array}$ & 6,24 & 0,03 & 0,49 & 0,49 & & 39 & 0,49 & 0,36 & & 0,36 \\
\hline
\end{tabular}

HAS = hipertensão arterial sistêmica; FE $=$ fração de ejeção; DDVE $=$ diâmetro diastólico do ventrículo esquerdo $(\mathrm{em} \mathrm{mm})$; DSVE = diâmetro sistólico do ventrículo esquerdo $(\mathrm{em} \mathrm{mm}) ; \mathrm{DD}=$ diâmetro diastólico $(\mathrm{em}$ $\mathrm{mm}) ; \mathrm{SIV}=$ diâmetro do septo intraventricular (em mm); PP = diâmetro da parede posterior do ventrículo esquerdo (em $\mathrm{mm}$ ).

As Tabelas 10 e 11 demonstram os dados do ecocardiograma obtidos no sexto dia do estudo. Encontramos diferença significativa na fração de ejeção e no tamanho do átrio esquerdo quando comparamos o grupo de pacientes sobreviventes e não-sobreviventes no primeiro e no sexto dia do estudo. Os sobreviventes apresentaram uma menor dilatação das câmaras esquerda, o que pode explicar uma menor incidência de arritmias no grupo (dados não mostrados). A fração de ejeção, apesar de estar maior no grupo 
de pacientes que sobreviveram, pode ser compatível com o estado circulatório hiperdinâmico.

Tabela 10 - Dados ecocardiográficos no sexto dia de internação em unidade de terapia intensiva dos pacientes sépticos que evoluíram a óbito. Dois doentes não aparecem na Tabela por terem evoluído a óbito no quinto dia

\begin{tabular}{|c|c|c|c|c|c|c|c|c|c|c|}
\hline $\begin{array}{l}\text { Identifi } \\
\text { cação }\end{array}$ & Sexo & Idade & $\begin{array}{l}\text { HAS } \\
\text { prévia }\end{array}$ & FE & Átrio $\mathrm{E}$ & DDVE & DSVE & $\mathrm{DD}$ & SIV & PP \\
\hline CAM & masculino & 65 & $\operatorname{sim}$ & 0,69 & 37 & 48 & 31 & 36 & 10 & 10 \\
\hline RCSF & masculino & 29 & não & 0,70 & 38 & 53 & 34 & 36 & 9 & 9 \\
\hline$A G$ & masculino & 59 & não & 0,69 & 38 & 52 & 35 & 32 & 11 & 11 \\
\hline $\mathrm{FN}$ & masculino & 67 & $\operatorname{sim}$ & 0,70 & 39 & 47 & 31 & 33 & 11 & 11 \\
\hline JNBS & masculino & 37 & não & 0,72 & 40 & 54 & 35 & 35 & 10 & 10 \\
\hline MSS & feminino & 46 & não & 0,65 & 36 & 51 & 33 & 42 & 10 & 10 \\
\hline JFB & feminino & 68 & $\operatorname{sim}$ & 0,65 & 37 & 53 & 34 & 30 & 10 & 10 \\
\hline RSO & feminino & 68 & $\operatorname{sim}$ & 0,62 & 38 & 52 & 33 & 30 & 10 & 10 \\
\hline $\mathrm{FC}$ & masculino & 69 & $\operatorname{sim}$ & 0,69 & 42 & 51 & 34 & 29 & 12 & 10 \\
\hline$E G A$ & masculino & 33 & não & 0,68 & 37 & 50 & 35 & 31 & 9 & 10 \\
\hline & Idade & FE & Átrio & DDVE & DS & & DD & SIV & & PP \\
\hline média & 54,1 & $0,69^{* \dagger}$ & $38,2^{*}$ & 51,1 & 33 & & 33,4 & $10,2^{*}$ & & $0,1^{\dagger}$ \\
\hline mediana & 62 & 0,69 & 38 & 51,5 & 3 & & 32,5 & 10 & & 10 \\
\hline $\begin{array}{l}\text { Erro } \\
\text { padrão } \\
\text { médio }\end{array}$ & 4,6 & 0,0086 & 0,50 & 0,64 & & & 1,140 & 0,26 & & 0,16 \\
\hline
\end{tabular}

${ }^{*} p<0,05$ comparando valores de sobreviventes e não-sobreviventes; $p<$ 0,05 comparando valores do primeiro contra o sexto dia; HAS = hipertensão arterial sistêmica; FE = fração de ejeção; DDVE = diâmetro diastólico do ventrículo esquerdo (em $\mathrm{mm})$; DSVE = diâmetro sistólico do ventrículo esquerdo (em mm); DD = diâmetro diastólico $(\mathrm{em} \mathrm{mm})$; SIV = diâmetro do septo intraventricular $(\mathrm{em} \mathrm{mm}) ; \mathrm{PP}=$ diâmetro da parede posterior do ventrículo esquerdo (em $\mathrm{mm}$ ). 
Tabela 11 - Dados ecocardiográficos no sexto dia de internação em unidade de terapia intensiva dos pacientes sépticos sobreviventes

\begin{tabular}{|c|c|c|c|c|c|c|c|c|c|c|}
\hline $\begin{array}{l}\text { Identifi } \\
\text { cação }\end{array}$ & Sexo & Idade & $\begin{array}{l}\text { HAS } \\
\text { prévia }\end{array}$ & FE & Átrio $\mathrm{E}$ & DDVE & DSVE & DD & SIV & PP \\
\hline JNA & masculino & 70 & $\operatorname{sim}$ & 0,72 & 33 & 52 & 35 & 34 & 10 & 11 \\
\hline $\mathrm{JCM}$ & masculino & 47 & não & 0,70 & 32 & 49 & 34 & 32 & 9 & 10 \\
\hline DRN & masculino & 19 & não & 0,75 & 30 & 48 & 30 & 37 & 10 & 10 \\
\hline $\mathrm{MCG}^{*}$ & feminino & 34 & não & 0,71 & 35 & 51 & 33 & 34 & 8 & 8 \\
\hline AFA & masculino & 63 & não & 0,68 & 33 & 49 & 36 & 36 & 10 & 10 \\
\hline BRM & masculino & 63 & $\operatorname{sim}$ & 0,69 & 36 & 48 & 34 & 31 & 9 & 10 \\
\hline $\mathrm{JRS}^{*}$ & feminino & 49 & não & 0,73 & 33 & 51 & 33 & 35 & 10 & 10 \\
\hline $\mathrm{FOB}^{*}$ & feminino & 19 & não & 0,80 & 28 & 48 & 28 & 42 & 9 & 9 \\
\hline KAPO* & feminino & 32 & Não & 0,75 & 31 & 48 & 30 & 37 & 10 & 10 \\
\hline MAJ & masculino & 43 & não & 0,75 & 33 & 54 & 30 & 35 & 8 & 8 \\
\hline MML & masculino & 52 & $\operatorname{sim}$ & 0,71 & 32 & 52 & 32 & 32 & 9 & 10 \\
\hline TPS & feminino & 65 & $\operatorname{sim}$ & 0,69 & 34 & 52 & 36 & 33 & 10 & 10 \\
\hline PF & masculino & 67 & não & 0,73 & 32 & 49 & 32 & 34 & 10 & 10 \\
\hline & Idade & FE & Átrio & DDVE & DSV & & D & SIV & & $P P$ \\
\hline média & 47,92 & 0,73 & 32,46 & 50,08 & 32,5 & & 4,77 & 9,39 & &, 77 \\
\hline mediana & 49 & 0,725 & 33 & 49 & 33 & & 34 & 10 & & 10 \\
\hline $\begin{array}{l}\text { Erro } \\
\text { padrão } \\
\text { médio }\end{array}$ & 5,11 & 0,0095 & $0,60^{*}$ & 0,58 & 0,7 & & 83 & 0,22 & & $27^{*}$ \\
\hline
\end{tabular}

${ }^{*} p<0,005$ comparando valores do primeiro contra o sexto dia; HAS $=$ hipertensão arterial sistêmica; FE = fração de ejeção; DDVE = diâmetro diastólico do ventrículo esquerdo $(\mathrm{em} \mathrm{mm})$; DSVE = diâmetro sistólico do ventrículo esquerdo $(\mathrm{em} \mathrm{mm}) ; \mathrm{DD}=$ diâmetro diastólico $(\mathrm{em} \mathrm{mm}) ; \mathrm{SIV}=$ diâmetro do septo intraventricular $(\mathrm{em} \mathrm{mm}) ; \mathrm{PP}=$ diâmetro da parede posterior do ventrículo esquerdo (em $\mathrm{mm})$. 
O índice cardíaco e a resistência vascular sistêmica não mostraram diferença significativa entre os dois grupos em nenhum momento do estudo.

A depressão da função cardíaca, detectada pelo índice de trabalho sistólico do ventrículo esquerdo, foi mais importante no grupo de nãosobreviventes, tornando-se significantemente maior no decorrer do estudo $(p<0,05)$.

O grupo de não-sobreviventes apresentou uma diminuição no índice de trabalho do ventrículo esquerdo $\left(34,0 \pm 6,7\right.$ versus $48,6 \pm 6,7 \mathrm{~g} \mathrm{x} \mathrm{m} / \mathrm{m}^{2}$, respectivamente não-sobreviventes e sobreviventes, $p<0,05$ ). A diferença no trabalho de ejeção aumentou do dia 3 ao dia 6 (Figura 2).
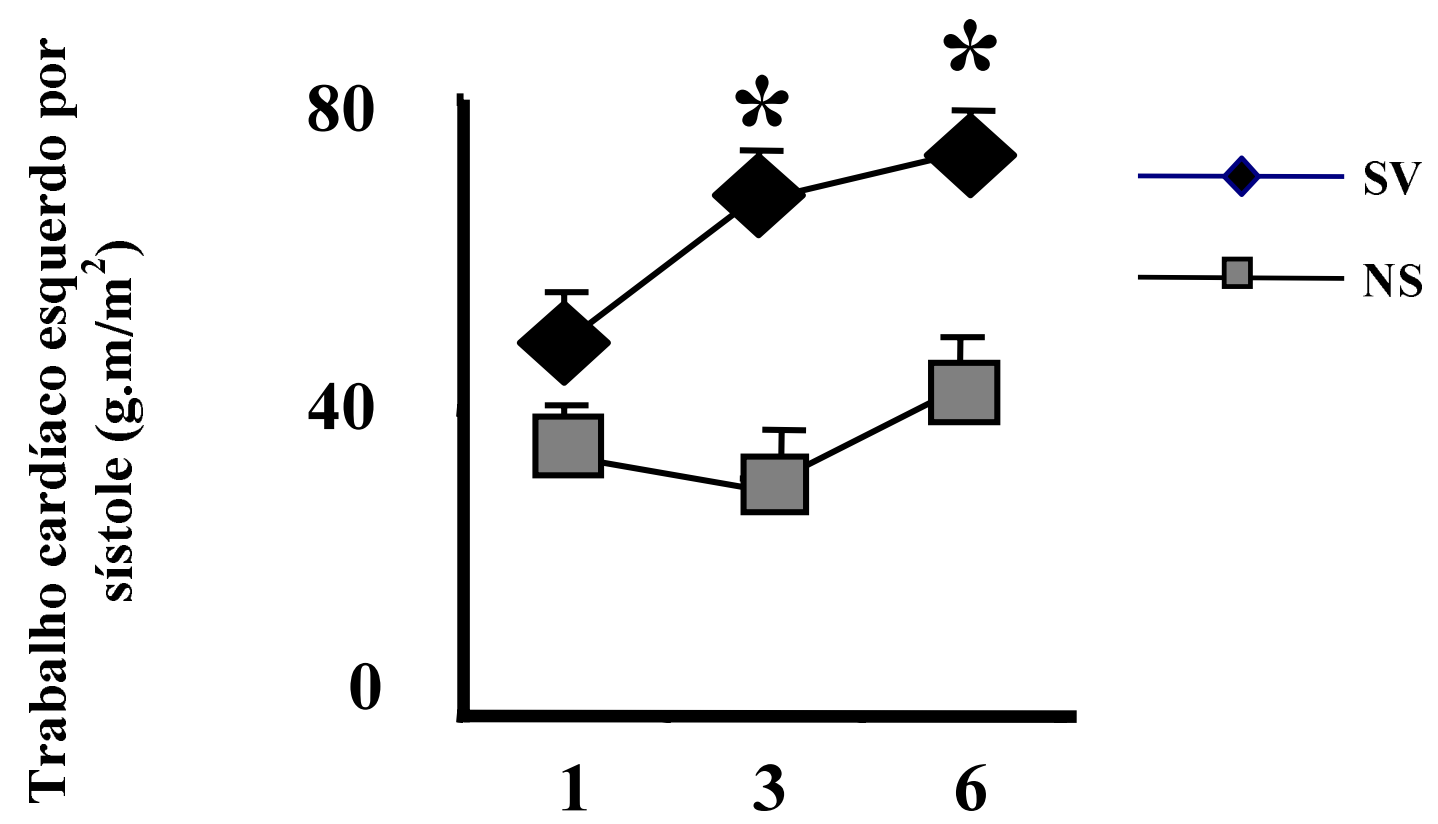

\section{Tempo (d)}

Figura 2 - Evolução temporal do índice de trabalho do ventrículo esquerdo por sístole, comparando os grupos sobreviventes (SV) e nãosobreviventes (NS), entre pacientes sépticos internados em unidade de terapia intensiva. Os dados são representados como erro padrão médio $(p<0,05)$ 
O volume diastólico final do ventrículo esquerdo mostrou aumento a partir do sexto dia entre o grupo de sobreviventes e não-sobreviventes, mostrando diferença significativa $(p<0,05)$. A dilatação ventricular parece ser um mecanismo protetor nesse grupo de doentes (Figura 3).

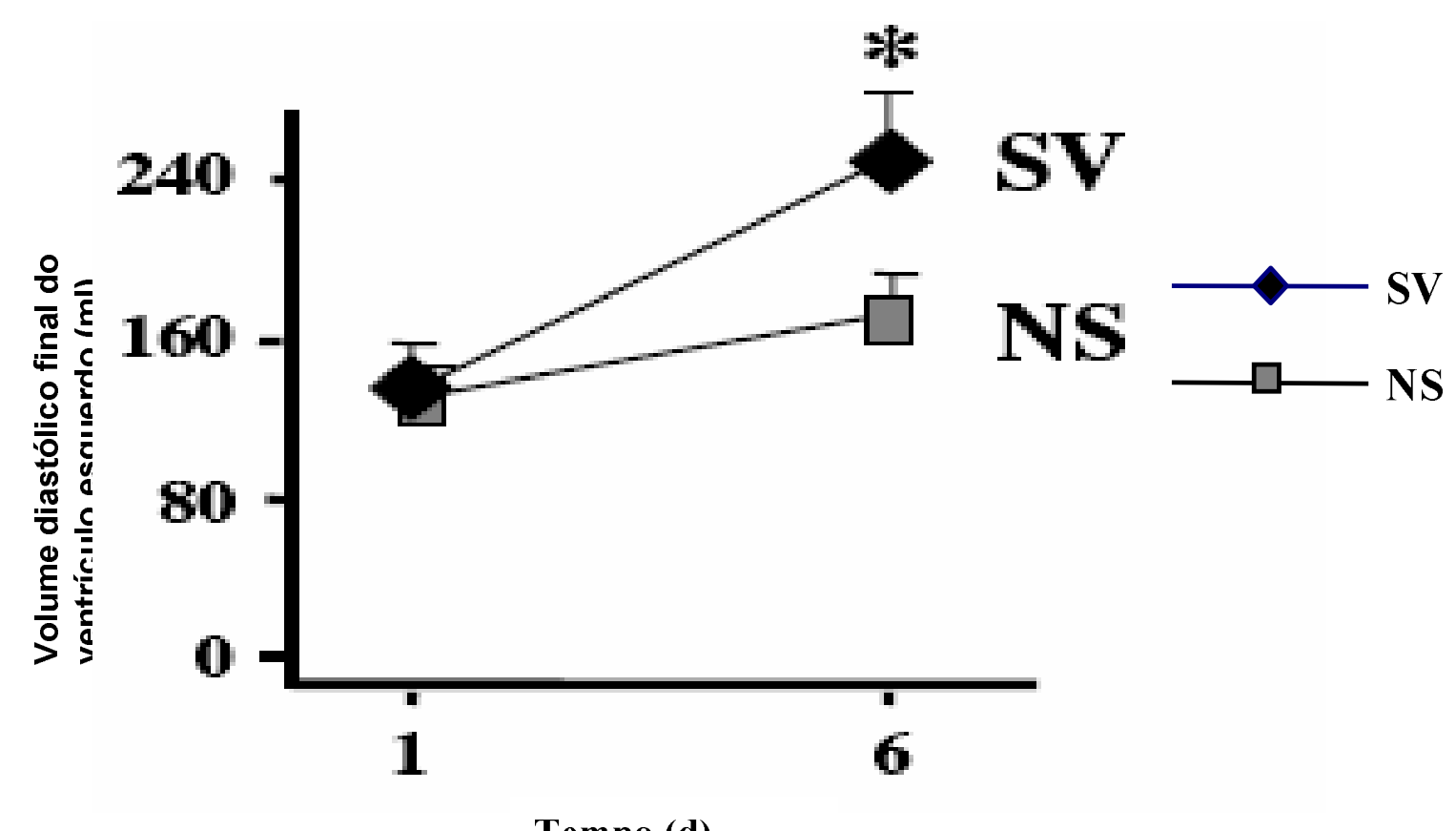

Figura 3 - Diferença do volume diastólico final do ventrículo nos grupos de pacientes sobreviventes (SV) e não-sobreviventes (NS) internados em unidade de terapia intensiva com sepse. Os dados são representados como erro padrão médio $\left({ }^{*} \mathrm{p}<0,05\right)$ 


\title{
4.4. Análise da variabilidade da freqüência cardíaca
}

\subsubsection{Análise das bandas de freqüência}

\begin{abstract}
A variabilidade da freqüência cardíaca mostrou diferença significativa da freqüência baixa (BF) máxima e mínima (Figuras 4a e 4b), o grupo de não-sobreviventes apresentou os menores valores. A análise multivariada apontou a BF como uma variável independente para predizer alta da unidade de terapia intensiva.
\end{abstract}



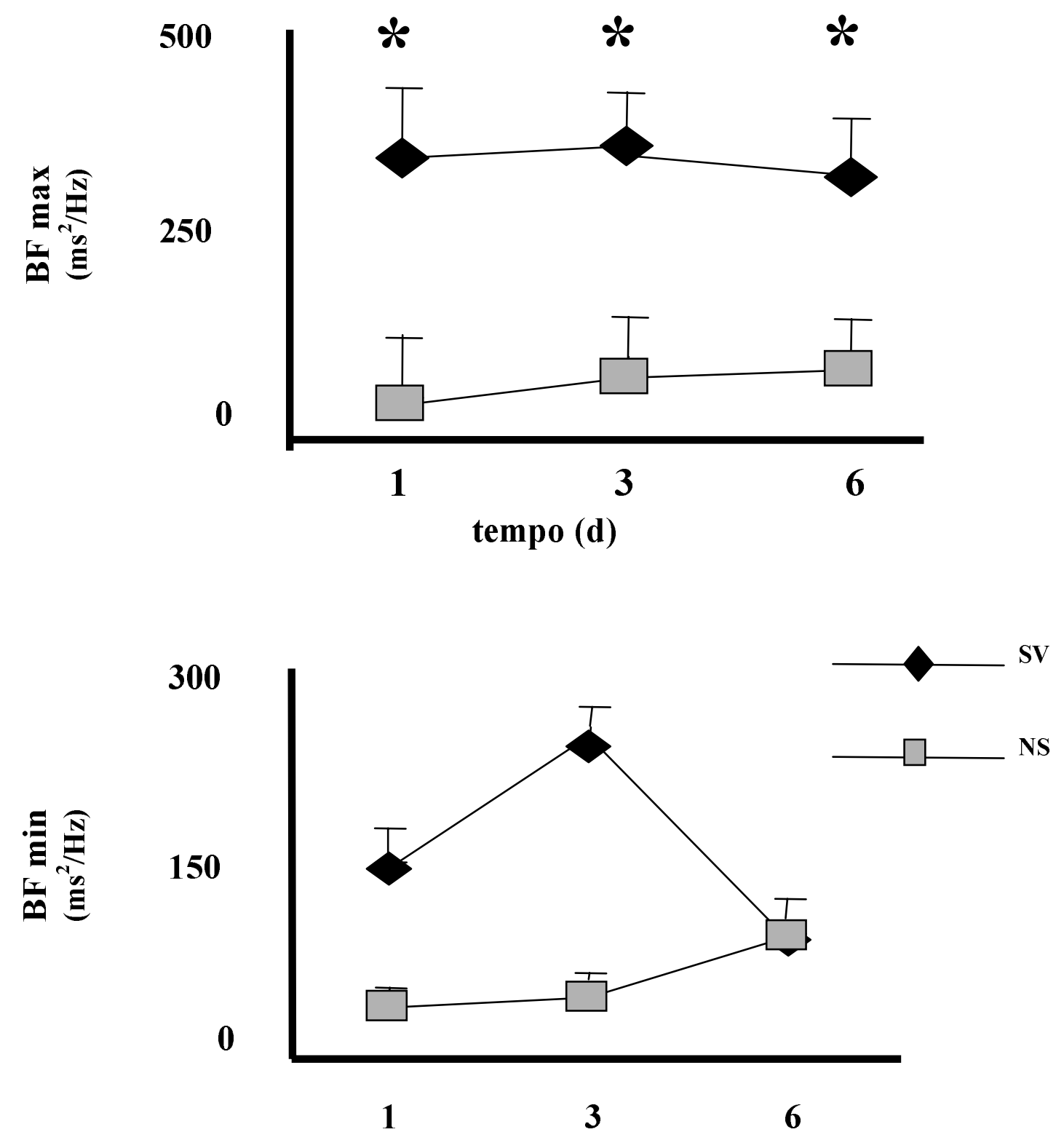

Tempo (d)

Figura 4A - Índices de baixa freqüência (BF) cardíaca, máxima e mínima, na análise da variabilidade de freqüência cardíaca de pacientes sépticos internados em unidade de terapia intensiva. Os dados foram representados como erro padrão médio $\left({ }^{*} p<0,05\right)$ 


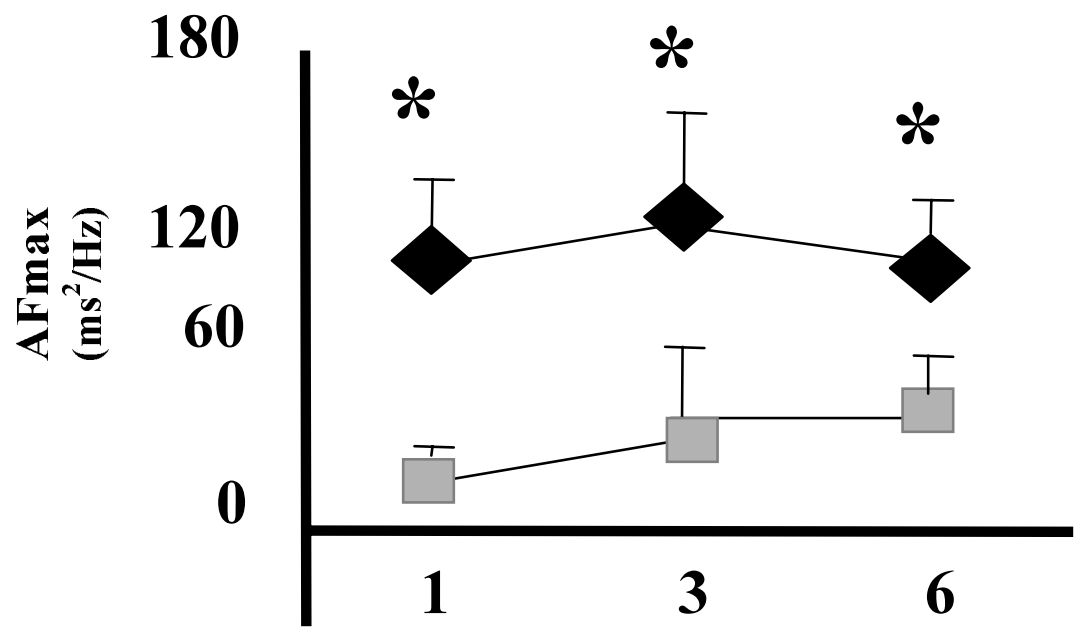

Tempo (d)

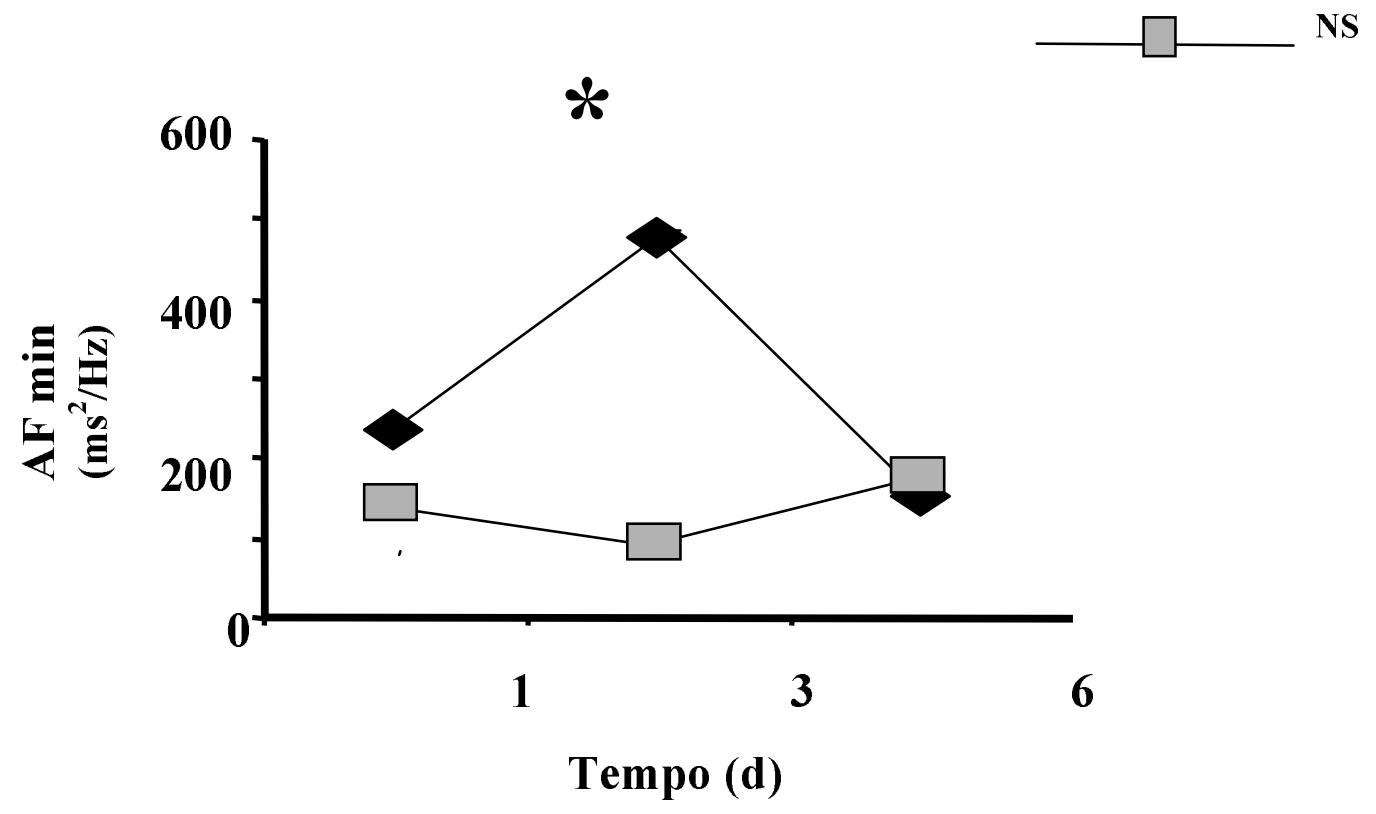

Figura 4B - Dados de alta freqüência (AF) cardíaca, da análise da variabilidade da freqüência cardíaca de pacientes sépticos internados em unidade de terapia intensiva, representados como erro padrão médio $\left({ }^{*} p<0,05\right)$ 
Os índices de baixa freqüência e alta freqüência, na razão LF/HF (low frequency/high frequency) máxima, se mostraram reduzidos no grupo de não-sobreviventes, indicando a capacidade diminuída em regular a variabilidade da freqüência cardíaca.

4.4.2. Análise do uso de medicamentos que podem alterar a variabilidade da freqüência cardíaca

\subsubsection{Drogas vasoativas}

As doses de noradrenalina, dopamina e dobutamina recebidas pelos grupos de sobreviventes e não-sobreviventes (drogas vasoativas que poderiam ter alterado o valor da variabilidade da freqüência cardíaca e aumentado a incidência de arritmias cardíacas) não mostraram diferenças significativas (Figura 5). 

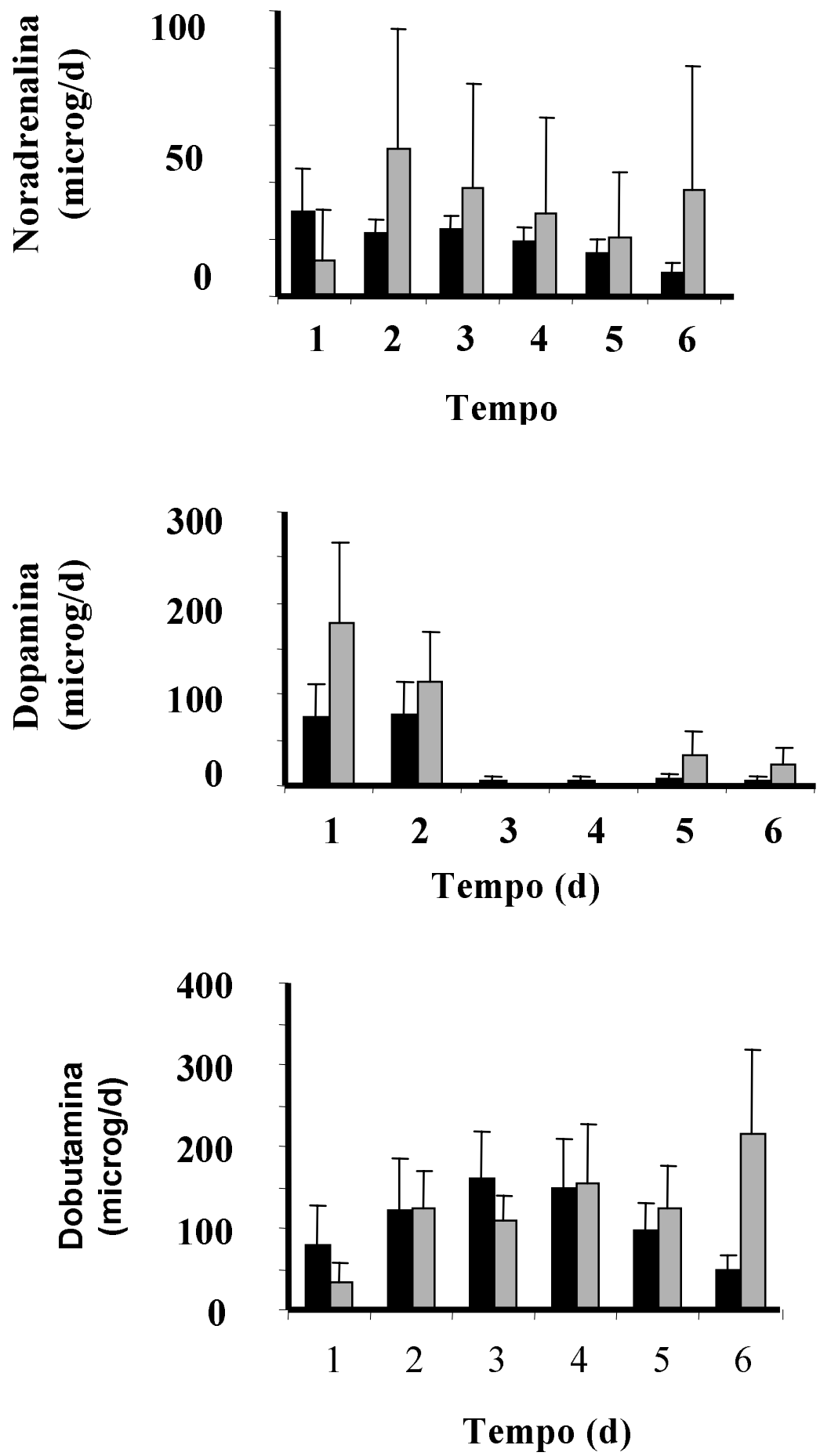

Figura 5-Quantidade de catecolaminas recebidas pelo pacientes sépticos internados em unidade de terapia intensiva. Não houve diferença significativa entre os dois grupos, de sobreviventes (SV) e não-sobreviventes (NS) 
4.4.2.2. Doses de sedação recebidas

As doses de sedação (fentanil e midazolam), recebidas não mostraram diferenças significativas entre os dois grupos (Figura 6). A sedação poderia alterar o cálculo da variabilidade da freqüência cardíaca e a quantidade de catecolaminas recebidas. 


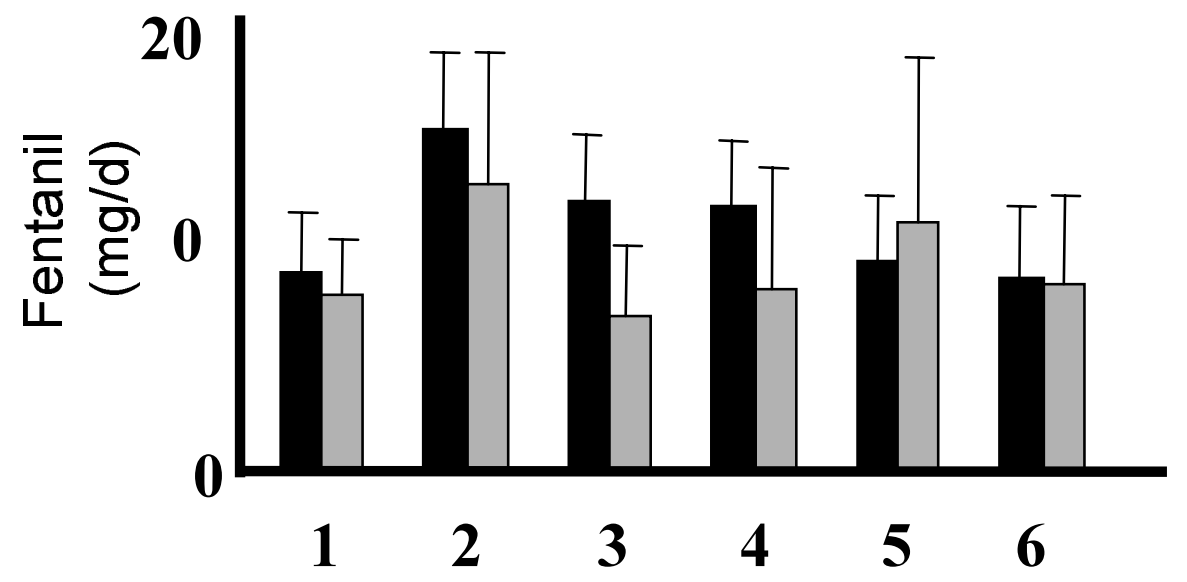

Tempo (d)

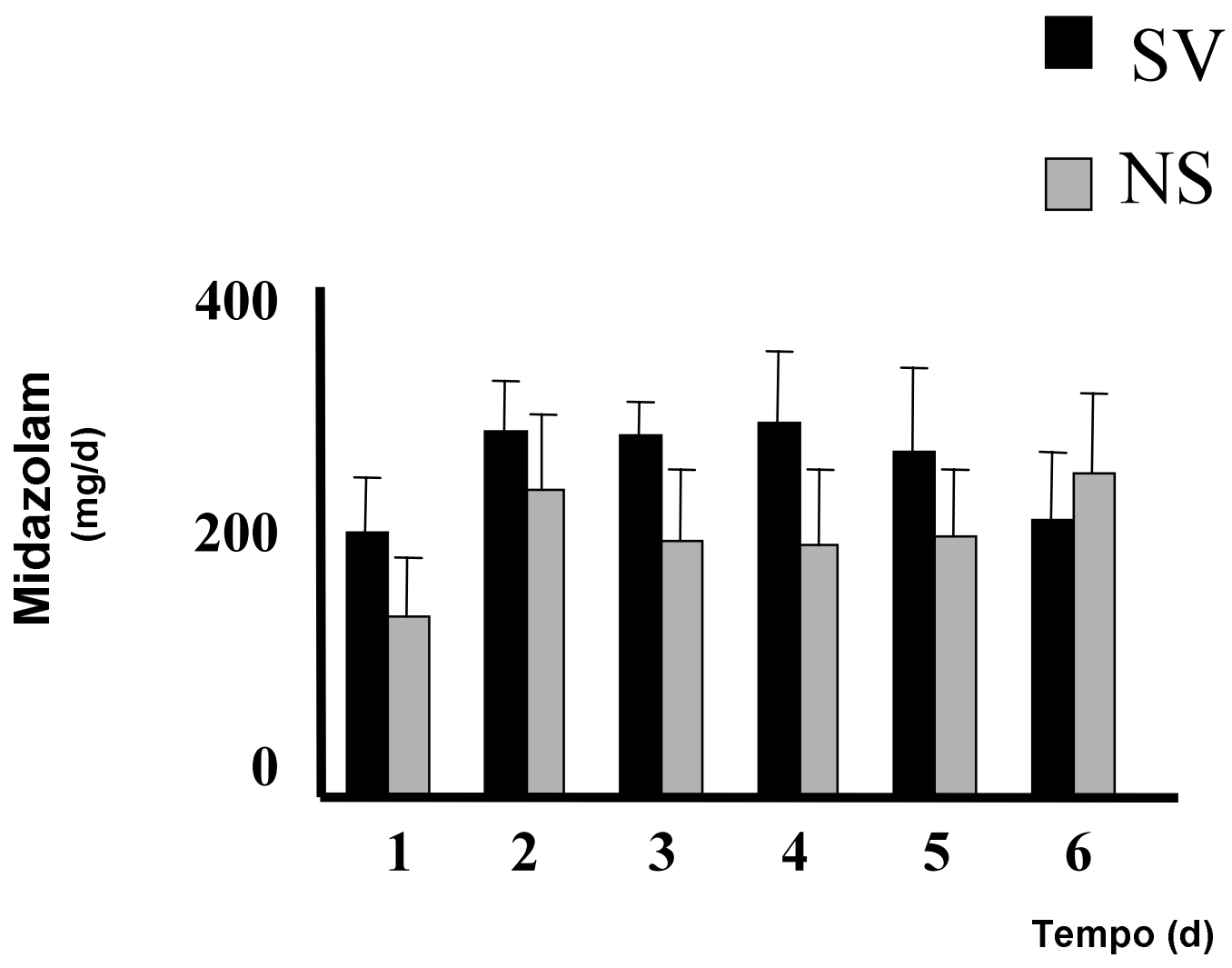

Figura 6 - Quantidade de sedativos utilizada pelo grupo de sobreviventes (SV) e não-sobreviventes (NS) internados em unidade de terapia intensiva. Os dados foram representados como erro padrão médio $\left({ }^{*} p<0,05\right)$ 
4.5. Análise da variabilidade da freqüência cardíaca

\subsubsection{Correlação da troponina I com o índice de baixa freqüência normalizado}

O aumento da troponina I nos pacientes não-sobreviventes mostrou correlação com o índice de baixa freqüência normalizado da variabilidade da freqüência cardíaca, não havendo correlação nos sobreviventes (Figuras 7 e 8 ).

A lesão cardíaca demonstrada pelo aumento da troponina pode contribuir para diminuição da resposta das células cardíacas ao controle autonômico, correlacionando com o índice da baixa freqüência da variabilidade da freqüência cardíaca. 


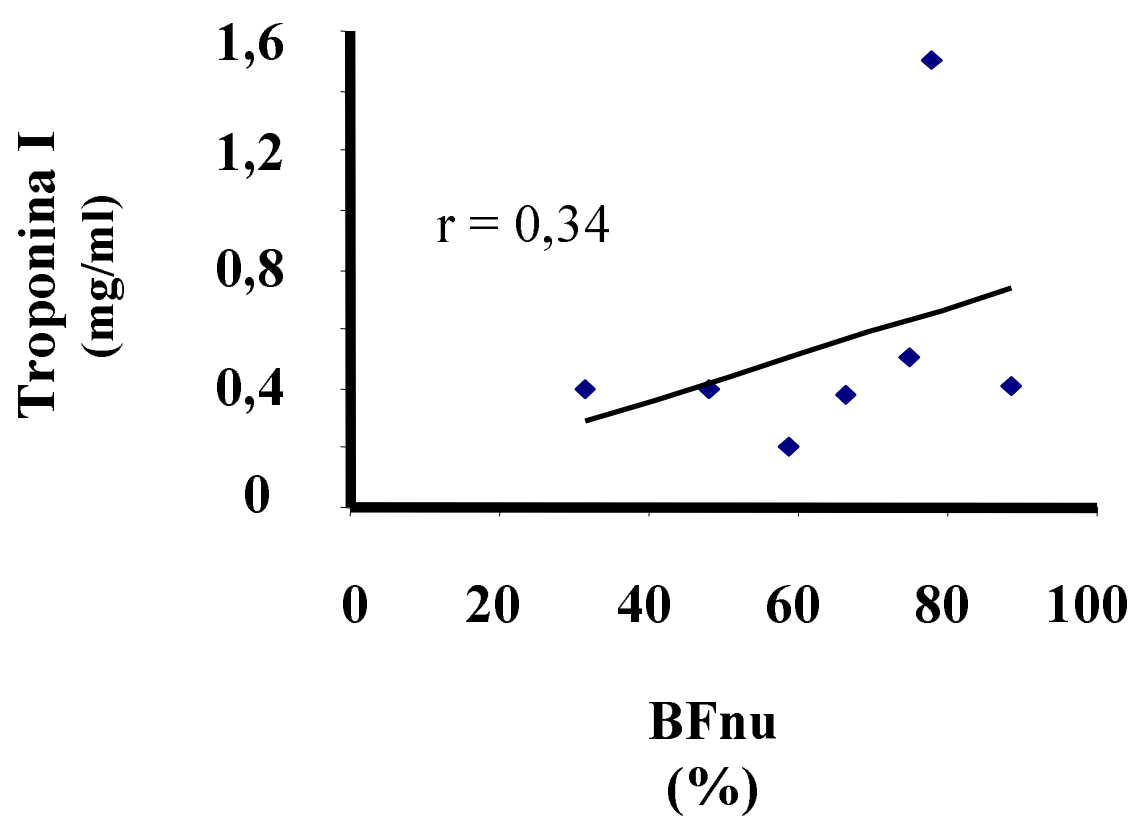

Figura 7 - Correlação da troponina I com a baixa freqüência normalizado (Bfnu) nos pacientes sobreviventes no primeiro dia de internação em unidade de terapia intensiva

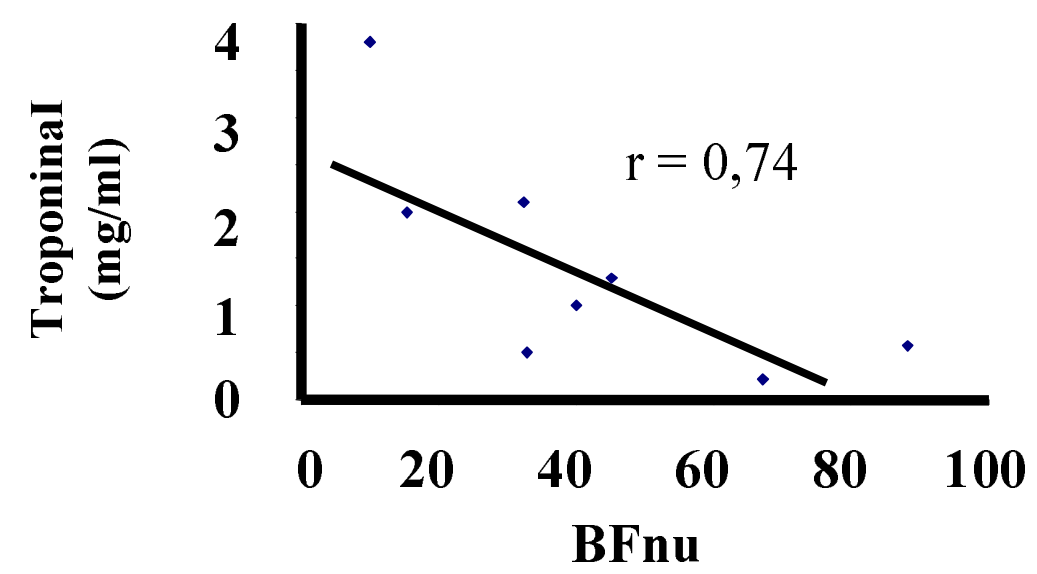

$(\%)$

Figura 8 - Correlação da troponina I com a baixa freqüência normalizado (Bfnu) nos pacientes sépticos não-sobreviventes no primeiro dia de internação em unidade de terapia intensiva 


\subsubsection{Correlação da proteína C-reativa com o índice de baixa} freqüência normalizado

O aumento da PCR nos não-sobreviventes correlacionou-se com a baixa freqüência normalizada (BFnu) da variabilidade da freqüência cardíaca. O dado pode sugerir uma interação entre a inflamação e a lesão cardíaca (Figuras 9 e 10).

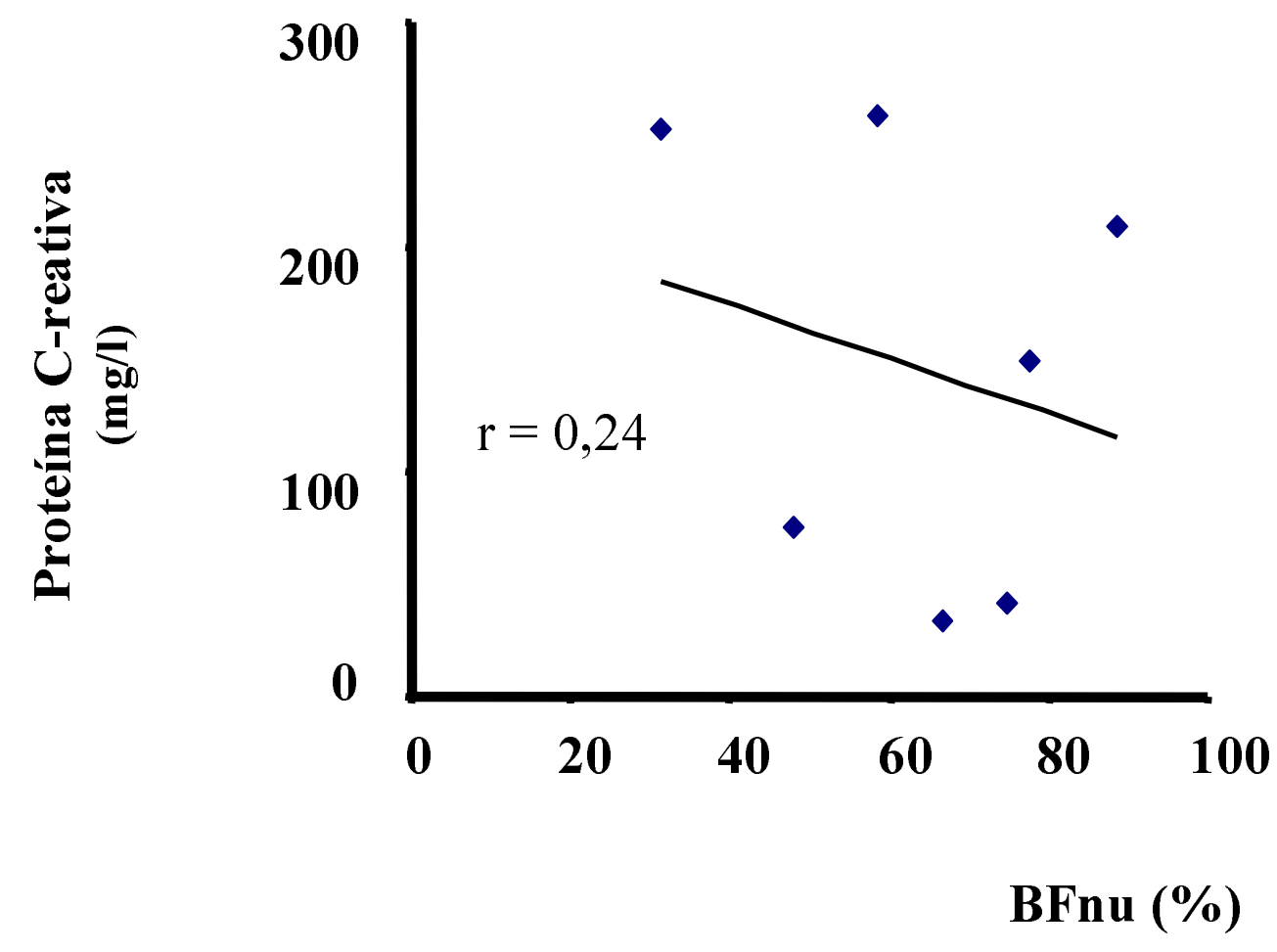

Figura 9 - Correlação da proteína C-reativa com o índice de baixa freqüência cardíaca normalizado (BFnu) no grupo de pacientes sépticos sobreviventes no primeiro dia do estudo, realizado em unidades de terapia intensiva 

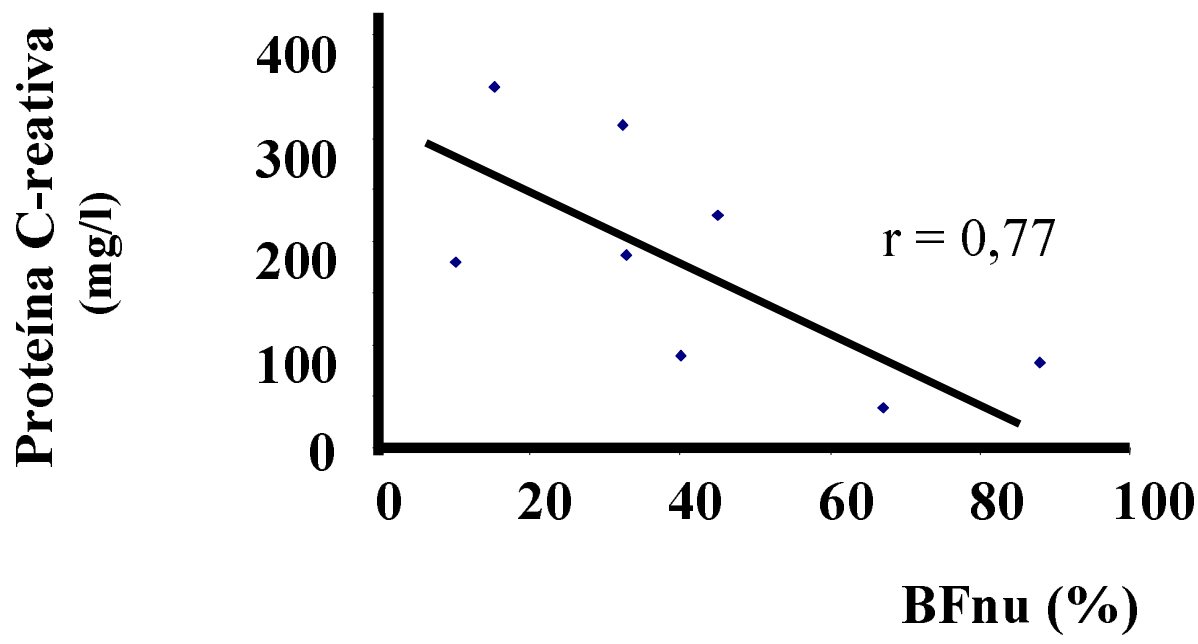

Figura 10 - Correlação da proteína C-reativa com o índice de baixa freqüência cardíaca normalizado (BFnu) no grupo de pacientes sépticos não-sobreviventes no primeiro dia do estudo, realizado em unidades de terapia intensiva

4.6. Correlação da poli(ADP-ribose) polimerase com a troponina I e com o trabalho sistólico do ventriculo esquerdo

A correlação da densitometria de imunocoloração da poli(ADP-ribose) polimerase (considerada marcadora da via final de vários tipos de lesão miocárdica) e da troponina sérica foi $R^{2}=0,73(p=0,00095)$ (Figura 11), e a correlação com o trabalho sistólico do ventrículo esquerdo de $R^{2}=0,33(p=$ 0,0509) (Figura 12). Os resultados podem sugerir que a ativação da poli(ADP-ribose) polimerase correlaciona-se com um marcador bioquímico de lesão miocárdica e com com alterações hemodinâmicas. 


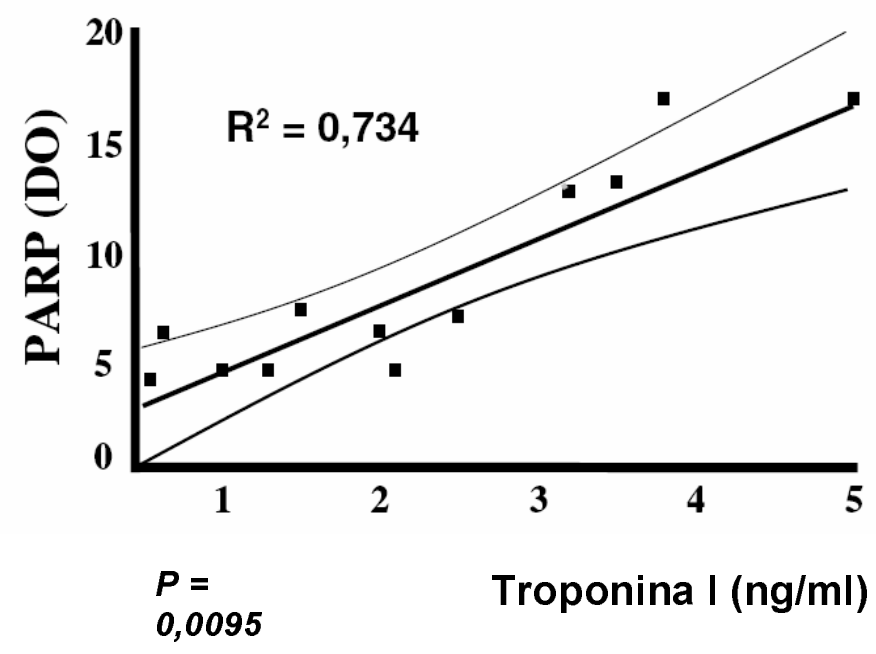

Figura 11 - Correlação da poli(ADP-ribose) polimerase (PARP) com os níveis de troponina sérica em pacientes sépticos internados em unidade de terapia intensiva

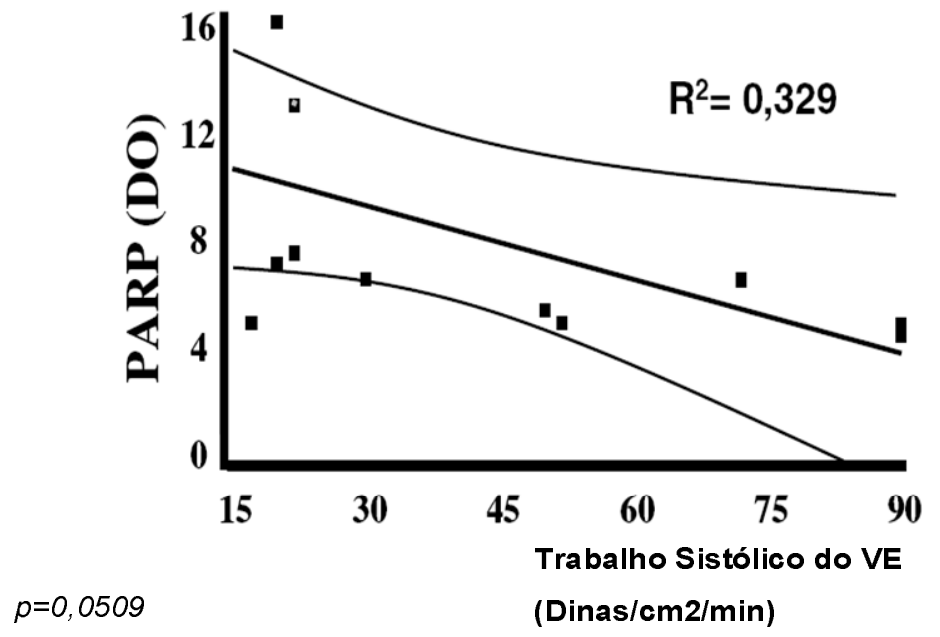

Figura 12 - Correlação da poli(ADP-ribose) polimerase (PARP) com 0 trabalho sistólico do ventrículo esquerdo (VE) em pacientes sépticos internados em unidade de terapia intensiva 


\subsection{Lesões histológicas cardíacas}

Todos pacientes que evoluíram a óbito apresentaram alterações histológicas importantes na histologia do miocárdio.

A Figura 13 demonstra uma lâmina de miocárdio normal. Os cortes e coloração por hematoxilina-eosina,demonstraram um aumento no número de células inflamatórias no tecido cardíaco (Figuras 14 e 15). 

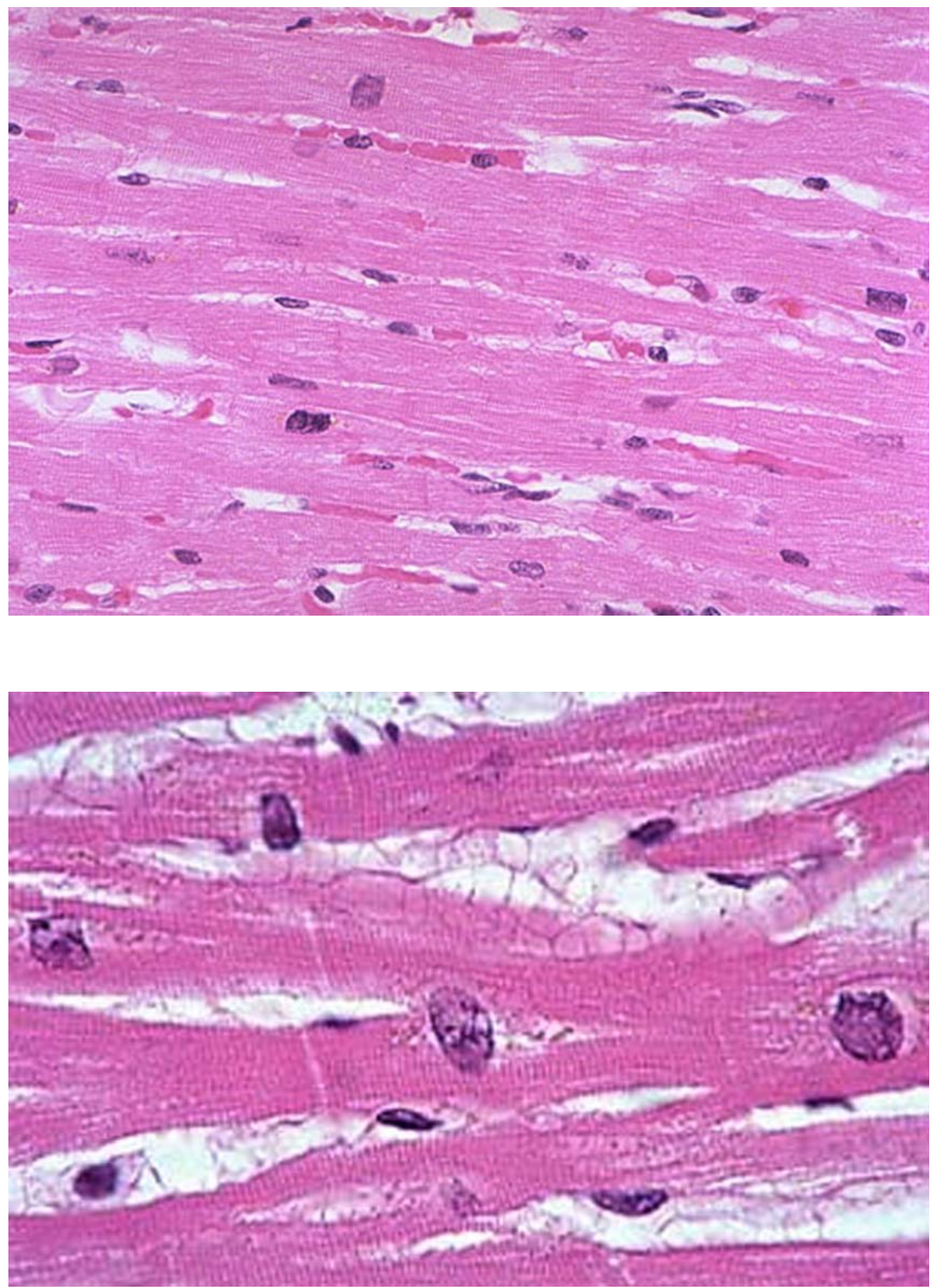

Figura 13 - Microscopia óptica com coloração de hematoxilina-eosinina de lâminas de miocárdio normal (aumento de $100 \mathrm{x}$ ) 

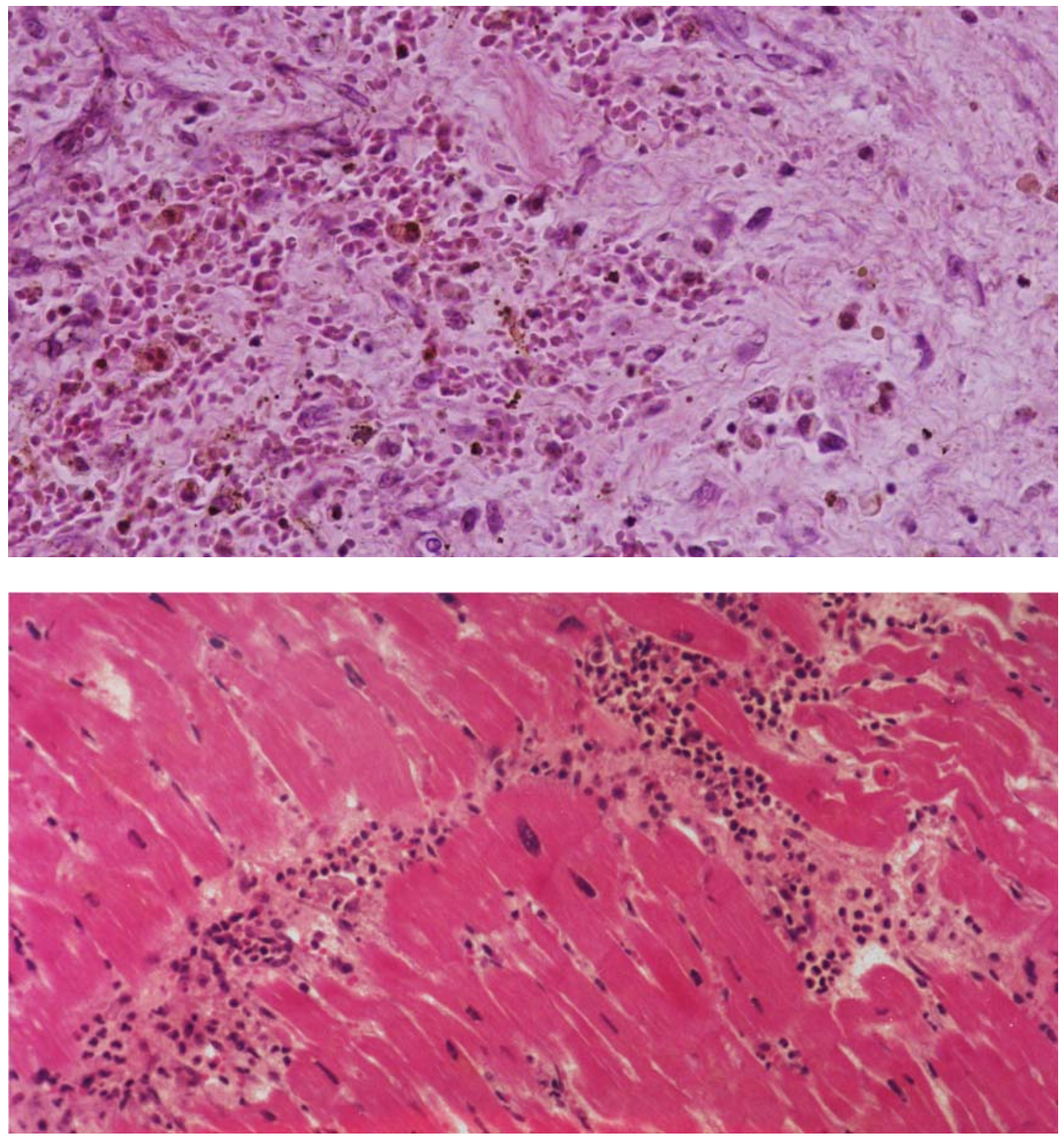

Figura 14 - Microscopia óptica de miocárdio de paciente em sepse, demonstrando intenso infiltrado inflamatório (coloração por hematoxilina-eosina, aumento de $40 \mathrm{x}$ ) 


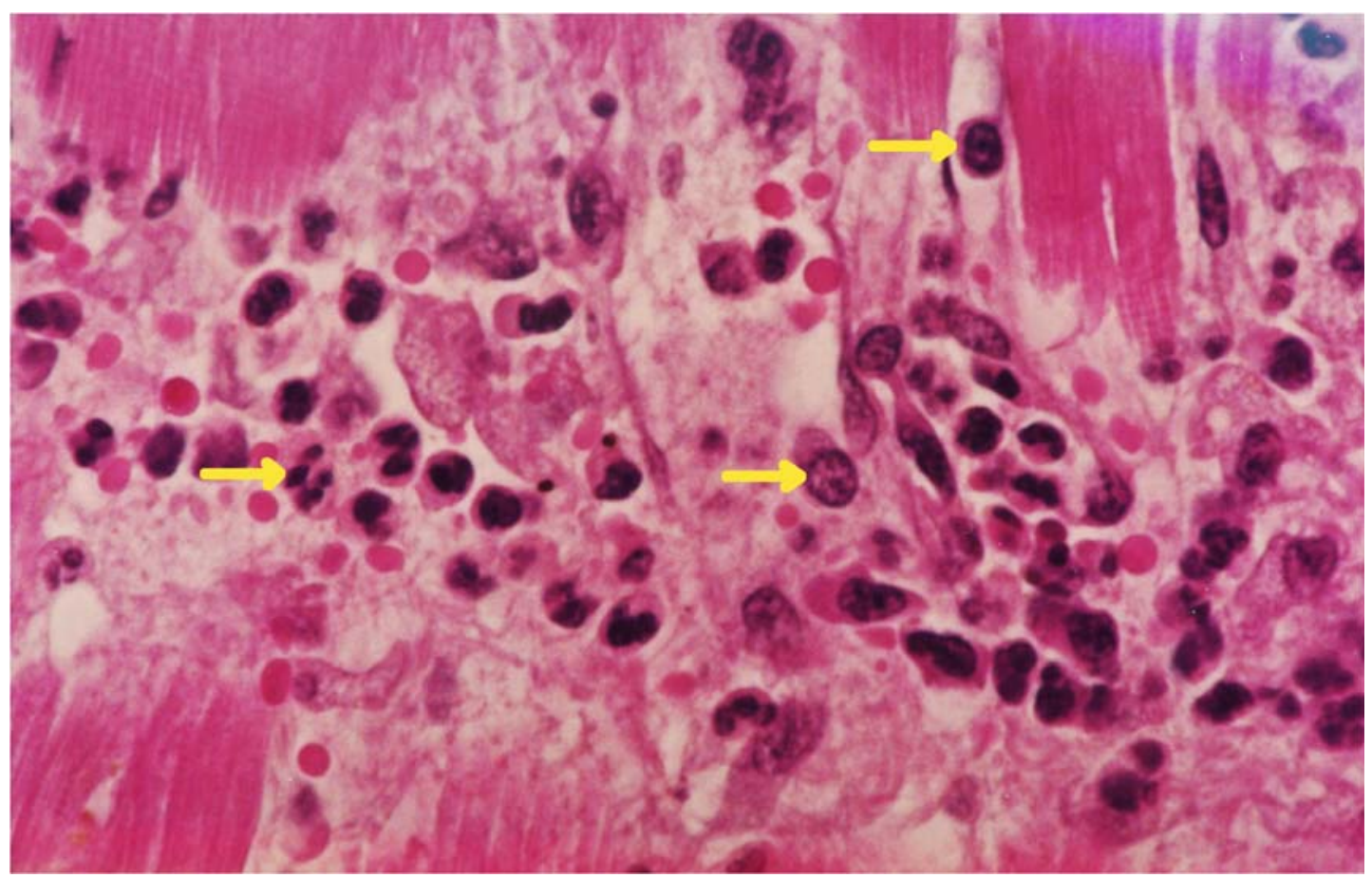

Figura 15 - Microscopia óptica de miocárdio de paciente em sepse, em maior aumento (100 x, coloração por hematoxilina-eosina), mostrando aumento no número de células inflamatórias no tecido cardíaco

A microscopia eletrônica mostrou alterações nas criptas das mitocôndrias com importante destruição mitocondrial (Figura 16 e 17), o que é compatível com estresse oxidativo e consumo inadequado de oxigênio. Estes achados podem explicar alguns dos achados clínicos, como a redução do índice do trabalho sistólico do ventrículo esquerdo, a não dilatação cardíaca nos pacientes não-sobreviventes e resposta inadequada a infusão de volume. 

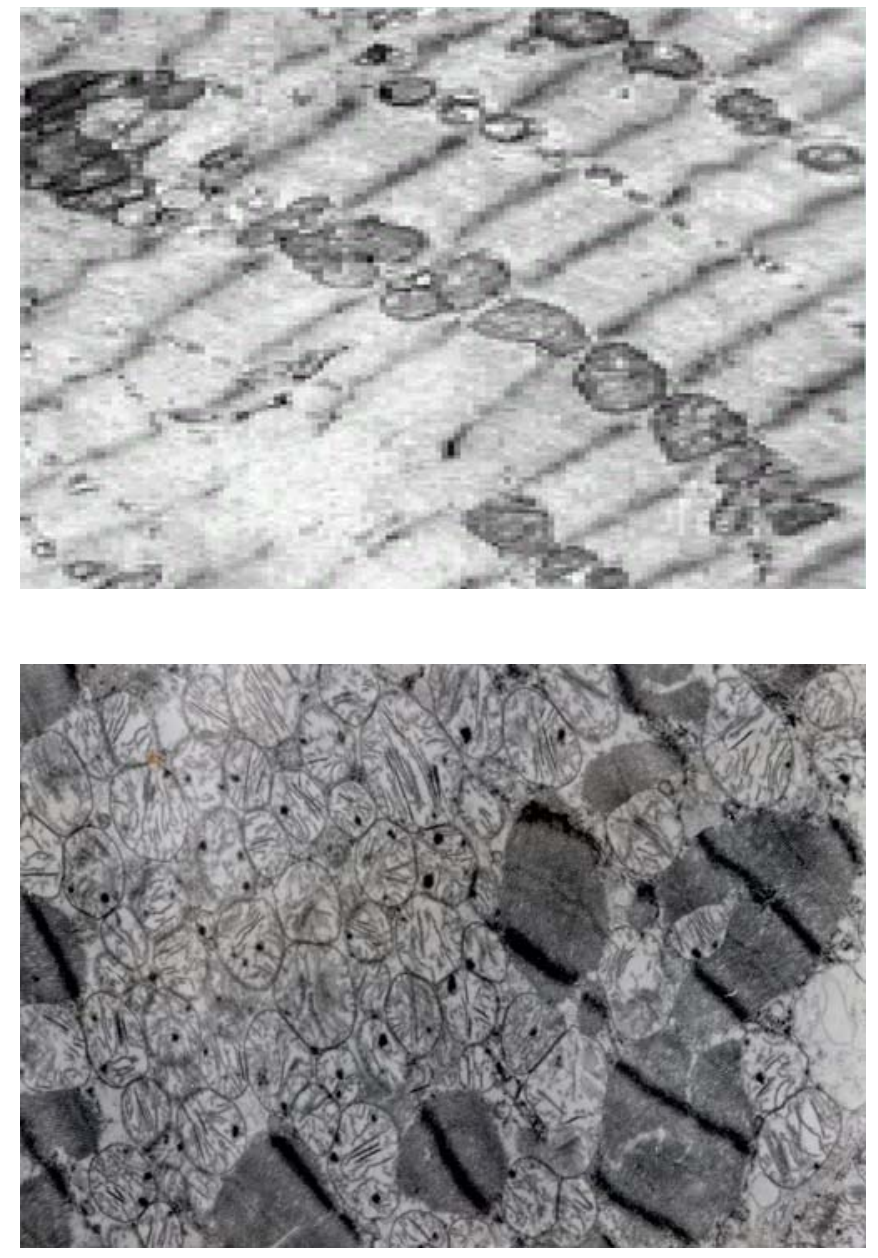

Figura 16 - Microscopia eletrônica do miocárdio (aumento de $16.800 \mathrm{~K}$, coloração por acetato e citrato de chumbo). A lâmina à esquerda demonstra distribuição normal das mitocôndrias em paciente com coração normal (não incluído neste estudo). A lâmina à direita, com amostra do miocárdio de um paciente séptico incluído, é exemplo do aumento importante do número de mitocôndrias e sua distribuição na sepse 


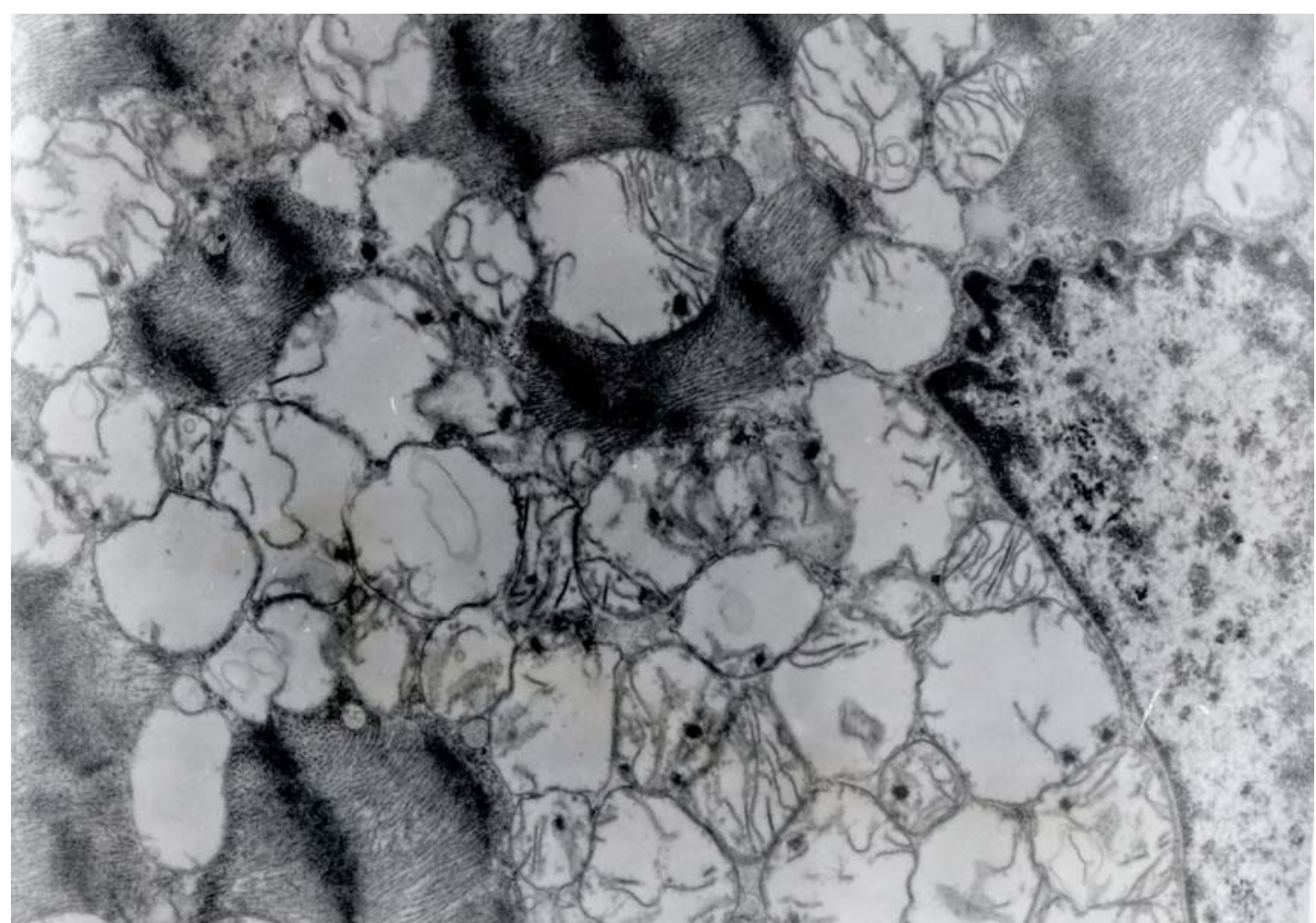

Figura 17 - Microscopia eletrônica do miocárdio de paciente em sepse demonstrando aumento do número e destruição de cristas mitocondriais. (aumento $28.000 \mathrm{~K}$, coloração por uranil acetato e citrato de chumbo)

A coloração de Picrosirius para o colágeno (Figura 18), mostrou um aumento no colágeno do interstício, talvez relacionado a rigidez cardíaca e a incapacidade de dilatação para a adaptação a sepse.

A Figura 19 demonstra a imunoistoquímica do miocárdio evidenciando a ativação da poli(ADP-ribose) polimerase. 

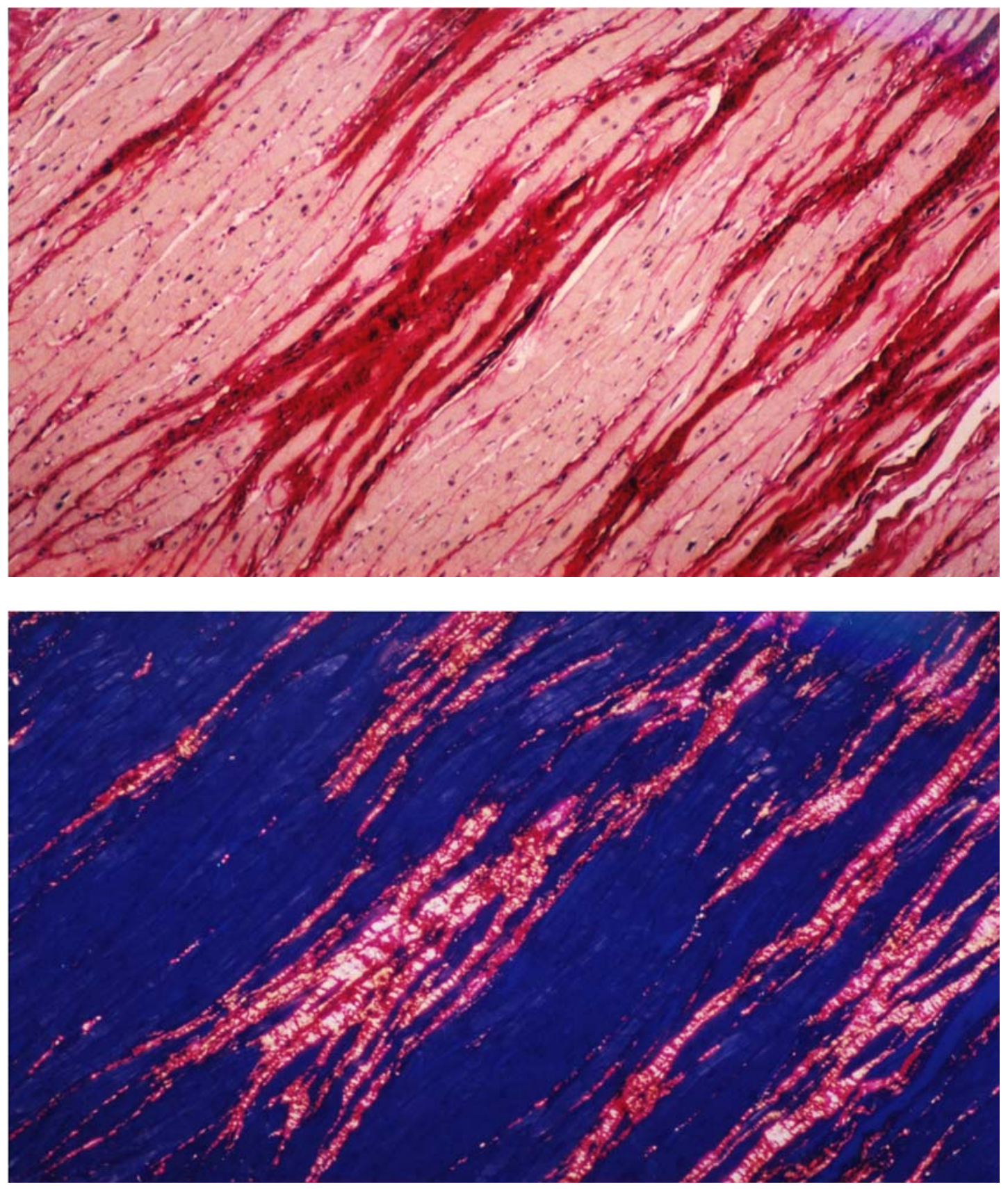

Figura 18 - Coloração red de Picrosirius demonstrando infiltração de colágeno no miocárdio em paciente do grupo de nãosobreviventes (aumento de $40 \mathrm{x}$ ) 

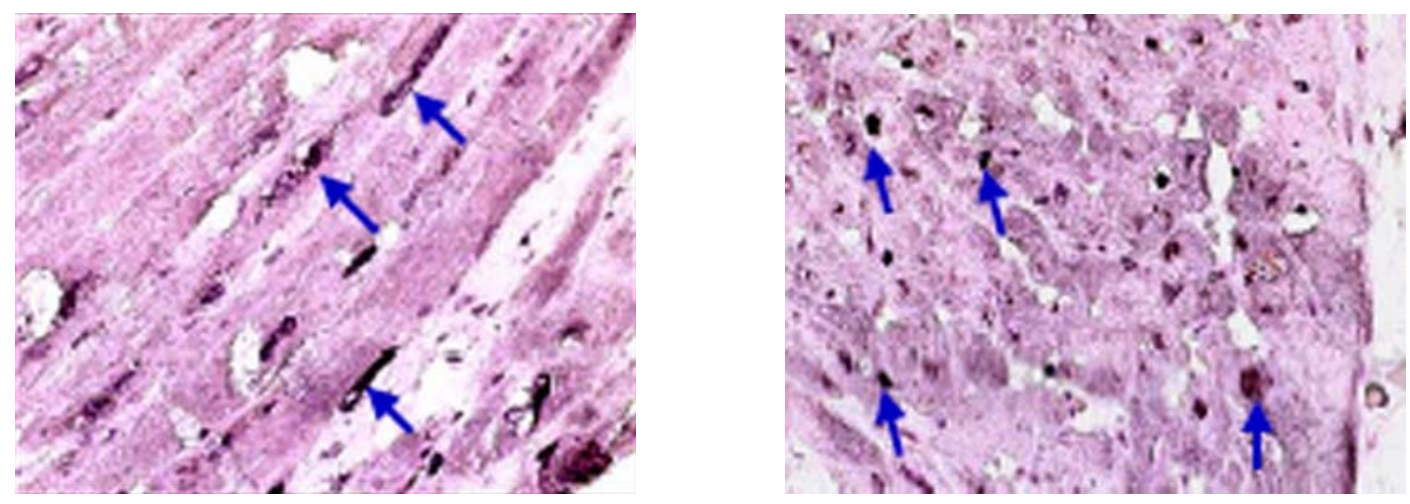

Figura 19 - Análise imunoistoquímica do miocárdio evidenciando a ativação da poli(ADP-ribose) polimerase em paciente do grupo de não-sobreviventes (aumento de 40 x, coloração múltipla usada em imunoistoquímica) 


\section{DISCUSSÃO}

Os resultados deste estudo demonstraram que a dosagem de troponina sérica e a determinação do índice de trabalho sístólico do ventrículo esquerdo podem ser úteis na detecção da lesão cardíaca. A histologia cardíca associada ainda à imunoistoquimica do miocárdio evidenciaram alterações celulares importantes.

O desarranjo metabólico e fisiológico do coração no contexto do choque séptico é bem documentado, ocorre em resposta a fatores produzidos na resposta inflamatória sistêmica. Alguns estudos sugeriram que a depressão miocárdica poderia ser causada por uma endotoxina liberada por microorganismos Gram-negativos e pelas citocinas liberadas na síndrome da resposta inflamatória sistêmica (SIRS), como o TNF- $\alpha$ e a interleucina-1 $\beta$ (IL-1 $\beta)^{54,149}$

Na sepse, o coração dilata e a fração de ejeção dos ventrículos diminui, com disfunção sistólica e diastólica, podendo ser global ou regional. ${ }^{85,86,150}$ Essas alterações parecem reversíveis, com o coração retornando à função normal ao redor de 7 a 10 dias após o término da sepse..$^{86,151,152} \mathrm{~A}$ sepse e a disfunção de múltiplos órgãos e sistemas são caracterizadas por uma complexa rede de mediadores e toxinas,$^{46}$ que podem influenciar os reflexos em vários estágios, aferente, central ou eferente; e a diminuição da reatividade do órgão ao estimulo reflexo também deve ser considerada. A resposta celular diminuída ou funcional pode contribuir para aumento ou 
diminuição da resposta reflexa dos órgãos-alvo, levando à diminuição do balanço autonômico. A elevação dos níveis séricos de troponina é associada com o aumento nos níveis de TNF- $\alpha$ e de interleucina-6; essas citocinas podem levar a ampliação na permeabilidade da membrana do cardiomiócito, resultando na elevação dos níveis de enzimas cardíacas. ${ }^{54}$ Além disso, o aumento no catabolismo, no débito cardíaco e na demanda de oxigênio, e a diminuição da pressão de perfusão coronariana e da oferta ou extração de oxigênio podem ocorrer durante a sepse. ${ }^{143,149,153}$ Esses fatores também podem lesar as células cardíacas, refletindo-se em níveis de troponina sérica elevados e depressão da função nos pacientes sépticos.

$\mathrm{Na}$ tentativa de investigar se existe lesão direta no coração dos pacientes com sepse, mensuramos os marcadores bioquímicos, dados hemodinâmicos com cateter de artéria pulmonar e ecocardiograma transtorácico. No nosso estudo, encontramos diferença significante entre os níveis de troponina nos sobreviventes e nos não-sobreviventes no primeiro dia do estudo. O estudo não mostrou diferença significativa entre a creatinoquinase (CK) e creatinoquinase fração MB (CK-MB). Nossos dados foram compatíveis com os da literatura, sendo que não encontramos associação entre a elevação dos marcadores bioquímicos cardíacos e as alterações do eletrocardiograma compatíveis com isquemia.

Entretanto, o índice de trabalho sístólico do ventrículo esquerdo mostrou, neste estudo, diferença significativa entre os sobreviventes e os não-sobreviventes, tornando-se maior entre os sobreviventes a partir do terceiro dia. O trabalho de ejeção apresentou-se como um preditor da 
evolução clínica, e foi o parâmetro mais sensível entre os dados hemodinâmicos para detectar a disfunção cardíaca nos pacientes sépticos.

O índice de trabalho sistólico do ventrículo esquerdo é influenciado por um número de fatores, incluindo pré-carga, pós-carga, complacência ventricular e grau de inotropismo. Nos pacientes com choque séptico, diminui e responde pouco à infusão de volume. Em paralelo à diminuição na fração de ejeção, que é mais pronunciada nos três primeiros dias após o choque séptico, o índice de trabalho sistólico do ventrículo esquerdo tende a se restabelecer em torno de 7 a 10 dias. $^{150}$

Devido ao aumento do débito cardíaco e à vasodilatação induzida pela sepse, medicações inotrópicas e agentes vasopressores são freqüentemente usados para suporte da função cardiovascular. Esses agentes podem induzir a necrose miocárdica e a necrose nas bandas de contração, podendo afetar a função cardíaca e aumentar a morbidade e a mortalidade. ${ }^{154,155}$ Em nosso estudo, ambos os grupos tiveram a mesma précarga, receberam a mesma quantidade de catecolaminas e sedativos - e, particularmente neste estudo, as catecolaminas poderiam alterar a freqüência cardíaca, interferindo na análise da variabilidade da freqüência cardíaca. Do mesmo modo, o uso de benzodiazepínicos e opiáceos poderia alterar a análise da variabilidade da freqüência cardíaca.

A diferença no índice do trabalho sistólico do ventrículo esquerdo e na troponina sérica encontrada entre sobreviventes e não-sobreviventes em nosso estudo não é devida aos medicamentos utilizados. A literatura mostra que o menor índice do trabalho sistólico do ventrículo esquerdo foi 
negativamente correlacionado com os níveis máximos de troponina encontrados. Portanto, pode-se especular que a diminuição no índice do trabalho sistólico do ventrículo esquerdo que é vista no choque séptico ocorre durante o processo de lesão ou estresse miocárdico, o que provavelmente se resolve com aumento na função ventricular esquerda nos pacientes que sobrevivem e continua nos que morrem de choque séptico.

Os cortes histológicos do miocárdio dos pacientes não-sobreviventes demonstraram aumento importante no número de células inflamatórias no tecido cardíaco (evidenciadas pela coloração de hematoxilina-eosina), demonstrando intensa reação inflamatória (Figuras 14 e 15). Uma das limitações do estudo é que não obtivemos amostra do miocárdio do grupo dos pacientes sobreviventes - pacientes normais não demonstram esse tipo de alteração (Figura 13).

A coloração de Picrosirius para o colágeno (Figura 19) evidenciou aumento no colágeno do interstício cardíaco nos pacientes dos quais obtivemos amostras para análise Esses achados histológicos podem estar relacionados à rigidez cardíaca e à incapacidade de dilatação para a adaptação à sepse, o que leva, provavelmente, a alterações hemodinâmicas que poderiam contribuir para a morte. De modo ainda não explicado, a rigidez pareceu ocorrer precocemente em nosso grupo de pacientes.

A microscopia eletrônica mostrou alterações nas criptas das mitocôndrias com importante destruição mitocondrial (Figuras 16 e 17), que é compatível com estresse oxidativo e consumo inadequado de oxigênio. Esses resultados podem explicar alguns dos achados clínicos nos não- 
sobreviventes, como a redução do índice do trabalho sistólico do ventrículo esquerdo, a não-dilatação cardíaca para adaptação e a resposta alterada à infusão de volume.

$\mathrm{Na}$ investigação das lesões histológicas do coração, os blocos foram submetidos à imunocoloração para a poli(ADP-ribose) polimerase (PARP). A ativação da PARP é considerada uma via final de vários tipos de lesão miocárdica, incluindo inflamação sistêmica, choque circulatório e lesão de isquemia e reperfusão. Os radicais livres e a produção de oxidantes e a citotoxicidade durante a isquemia/reperfusão ou inflamação levam a quebra do DNA, que pode ativar a enzima nuclear PARP e iniciar consumo de energia, metabolismo celular ineficiente e transferência do grupamento funcional ribosila ADP para aceptores de proteínas. Nos últimos cinco anos, vários trabalhos demonstraram os efeitos benéficos da inibição da PARP em culturas de células de roedores e mais recentemente em estudos préclínicos em modelos animais maiores de lesão isquêmica e reperfusão. ${ }^{156}$

O produto da PARP ativada no miocárdio dos pacientes sépticos nãosobreviventes se mostrou positivo (Figura 18). A análise da correlação entre o índice de coloração da PARP e a troponina mostrou valor de $r^{2}=0,73$ (Figura 11); e a correlação do índice de coloração da PARP com o índice de trabalho esquerdo por sístole foi de $r^{2}=0,33$ (Figura 12).

Na sepse, há aumento da produção de espécies reativas de oxigênio (superóxido, peróxido de hidrogênio, radicais hidroxila), ${ }^{156,157}$ havendo também produção aumentada de óxido nítrico, devido à expressão da isoforma induzível da óxido nítrico sintase (iNOS). ${ }^{156,157}$ Um estudo recente 
sugeriu a correlação entre a expressão aumentada da iNOS e a geração de peroxinitritos com o aumento da área cardíaca, defeitos da condução, morte súbita e, menos comumente, insuficiência cardíaca em ratos. ${ }^{158}$

A combinação de óxido nítrico e superóxido produz peroxinitrito, que leva a quebra das fitas de DNA e ativação da PARP. ${ }^{159}$ A geração de peroxinitrito foi demonstrada em vários modelos de sepse e essas espécies deprimiram a função cardíaca por vários mecanismos. ${ }^{160,161} \mathrm{O}$ aumento da sensibilidade dos miócitos aos efeitos tóxicos do óxido nítrico foi demonstrado diretamente em um modelo induzindo a hipertrofia miocárdica. ${ }^{162}$ Também em modelos suínos e bovinos de disfunção miocárdica devida a sepse (obtida pela implantação de E. coli ou pela injeção de lipopolissacáride bacteriano), há evidência da ativação da PARP no miocárdio e aumento significante da contratilidade miocárdica em resposta aos inibidores farmacológicos da PARP. ${ }^{159,163}$ Mais evidências para a nossa hipótese de maior mortalidade entre pacientes com sepse e lesão no coração são fornecidas por resultados de um estudo em humanos, em que o plasma de pacientes sépticos mostrou induzir disfunção miocárdica in vitro, um efeito atenuado pela inibição farmacológica da PARP. ${ }^{164}$

A análise da correlação entre o índice de coloração da PARP e a troponina I sérica e entre o índice de coloração da PARP e o índice de trabalho sistólico do ventrículo esquerdo podem sugerir (entretanto não provar) uma relação causal. A eficácia dos inibidores farmacológicos da PARP está sendo testada em um ensaio clínico, ${ }^{165}$ sendo que novidades 
podem surgir em breve em relação à PARP e à disfunção cardíaca na sepse.

O ritmo e a freqüência cardíaca são fortemente influenciados pelo impacto do tônus de modulação simpático e parassimpático. A redução da variabilidade da freqüência cardíaca pode representar um desbalanço simpatovagal e também representar um aumento no isolamento do coração e diminuição de sua interação com outros órgãos. ${ }^{90}$ Godin e Buchman sugeriram que a redução da variabilidade da freqüência cardíaca nos pacientes críticos, causada pela resposta imune e inflamatória exagerada, e subseqüentemente o desacoplamento dos órgãos e sistemas são a causa da disfunção de múltiplos órgãos e sistemas (DMOS).${ }^{90} \mathrm{~A}$ literatura tem mostrado a redução da variabilidade da freqüência cardíaca nos pacientes sépticos; esses estudos mostram ainda uma correlação positiva entre redução no índice de baixa freqüência da variabilidade da freqüência cardíaca e mortalidade na unidade de terapia intensiva (UTI) e o risco para o desenvolvimento de DMOS. ${ }^{120,166}$ Em nosso estudo, a diminuição da variabilidade da freqüência cardíaca esteve presente em todos pacientes, e o grupo de não-sobreviventes exibiu menor baixa freqüência da variabilidade da freqüência cardíaca. Esse dado foi compatível com estudos prévios que relataram que a baixa freqüência tem correlação forte com o sistema nervoso simpático. ${ }^{167,168}$

Também encontramos redução dos valores da baixa freqüência (BF) da variabilidade da freqüência cardíaca nos pacientes sépticos quando comparados com pessoas sadias, e o grupo de não-sobreviventes 
apresentou os menores valores. A análise multivariada apontou a baixa freqüência como uma variável independente para predizer a alta da UTI. A dissociação dos componentes autonômicos a cardíacos causando alteração na variabilidade da freqüência cardíaca é tecnicamente difícil, entretanto parece ser importante para o tratamento a determinação de qual componente está alterado.

Houve correlação $\left(r^{2}=0,75\right)$ entre 0 índice de baixa freqüência da variabilidade da freqüência cardíaca e a troponina sérica no primeiro dia da sepse. Elaboramos a hipótese de que a lesão miocárdica encontrada no coração produz diminuição na resposta adequada do coração ao controle autonômico. A lesão cardíaca encontrada possivelmente se deve à exacerbação da resposta inflamatória sistêmica, como de fato verificado por meio da dosagem da proteína C-reativa. Mostramos correlação da baixa freqüência cardíaca com os níveis plasmáticos aumentados de proteína Creativa, confirmando a interação entre inflamação e lesão cardíaca. Possivelmente, a disfunção orgânica leve a um desacoplamento da interconetividade do sistema orgânico, se um órgão apresenta disfunção, ele reduz ou interrompe a responsividade às demandas do corpo. ${ }^{46,118,167,169} \mathrm{~A}$ redução da variabilidade da freqüência cardíaca poderia representar o efeito de uma "descomplexificação" precoce do coração. Portanto, poderíamos encarar a variabilidade da freqüência cardíaca como uma ferramenta para a avaliação precoce da alteração cardíaca na sepse.

Por outro lado, a redução da variabilidade da freqüência cardíaca, em especial a baixa freqüência, relaciona-se aos efeitos da ação simpática e 
substâncias adrenérgicas. Nos pacientes sépticos, o sistema simpático é supraregulado, na tentativa de se manter a pressão sangüínea. Esta é a resposta hemodinâmica regular sobre a redução da variabilidade da freqüência cardíaca.

Parece ainda que a variabilidade da freqüência cardíaca é similar a muitos outros aspectos da sepse: é uma reação exacerbada, levando a desregulação dos mecanismos homeostáticos. Uma importante causa da redução da variabilidade da freqüência cardíaca parece ser a lesão miocárdica, demonstrada em nosso estudo. As intervenções que melhorem a perfusão e reduzam a inflamação sistêmica poderiam diminuir a lesão cardíaca e, conseqüentemente, a mortalidade.

Em conclusão, nosso estudo encontrou uma disfunção cardíaca significante em pacientes sépticos, a medida de parâmetros sensíveis como a troponina sérica, o índice de trabalho sistólico do ventrículo esquerdo e a análise da variabilidade da freqüência cardíaca são importantes para diagnóstico da lesão cardíaca. Os dados da variabilidade da freqüência cardíaca e o índice de baixa freqüência cardíaca correlacionaram-se com os níveis da troponina sérica. A variabilidade da freqüência cardíaca pode representar uma disfunção cardíaca direta, ao contrário de um desbalanço no sistema autonômico. Terapêutica especial deveria ser desenvolvida para pacientes em sepse, para se evitar lesão cardíaca, na tentativa de diminuir a mortalidade. 


\section{CONCLUSÕES}

1) $\mathrm{Na}$ sepse, a variabilidade da freqüência cardíaca está alterada e, associada à troponina sérica elevada, é marcador precoce de lesão cardíaca e de pior evolução clínica.

2) O dano celular ao miocárdio, demonstrado pela dosagem da troponina cardíaca sérica e pela microscopia do miocárdio, pode tornar o coração menos responsivo aos estímulos do sistema nervoso simpático e parassimpático.

3) A microscopia eletrônica demonstrou aumento no número de mitocôndrias, alteração na sua disposição e importante lesão mitocondrial. Evidenciou também intenso infiltrado inflamatório e aumento das fibras de colágeno no miocárdio em todos os pacientes com sepse e que evoluíram a óbito no estudo. 


\section{REFERÊNCIAS}

1. Abraham E, Matthay MA, Dinarello CA, Vincent JL, Cohen J, Opal SM, et al. Consensus conference definitions for sepsis, septic shock, acute lung injury, and acute respiratory distress syndrome: time for a reevaluation. Crit Care Med. 2000;28(1):232-5.

2. Moore FA, Moore EE, Read RA. Postinjury multiple organ failure: role of extrathoracic injury and sepsis in adult respiratory distress syndrome. New Horiz. 1993;1(4):538-49.

3. Salvo I, de Cian W, Musicco M, Langer M, Piadena R, Wolfler A, et al. The Italian SEPSIS study: preliminary results on the incidence and evolution of SIRS, sepsis, severe sepsis and septic shock. Intensive Care Med. 1995;21(Suppl 2):S244-9.

4. Cipolle MD, Pasquale MD, Cerra FB. Secondary organ dysfunction. From clinical perspectives to molecular mediators. Crit Care Clin. 1993;9(2):26198.

5. Vincent JL, Slotman G, Van Leeuwen PA, Shelly M, Nasraway S, Tenaillon A, et al. IL-1ra administration does not improve cardiac function in patients with severe sepsis. J Crit Care. 1999;14(2):69-72.

6. Friedman G, Jankowski S, Shahla M, Goldman M, Rose RM, Kahn RJ, et al. Administration of an antibody to E-selectin in patients with septic shock. Crit Care Med. 1996;24(2):229-33.

7. Angus DC, Linde-Zwirble WT, Lidicker J, Clermont G, Carcillo J, Pinsky MR. Epidemiology of severe sepsis in the United States: analysis of incidence, outcome, and associated costs of care. Crit Care Med. 2001;29(7):1303-10.

8. Vincent JL, Sakr Y, Sprung CL, Ranieri M, Reinhart K, Gerlach H, et al. Sepsis in European intensive care units: results of the SOAP study. Crit Care Med. $2005 . \quad$ Disponível em: http://ccmjournal.com/pt/re/ccm/publishAheadAbstract.htm;jsessionid=D11Xu 7VgjqdO0P1hPoyyPgyDhznc8Cbhh0EGTHRzJq721CtQTfnL!231839128!949856145 ! 9001 ! -1 ? issn $=0090-$ 3493\&filename $=01 . \mathrm{ccm} .0000194725 .48928 .3 a . x m l$

9. Silva E, Pedro Mde A, Sogayar AC, Mohovic T, Silva CL, Janiszewski M, et al. Brazilian Sepsis Epidemiological Study (BASES study). Crit Care. 2004;8(4):R251-60.

10. Vincent JL. Update on sepsis: pathophysiology and treatment. Acta Clin Belg. 2000;55(2):79-87. 
11. Angus DC, Wax RS. Epidemiology of sepsis: an update. Crit Care Med. 2001;29(7 Suppl):S109-16.

12. Dellinger RP, Carlet JM, Masur H, Gerlach H, Calandra T, Cohen J, et al. Surviving Sepsis Campaign guidelines for management of severe sepsis and septic shock. Crit Care Med. 2004;32(3):858-73.

13. Pollack M, Ohl CA. Endotoxin-based molecular strategies for the prevention and treatment of gram-negative sepsis and septic shock. Curr Top Microbiol Immunol. 1996;216:275-97.

14. Marik PE, Zaloga GP. Adrenal insufficiency in the critically ill: a new look at an old problem. Chest. 2002;122(5):1784-96.

15. Van den Berghe G. Insulin therapy for the critically ill patient. Clin Cornerstone. 2003;5(2):56-63.

16. van den Berghe $G$, Wouters $P$, Weekers $F$, Verwaest $C$, Bruyninckx F, Schetz $\mathrm{M}$, et al. Intensive insulin therapy in the critically ill patients. $N$ Engl $J$ Med. 2001;345(19):1359-67.

17. Van den Berghe G, Wouters PJ, Bouillon R, Weekers F, Verwaest C, Schetz $M$, et al. Outcome benefit of intensive insulin therapy in the critically ill: Insulin dose versus glycemic control. Crit Care Med. 2003;31(2):359-66.

18. Van den Berghe G. Beyond diabetes: saving lives with insulin in the ICU. Int J Obes Relat Metab Disord. 2002;26(Suppl 3):S3-8.

19. Rivers E, Nguyen B, Havstad S, Ressler J, Muzzin A, Knoblich B, et al. Early goal-directed therapy in the treatment of severe sepsis and septic shock. N Engl J Med. 2001;345(19):1368-77.

20. Dembic Z. Immune system protects integrity of tissues. Mol Immunol. 2000;37(10):563-9.

21. Pinsky MR, Vincent JL, Deviere J, Alegre M, Kahn RJ, Dupont E. Serum cytokine levels in human septic shock. Relation to multiple-system organ failure and mortality. Chest. 1993;103(2):565-75.

22. Cao $\mathrm{C}$, Matsumura $\mathrm{K}$, Yamagata $\mathrm{K}$, Watanabe $\mathrm{Y}$. Involvement of cyclooxygenase-2 in LPS-induced fever and regulation of its mRNA by LPS in the rat brain. Am J Physiol. 1997;272(6 Pt 2):R1712-25.

23. Strieter RM, Kunkel SL, Bone RC. Role of tumor necrosis factor-alpha in disease states and inflammation. Crit Care Med. 1993;21(10 Suppl):S44763. 
24. Oberholzer A, Oberholzer C, Moldawer LL. Interleukin-10: A complex role in the pathogenesis of sepsis syndromes and its potential as an antiinflammatory drug. Crit Care Med. 2002;30(1 Suppl):S58-63.

25. Kourilsky $P$, Truffa-Bachi $P$. Cytokine fields and the polarization of the immune response. Trends Immunol. 2001;22(9):502-9.

26. Rey L. Dicionário de Termos Técnicos de Medicina e Saúde. Rio de Janeiro: Guanabara Koogan; 1999.

27. Rietschel ET, Brade H, Holst O, Brade L, Muller-Loennies S, Mamat U, et al. Bacterial endotoxin: Chemical constitution, biological recognition, host response, and immunological detoxification. Curr Top Microbiol Immunol. 1996;216:39-81.

28. Vreugdenhil AC, Rousseau $\mathrm{CH}$, Hartung $\mathrm{T}$, Greve JW, van't Veer $\mathrm{C}$, Buurman WA. Lipopolysaccharide (LPS)-binding protein mediates LPS detoxification by chylomicrons. J Immunol. 2003;170(3):1399-405.

29. Wurfel MM, Wright SD. Lipopolysaccharide (LPS) binding protein catalyzes binding of LPS to lipoproteins. Prog Clin Biol Res. 1995;392:287-95.

30. Kaisho T, Akira S. Dendritic-cell function in Toll-like receptor- and MyD88knockout mice. Trends Immunol. 2001;22(2):78-83.

31. Kaisho T, Akira S. Toll-like receptors and their signaling mechanism in innate immunity. Acta Odontol Scand. 2001;59(3):124-30.

32. Rulifson IC, Szot GL, Palmer E, Bluestone JA. Inability to induce tolerance through direct antigen presentation. Am J Transplant. 2002;2(6):510-9.

33. Hollander GA, Castigli E, Kulbacki R, Su M, Burakoff SJ, Gutierrez-Ramos JC, Geha RS. Induction of alloantigen-specific tolerance by B cells from CD40-deficient mice. Proc Natl Acad Sci U S A. 1996;93(10):4994-8.

34. Medzhitov R, Janeway C Jr. Innate immunity. N Engl J Med. 2000;343(5):338-44.

35. Lien E, Ingalls RR. Toll-like receptors. Crit Care Med. 2002;30(1 Suppl): S1S11.

36. Ryan AJ, Flanagan SW, Moseley PL, Gisolfi CV. Acute heat stress protects rats against endotoxin shock. J Appl Physiol. 1992;73(4):1517-22.

37. Young JD, Cameron EM. Dynamics of skin blood flow in human sepsis. Intensive Care Med. 1995;21(8):669-74.

38. Brealey D, Brand M, Hargreaves I, Heales S, Land J, Smolenski R, et al. Association between mitochondrial dysfunction and severity and outcome of septic shock. Lancet. 2002;360(9328):219-23. 
39. Schoonover LL, Stewart AS, Clifton GD. Hemodynamic and cardiovascular effects of nitric oxide modulation in the therapy of septic shock. Pharmacotherapy. 2000;20(10):1184-97.

40. Pattanaik U, Prasad K. Reactive oxygen species and endotoxic shock: effect of dimethylthiourea. J Cardiovasc Pharmacol Ther. 2001;6(3):273-85.

41. Bakker J, Grover R, McLuckie A, Holzapfel L, Andersson J, Lodato R, et al. Administration of the nitric oxide synthase inhibitor NG-methyl-L-arginine hydrochloride $(546 \mathrm{C} 88)$ by intravenous infusion for up to 72 hours can promote the resolution of shock in patients with severe sepsis: results of a randomized, double-blind, placebo-controlled multicenter study (study no. 144-002). Crit Care Med. 2004;32(1):1-12.

42. Watson D, Grover R, Anzueto A, Lorente J, Smithies M, Bellomo R, et al. Cardiovascular effects of the nitric oxide synthase inhibitor NG-methyl-Larginine hydrochloride $(546 \mathrm{C} 88$ ) in patients with septic shock: results of a randomized, double-blind, placebo-controlled multicenter study (study no. 144-002). Crit Care Med. 2004;32(1):13-20.

43. Arlati S, Brenna S, Prencipe L, Marocchi A, Casella GP, Lanzani M, et al. Myocardial necrosis in ICU patients with acute non-cardiac disease: a prospective study. Intensive Care Med. 2000;26(1):31-7.

44. Jardin F, Brun-Ney D, Auvert B, Beauchet A, Bourdarias JP. Sepsis-related cardiogenic shock. Crit Care Med. 1990;18(10):1055-60.

45. Kumar A, Krieger A, Symeoneides S, Kumar A, Parrillo JE. Myocardial dysfunction in septic shock: Part II. Role of cytokines and nitric oxide. J Cardiothorac Vasc Anesth. 2001;15(4):485-511.

46. Ellenby MS, McNames J, Lai S, McDonald BA, Krieger D, Sclabassi RJ, et al. Uncoupling and recoupling of autonomic regulation of the heart beat in pediatric septic shock. Shock. 2001;16(4):274-7.

47. Wu LL, Tang C, Liu MS. Altered phosphorylation and calcium sensitivity of cardiac myofibrillar proteins during sepsis. Am J Physiol Regul Integr Comp Physiol. 2001;281(2):R408-16.

48. Parker MM, Shelhamer JH, Bacharach SL, Green MV, Natanson C, Frederick TM, et al. Profound but reversible myocardial depression in patients with septic shock. Ann Intern Med. 1984;100(4):483-90.

49. Bersten $A D$, Sibbald WJ, Hersch M, Cheung H, Rutledge FS. Interaction of sepsis and sepsis plus sympathomimetics on myocardial oxygen availability. Am J Physiol. 1992;262(4 Pt 2):H1164-73.

50. Dhainaut JF, Huyghebaert MF, Monsallier JF, Lefevre G, Dall'Ava-Santucci $\mathrm{J}$, Brunet $\mathrm{F}$, et al. Coronary hemodynamics and myocardial metabolism of 
lactate, free fatty acids, glucose, and ketones in patients with septic shock. Circulation. 1987;75(3):533-41.

51. Turner A, Tsamitros M, Bellomo R. Myocardial cell injury in septic shock. Crit Care Med. 1999;27(9):1775-80.

52. Rudinsky B, Hipps R, Bell A, Lozon M, Meadow W. Hemodynamic homeostasis during acute hypoxia in septic and nonseptic piglets: differential role of prostaglandins and nitric oxide. Pediatr Res. 2000;47(4 Pt 1):516-23.

53. ver Elst KM, Spapen HD, Nguyen DN, Garbar C, Huyghens LP, Gorus FK. Cardiac troponins I and $\mathrm{T}$ are biological markers of left ventricular dysfunction in septic shock. Clin Chem. 2000;46(5):650-7.

54. Ammann P, Fehr T, Minder El, Gunter C, Bertel O. Elevation of troponin I in sepsis and septic shock. Intensive Care Med. 2001;27(6):965-9.

55. Waisbren BA. Bacteremia due to gram-negative bacilli other than the Salmonella; a clinical and therapeutic study. AMA Arch Intern Med. 1951;88(4):467-88.

56. Fernandes $\mathrm{CJ} \mathrm{Jr}$, Akamine $\mathrm{N}$, Knobel E. Cardiac troponin: a new serum marker of myocardial injury in sepsis. Intensive Care Med. 1999;25(10):1165-8.

57. Weil MH, Spink WW. A comparison of shock due to endotoxin with anaphylactic shock. J Lab Clin Med. 1957;50(4):501-15.

58. Wilson MF, Brackett DJ, Hinshaw LB, Tompkins P, Archer LT, Benjamin BA. Vasopressin release during sepsis and septic shock in baboons and dogs. Surg Gynecol Obstet. 1981;153(6):869-72.

59. Heyndrickx GR, Millard RW, McRitchie RJ, Maroko PR, Vatner SF. Regional myocardial functional and electrophysiological alterations after brief coronary artery occlusion in conscious dogs. J Clin Invest. 1975;56(4):97885.

60. Braunwald E, Kloner RA. The stunned myocardium: prolonged, postischemic ventricular dysfunction. Circulation. 1982;66(6):1146-9.

61. Hare JM, Loh E, Creager MA, Colucci WS. Nitric oxide inhibits the positive inotropic response to beta-adrenergic stimulation in humans with left ventricular dysfunction. Circulation. 1995;92(8):2198-203.

62. Rhodes A, Lamb FJ, Malagon I, Newman PJ, Grounds RM, Bennett ED. A prospective study of the use of a dobutamine stress test to identify outcome in patients with sepsis, severe sepsis, or septic shock. Crit Care Med. 1999;27(11):2571-3. 
63. Poelaert J, Declerck C, Vogelaers D, Colardyn F, Visser CA. Left ventricular systolic and diastolic function in septic shock. Intensive Care Med. 1997;23(5):553-60.

64. Cunnion RE, Schaer GL, Parker MM, Natanson C, Parrillo JE. The coronary circulation in human septic shock. Circulation. 1986;73(4):637-44.

65. Vincent JL, Gris P, Coffernils M, Leon M, Pinsky M, Reuse C, et al. Myocardial depression characterizes the fatal course of septic shock. Surgery. 1992;111(6):660-7.

66. Jafri SM, Lavine S, Field BE, Bahorozian MT, Carlson RW. Left ventricular diastolic function in sepsis. Crit Care Med. 1990;18(7):709-14.

67. Vallet B, Chopin C, Curtis SE, Dupuis BA, Fourrier F, Mehdaoui H, et al. Prognostic value of the dobutamine test in patients with sepsis syndrome and normal lactate values: a prospective, multicenter study. Crit Care Med. 1990;21(12):1868-75.

68. Price S, Anning PB, Mitchell JA, Evans TW. Myocardial dysfunction in sepsis: mechanisms and therapeutic implications. Eur Heart $\mathrm{J}$. 1999;20(10):715-24.

69. Crews JR, Harrison JK, Corey GR, Steenbergen C, Bashore TM. Stunned myocardium in the toxic shock syndrome. Ann Intern Med. 1992;117(11):912-3.

70. Parker MM, McCarthy KE, Ognibene FP, Parrillo JE. Right ventricular dysfunction and dilatation, similar to left ventricular changes, characterize the cardiac depression of septic shock in humans. Chest. 1990;97(1):12631.

71. Yu P, Boughner DR, Sibbald WJ, Keys J, Dunmore J, Martin CM. Myocardial collagen changes and edema in rats with hyperdynamic sepsis. Crit Care Med. 1997;25(4):657-62.

72. Ellrodt AG, Riedinger MS, Kimchi A, Berman DS, Maddahi J, Swan HJ, et al. Left ventricular performance in septic shock: reversible segmental and global abnormalities. Am Heart J. 1985;110(2):402-9.

73. Monsalve F, Rucabado L, Salvador A, Bonastre J, Cunat J, Ruano M. Myocardial depression in septic shock caused by meningococcal infection. Crit Care Med. 1984;12(12):1021-3.

74. Sharkey SW, Shear W, Hodges M, Herzog CA. Reversible myocardial contraction abnormalities in patients with an acute noncardiac illness. Chest. 1998;114(1):98-105. 
75. Hoffmann JN, Werdan K, Hartl WH, Jochum M, Faist E, Inthorn D. Hemofiltrate from patients with severe sepsis and depressed left ventricular contractility contains cardiotoxic compounds. Shock. 1999;12(3):174-80.

76. Kumar A, Haery C, Parrillo JE. Myocardial dysfunction in septic shock. Crit Care Clin. 2000;16(2):251-87.

77. Walley KR, Hebert PC, Wakai Y, Wilcox PG, Road JD, Cooper DJ. Decrease in left ventricular contractility after tumor necrosis factor-alpha infusion in dogs. J Appl Physiol. 1994;76(3):1060-7.

78. Hotchkiss RS, Karl IE. Reevaluation of the role of cellular hypoxia and bioenergetic failure in sepsis. JAMA. 1992;267(11):1503-10.

79. Hotchkiss RS, Rust RS, Dence CS, Wasserman TH, Song SK, Hwang DR, et al. Evaluation of the role of cellular hypoxia in sepsis by the hypoxic marker [18F]fluoromisonidazole. Am J Physiol. 1991;261(4 Pt 2):R965-72.

80. Solomon MA, Correa R, Alexander HR, Koev LA, Cobb JP, Kim DK, et al. Myocardial energy metabolism and morphology in a canine model of sepsis. Am J Physiol. 1994;266(2 Pt 2):H757-68.

81. Chen HW, Hsu C, Lu TS, Wang SJ, Yang RC. Heat shock pretreatment prevents cardiac mitochondrial dysfunction during sepsis. Shock. 2003;20(3):274-9.

82. Han YY, Huang L, Jackson EK, Dubey RK, Gillepsie DG, Carcillo JA. Liposomal atp or NAD+ protects human endothelial cells from energy failure in a cell culture model of sepsis. Res Commun Mol Pathol Pharmacol. 2001;110(1-2):107-16.

83. Levy B, Mansart A, Bollaert PE, Franck P, Mallie JP. Effects of epinephrine and norepinephrine on hemodynamics, oxidative metabolism, and organ energetics in endotoxemic rats. Intensive Care Med. 2003;29(2):292-300.

84. Mutschler DK, Eriksson MB, Wikstrom BG, Lind L, Larsson Am, BergrenKiiski $R$, et al. Microdialysis-evaluated myocardial cyclooxygenasemediated inflammation and early circulatory depression in porcine endotoxemia. Crit Care Med. 2003;31(6):1780-5.

85. Buchman TG, Stein PK, Goldstein B. Heart rate variability in critical illness and critical care. Curr Opin Crit Care. 2002;8(4):311-5.

86. Korach M, Sharshar T, Jarrin I, Fouillot JP, Raphael JC, Gajdos P, et al. Cardiac variability in critically ill adults: influence of sepsis. Crit Care Med. 2001;29(7):1483-4.

87. Lopera GA, Huikuri HV, Makikallio TH, Tapanainen J, Chakko S, Mitrani $\mathrm{RD}$, et al. Is abnormal heart rate variability a specific feature of congestive heart failure? Am J Cardiol. 2001;87(10):1211-3; A7. 
88. Goldberger AL, Amaral LA, Hausdorff JM, Ivanov PCh, Peng CK, Stanley HE. Fractal dynamics in physiology: alterations with disease and aging. Proc Natl Acad Sci U S A. 2002;99(Suppl 1):2466-72.

89. Baillard C, Vivien B, Mansier P, Mangin L, Jasson S, Riou B, et al. Brain death assessment using instant spectral analysis of heart rate variability. Crit Care Med. 2002;30(2):306-10.

90. Godin PJ, Buchman TG. Uncoupling of biological oscillators: a complementary hypothesis concerning the pathogenesis of multiple organ dysfunction syndrome. Crit Care Med. 1996;24(7):1107-16.

91. Michalek SM, Moore RN, McGhee JR, Rosenstreich DL, Mergenhagen SE. The primary role of lymphoreticular cells in the mediation of host responses to bacterial endotoxim. J Infect Dis. 1980;141(1):55-63.

92. Pincus SM. Greater signal regularity may indicate increased system isolation. Math Biosci. 1994;122(2):161-81.

93. Buga GM, Griscavage JM, Rogers NE, Ignarro LJ. Negative feedback regulation of endothelial cell function by nitric oxide. Circ Res. 1993;73(5):808-12.

94. Sun JZ, Tang XL, Knowlton AA, Park SW, Qiu Y, Bolli R. Late preconditioning against myocardial stunning. An endogenous protective mechanism that confers resistance to postischemic dysfunction $24 \mathrm{~h}$ after brief ischemia in conscious pigs. J Clin Invest. 1995;95(1):388-403.

95. Winchell RJ, Hoyt DB. Analysis of heart-rate variability: a noninvasive predictor of death and poor outcome in patients with severe head injury. $J$ Trauma. 1997;43(6):927-33.

96. Sun JZ, Tang XL, Park SW, Qiu Y, Turrens JF, Bolli R. Evidence for an essential role of reactive oxygen species in the genesis of late preconditioning against myocardial stunning in conscious pigs. J Clin Invest. 1996;97(2):562-76.

97. Flachenecker $P$, Hartung HP, Reiners K. Power spectrum analysis of heart rate variability in Guillain-Barre syndrome. A longitudinal study. Brain. 1997;120(Pt 10):1885-94.

98. Jennings RB, Reimer KA. Factors involved in salvaging ischemic myocardium: effect of reperfusion of arterial blood. Circulation. 1983;68(2 Pt 2):125-36.

99. Ambrosio G, Jacobus WE, Bergman CA, Weisman HF, Becker LC. Preserved high energy phosphate metabolic reserve in globally "stunned" hearts despite reduction of basal ATP content and contractility. $J \mathrm{Mol} \mathrm{Cell}$ Cardiol. 1987;19(10):953-64. 
100. Carney RM, Blumenthal JA, Stein PK, Watkins L, Catellier D, Berkman LF, et al. Depression, heart rate variability, and acute myocardial infarction. Circulation. 2001;104(17):2024-8.

101. La Rovere MT, Pinna GD, Hohnloser SH, Marcus FI, Mortara A, Nohara R, et al. Baroreflex sensitivity and heart rate variability in the identification of patients at risk for life-threatening arrhythmias: implications for clinical trials. Circulation. 2001;103(16):2072-7.

102. Cohen MV, Downey JM. Myocardial stunning in dogs: preconditioning effect and influence of coronary collateral flow. Am Heart $J$. 1990;120(2):282-91.

103. Park SW, Tang XL, Qiu Y, Sun JZ, Bolli R. Nisoldipine attenuates myocardial stunning induced by multiple coronary occlusions in conscious pigs and this effect is independent of changes in hemodynamics or coronary blood flow. J Mol Cell Cardiol. 1996;28(4):655-66.

104. Charlat ML, O'Neil PG, Hartley CJ, Roberts R, Bolli R. Prolonged abnormalities of left ventricular diastolic wall thinning in the "stunned" myocardium in conscious dogs: time course and relation to systolic function. J Am Coll Cardiol. 1989;13(1):185-94.

105. Molnar J, Weiss JS, Rosenthal JE. Does heart rate identify sudden death survivors? Assessment of heart rate, QT interval, and heart rate variability. Am J Ther. 2002;9(2):99-110.

106. Schmitt C, Barthel P, Ndrepepa G, Schreirck J, Plewan A, Schomig A, et al. Value of programmed ventricular stimulation for prophylactic internal cardioverter-defibrillator implantation in postinfarction patients preselected by noninvasive risk stratifiers. J Am Coll Cardiol. 2001;37(7):1901-7.

107. Boveda S, Galinier M, Pathak A, Fourcade J, Dongay B, Benchendikh D, et al. Prognostic value of heart rate variability in time domain analysis in congestive heart failure. J Interv Card Electrophysiol. 2001;5(2):181-7.

108. Cashion AK, Cowan PA, Milstead EJ, Gaber AO, Hathaway DK. Heart rate variability, mortality, and exercise in patients with end-stage renal disease. Prog Transplant. 2000;10(1):10-6.

109. Rangari M, Sinha S, Kapoor D, Mohan JC, Sarin SK. Prevalence of autonomic dysfunction in cirrhotic and noncirrhotic portal hypertension. Am J Gastroenterol. 2002;97(3):707-13.

110. Yang CC, Chao TC, Kuo TB, Yin CS, Chen HI. Preeclamptic pregnancy is associated with increased sympathetic and decreased parasympathetic control of HR. Am J Physiol Heart Circ Physiol. 2000;278(4):H1269-73. 
111. Goto T, Fukushima H, Sasaki G, Matsuo N, Takahashi T. Evaluation of autonomic nervous system function with spectral analysis of heart rate variability in a case of tetanus. Brain Dev. 2001;23(8):791-5.

112. Mussalo $H$, Vanninen $E$, Ikaheimo $R$, Laitinen $T$, Laakso $M$, Lansimies $E$, et al. Heart rate variability and its determinants in patients with severe or mild essential hypertension. Clin Physiol. 2001;21(5):594-604.

113. Laitio TT, Huikuri HV, Kentala ES, Makikallio TH, Jalonen JR, Helenius H, et al. Correlation properties and complexity of perioperative RR-interval dynamics in coronary artery bypass surgery patients. Anesthesiology. 2000;93(1):69-80.

114. van De Borne $P$, Neubauer J, Rahnama M, Jansens JL, Montano N, Porta $A$, et al. Differential characteristics of neural circulatory control: early versus late after cardiac transplantation. Circulation. 2001;104(15):180913.

115. Stein PK, Schmieg RE Jr, El-Fouly A, Domitrovich PP, Buchman TG. Association between heart rate variability recorded on postoperative day 1 and length of stay in abdominal aortic surgery patients. Crit Care Med. 2001;29(9):1738-43.

116. Skillman JJ, Bushnell LS, Goldman H, Silen W. Respiratory failure, hypotension, sepsis, and jaundice. A clinical syndrome associated with lethal hemorrhage from acute stress ulceration of the stomach. Am J Surg. 1969;117(4):523-30.

117. Tilney NL, Bailey GL, Morgan AP. Sequential system failure after rupture of abdominal aortic aneurysms: an unsolved problem in postoperative care. Ann Surg. 1973;178(2):117-22.

118. Seely AJ, Christou NV. Multiple organ dysfunction syndrome: exploring the paradigm of complex nonlinear systems. Crit Care Med. 2000;28(7):2193200.

119. Toweill D, Sonnenthal K, Kimberly B, Lai S, Goldstein B. Linear and nonlinear analysis of hemodynamic signals during sepsis and septic shock. Crit Care Med. 2000;28(6):2051-7.

120. Pontet J, Contreras P, Curbelo A, Medina J, Noveri S, Bentancourt S, et al. Heart rate variability as early marker of multiple organ dysfunction syndrome in septic patients. J Crit Care. 2003;18(3):156-63.

121. Cummins B, Auckland ML, Cummins P. Cardiac-specific troponin-I radioimmunoassay in the diagnosis of acute myocardial infarction. $A m$ Heart J. 1987;113(6):1333-44.

122. Antman EM, Tanasijevic MJ, Thompson B, Schactman M, McCabe $\mathrm{CH}$, Cannon CP, et al. Cardiac-specific troponin I levels to predict the risk of 
mortality in patients with acute coronary syndromes. $N$ Engl $\mathrm{J}$ Med. 1996;335(18):1342-9.

123. Bertrand ME, Simoons ML, Fox KA, Wallentin LC, Hamm CW, McFadden $\mathrm{E}$, et al. Management of acute coronary syndromes: acute coronary syndromes without persistent ST segment elevation; recommendations of the Task Force of the European Society of Cardiology. Eur Heart J. 2000;21(17):1406-32.

124. Braunwald E, Antman EM, Beasley JW, Califf RM, Cheitlin MD, Hochman JS, et al. ACC/AHA guidelines for the management of patients with unstable angina and non-ST-segment elevation myocardial infarction. A report of the American College of Cardiology/American Heart Association Task Force on Practice Guidelines (Committee on the Management of Patients With Unstable Angina). J Am Coll Cardiol. 2000;36(3):970-1062.

125. Smith SC, Ladenson JH, Mason JW, Jaffe AS. Elevations of cardiac troponin I associated with myocarditis. Experimental and clinical correlates. Circulation. 1997;95(1):163-8.

126. Missov E, Calzolari C, Pau B. Circulating cardiac troponin I in severe congestive heart failure. Circulation. 1997;96(9):2953-8.

127. Perna ER, Macin SM, Parras JI, Pantich R, Farias EF, Badaracco JR, et al. Cardiac troponin $T$ levels are associated with poor short- and long-term prognosis in patients with acute cardiogenic pulmonary edema. Am Heart J. 2002;143(5):814-20.

128. Karjalainen J, Heikkila J. "Acute pericarditis": myocardial enzyme release as evidence for myocarditis. Am Heart J. 1986;111(3):546-52.

129. Bonnefoy E, Godon P, Kirkorian G, Fatemi M, Chevalier P, Touboul P. Serum cardiac troponin I and ST-segment elevation in patients with acute pericarditis. Eur Heart J. 2000;21(10):832-6.

130. Hamm CW, Giannitsis E, Katus HA. Cardiac troponin elevations in patients without acute coronary syndrome. Circulation. 2002;106(23):2871-2.

131. Douketis JD, Crowther MA, Stanton EB, Ginsberg JS. Elevated cardiac troponin levels in patients with submassive pulmonary embolism. Arch Intern Med. 2002;162(1):79-81.

132. French JK, White HD. Clinical implications of the new definition of myocardial infarction. Heart. 2004;90(1):99-106.

133. Higgins JP, Higgins JA. Elevation of cardiac troponin I indicates more than myocardial ischemia. Clin Invest Med. 2003;26(3):133-47. 
134. Harvey MG, Hancox RJ. Elevation of cardiac troponins in exacerbation of chronic obstructive pulmonary disease. Emerg Med Australas. 2004;16(3):212-5.

135. Dasgupta A, Banerjee SK, Datta P. False-positive troponin I in the MEIA due to the presence of rheumatoid factors in serum. Elimination of this interference by using a polyclonal antisera against rheumatoid factors. Am J Clin Pathol. 1999;112(6):753-6.

136. Fitzmaurice TF, Brown C, Rifai N, Wu AH, Yeo KT. False increase of cardiac troponin I with heterophilic antibodies. Clin Chem. 1998;44(10):2212-4 .

137. Roongsritong C, Warraich I, Bradley C. Common causes of troponin elevations in the absence of acute myocardial infarction: incidence and clinical significance. Chest. 2004;125(5):1877-84.

138. Galambos C, Brink DS, Ritter D, Chung HD, Creer MH. False-positive plasma troponin I with the AXSYM analyzer. Clin Chem. 2000;46(7):10145.

139. Spies C, Haude V, Fitzner R, Schroder K, Overbeck M, Runkel N, et al. Serum cardiac troponin $\mathrm{T}$ as a prognostic marker in early sepsis. Chest. 1998;113(4):1055-63.

140. Kumar A, Thota V, Dee L, Olson J, Uretz E, Parrillo JE. Tumor necrosis factor alpha and interleukin 1 beta are responsible for in vitro myocardial cell depression induced by human septic shock serum. J Exp Med. 1996;183(3):949-58.

141. Brett J, Gerlach H, Nawroth P, Steinberg S, Godman G, Stern D. Tumor necrosis factor/cachectin increases permeability of endothelial cell monolayers by a mechanism involving regulatory $\mathrm{G}$ proteins. $J$ Exp Med. 1989;169(6):1977-91.

142. Piper HM, Schwartz P, Spahr R, Hutter JF, Spieckermann PG. Early enzyme release from myocardial cells is not due to irreversible cell damage. J Mol Cell Cardiol. 1984;16(4):385-8.

143. Ammann $\mathrm{P}$, Maggiorini $\mathrm{M}$, Bertel $\mathrm{O}$, Haenseler $\mathrm{E}$, Joller-Jemelka $\mathrm{HI}$, Oechslin E, et al. Troponin as a risk factor for mortality in critically ill patients without acute coronary syndromes. J Am Coll Cardiol. 2003;41(11):2004-9.

144. Hinshaw LB. Sepsis/septic shock: participation of the microcirculation: an abbreviated review. Crit Care Med. 1996;24(6):1072-8.

145. Kollef MH, Ladenson JH, Eisenberg PR. Clinically recognized cardiac dysfunction: an independent determinant of mortality among critically ill 
patients. Is there a role for serial measurement of cardiac troponin I? Chest. 1997;111(5):1340-7.

146. Nomenclature and Criteria for Diagnosis of Diseases of the Heart and Great Vessels. 9 ${ }^{\text {th }}$ ed. Boston: Little, Brown \& Co; 1994.

147. Knaus W, Wagner D, Draper E. APACHE III study design: analytic plan for evaluation of severity and outcome in intensive care unit patients. Implications. Crit Care Med. 1989;17(12 Pt 2):S219-21.

148. Xiao CY, Chen M, Zsengeller Z, Li H, Kiss L, Kollai M, et al. Poly(ADPRibose) polymerase promotes cardiac remodeling, contractile failure, and translocation of apoptosis-inducing factor in a murine experimental model of aortic banding and heart failure. $J$ Pharmacol Exp Ther. 2005;312(3):891-8.

149. Quezado ZM, Natanson C. Systemic hemodynamic abnormalities and vasopressor therapy in sepsis and septic shock. Am J Kidney Dis. 1992;20(3):214-22.

150. Goldstein B, Kempski MH, Stair D, Tipton RB, DeKing D, DeLong DJ, et al. Autonomic modulation of heart rate variability during endotoxin shock in rabbits. Crit Care Med. 1995;23(10):1694-702.

151. Akselrod S, Gordon D, Ubel FA, Shannon DC, Berger AC, Cohen RJ. Power spectrum analysis of heart rate fluctuation: a quantitative probe of beat-to-beat cardiovascular control. Science. 1981;213(4504):220-2.

152. Pagani M, Lombardi F, Guzzetti S, Rimoldi O, Furlan R, Pizzinelli P, et al. Power spectral analysis of heart rate and arterial pressure variabilities as a marker of sympatho-vagal interaction in man and conscious dog. Circ Res. 1986;59(2):178-93.

153. Wu TT, Yuan A, Chen CY, Chen WJ, Luh KT, Kuo SH, et al. Cardiac troponin I levels are a risk factor for mortality and multiple organ failure in noncardiac critically ill patients and have an additive effect to the APACHE II score in outcome prediction. Shock. 2004;22(2):95-101.

154. Ziegler D, Laude D, Akila F, Elghozi JL. Time- and frequency-domain estimation of early diabetic cardiovascular autonomic neuropathy. Clin Auton Res. 2001;11(6):369-76.

155. Montano N, Ruscone TG, Porta A, Lombardi F, Pagani M, Malliani A. Power spectrum analysis of heart rate variability to assess the changes in sympathovagal balance during graded orthostatic tilt. Circulation. 1994;90(4):1826-31.

156. Szabo G, Liaudet L, Hagl S, Szabo C. Poly(ADP-ribose) polymerase activation in the reperfused myocardium. Cardiovasc Res. 2004;61(3):47180 . 
157. Liaudet L, Soriano FG, Szabo C. Biology of nitric oxide signaling. Crit Care Med. 2000;28(4 Suppl):N37-52.

158. Mungrue IN, Gros R, You X, Pirani A, Azad A, Csont T, et al. Cardiomyocyte overexpression of iNOS in mice results in peroxynitrite generation, heart block, and sudden death. J Clin Invest. 2002;109(6):73543.

159. Goldfarb RD, Marton A, Szabo E, Virag L, Salzman AL, Glock D, et al. Protective effect of a novel, potent inhibitor of poly(adenosine 5'diphosphate-ribose) synthetase in a porcine model of severe bacterial sepsis. Crit Care Med. 2002;30(5):974-80.

160. Mihm MJ, Coyle CM, Schanbacher BL, Weinstein DM, Bauer JA. Peroxynitrite induced nitration and inactivation of myofibrillar creatine kinase in experimental heart failure. Cardiovasc Res. 2001;49(4):798-807.

161. Liaudet L, Szabo C, Evgenov OV, Murthy KG, Pacher P, Virag L, et al. Flagellin from gram-negative bacteria is a potent mediator of acute pulmonary inflammation in sepsis. Shock. 2003;19(2):131-7.

162. Brookes PS, Zhang J, Dai L, Zhou F, Parks DA, Darley-Usmar VM, et al. Increased sensitivity of mitochondrial respiration to inhibition by nitric oxide in cardiac hypertrophy. J Mol Cell Cardiol. 2001;33(1):69-82.

163. Liaudet L, Murthy KG, Mabley JG, Pacher P, Soriano FG, Salzman AL, et al. Comparison of inflammation, organ damage, and oxidant stress induced by Salmonella enterica serovar Muenchen flagellin and serovar Enteritidis lipopolysaccharide. Infect Immun. 2002;70(1):192-8.

164. Boulos M, Astiz ME, Barua RS, Osman M. Impaired mitochondrial function induced by serum from septic shock patients is attenuated by inhibition of nitric oxide synthase and poly(ADP-ribose) synthase. Crit Care Med. 2003;31(2):353-8.

165. Southan GJ, Szabo C. Poly(ADP-ribose) polymerase inhibitors. Curr Med Chem. 2003;10(4):321-40.

166. Garrard CS, Kontoyannis DA, Piepoli M. Spectral analysis of heart rate variability in the sepsis syndrome. Clin Auton Res. 1993;3(1):5-13.

167. Goldberger AL, West BJ. Chaos and order in the human body. $M D$ Comput. 1992;9(1):25-34.

168. Kennedy HL. Heart rate variability--a potential, noninvasive prognostic index in the critically ill patient. Crit Care Med. 1998;26(2):213-4.

169. Goldstein B, Fiser DH, Kelly MM, Mickelsen D, Ruttimann U, Pollack MM. Decomplexification in critical illness and injury: relationship between heart 
rate variability, severity of illness, and outcome. Crit Care Med. 1998;26(2):352-7. 


\section{APÊNDICE}

\subsection{Cálculo da variabilidade da freqüência cardíaca e medidas e índices obtidos}

A variabilidade da freqüência cardíaca é normalmente calculada através dos intervalos entre batimentos cardíacos. Os dados da variabilidade da freqüência cardíaca são derivados da gravação de eletrocardiogramas contínuos que são digitalizados na freqüência de $125 \mathrm{Hertz}(\mathrm{Hz})$, ou maior, sendo reavaliados para excluir os artefatos elétricos, que geralmente são classificados como batimentos não-sinusais.

O período analítico ótimo em pacientes críticos é freqüentemente considerado de 500 a 1.500 ciclos cardíacos, aproximadamente 5 a 15 minutos de avaliação dos dados. A análise de períodos curtos semelhantes, entretanto, pode perder a variabilidade circadiana, uma vez que a suposição de estacionário (a noção de que o paciente é um estado fisiológico simples durante a aquisição dos dados) é violada quando os períodos são prolongados. Uma estratégia útil pode ser a coleta de dados em período arbitrário, baseada nas hipóteses do investigador e na estratégia do analista.

Os dados de análise da variabilidade da freqüência cardíaca são agrupados em métodos lineares e não-lineares. Os métodos não-lineares baseiam-se na teoria do caos (fenômenos altamente irregulares, mas não ao acaso), não sendo utilizados na pesquisa dada a sua complexidade e devido ao fato de estarem em fase de investigação. A análise da variabilidade da 
freqüência cardíaca como método linear é realizada no domínio do tempo e no domínio da freqüência.

\subsubsection{Métodos lineares}

a) Domínio do tempo

a1) Análise de índices estatísticos:

- SDNN (desvio-padrão das médias dos intervalos RR normais);

- SDANN (desvio-padrão das médias dos intervalos RR normais a cada cinco minutos);

- SDNN index (média dos desvios-padrão dos intervalos RR, medidos em intervalos de cinco minutos);

- pNN50 (porcentagem de intervalos RR adjacentes com diferença de duração superior a 50 milissegundos);

- rMSSD (raiz quadrada da média do quadrado das diferenças entre intervalos RR normais adjacentes);

a2) Análise de índices geométricos: índice triangular, plotagem de Lorenz.

b) Domínio da Freqüência

Transformação de Fourier e autoregressão. 


\subsubsection{Métodos não-lineares}

Dimensão fractal, entropia, expoentes de Lyapunov.

A análise da variabilidade da freqüência cardíaca (VFC) no domínio do tempo é expressa os resultados em unidade de tempo (milissegundos). Mede-se cada intervalo RR normal (batimentos sinusais) durante determinado intervalo de tempo (habitualmente 24 horas) e, a partir daí, com base em métodos estatísticos ou geométricos, calculam-se os índices tradutores de flutuações na duração dos ciclos cardíacos (por exemplo: média, desvio-padrão e índices derivados do histograma ou do mapa de coordenadas cartesianas dos intervalos RR).

Os índices de VFC, calculados por meio de métodos estatísticos, podem ser divididos em duas categorias: índices baseados na medida dos intervalos RR individualmente (SDNN, SDANN e SDNN index) e índices baseados na comparação entre os dois intervalos RR adjacentes (pNN50 e rMSSD). Como a estimulação parassimpática resulta numa resposta rápida e de curta duração, fazendo-se notar já no primeiro ou segundo batimentos subseqüentes, índices baseados na comparação entre a duração de dois ciclos adjacentes, como o pNN50 (percentagem de intervalos RR adjacentes com diferença de duração superior a 50 milissegundos) e rMSSD (raiz quadrada da média do quadrado das diferenças entre intervalos RR normais adjacentes, expressa em milissegundos, ou seja, o desvio-padrão das diferenças entre os intervalos $\mathrm{RR}$ normais adjacentes), refletem predominantemente o tônus vagal. 
A estimulação simpática, por sua vez, tarda alguns segundos para se manifestar. Após período latente de cerca de cinco segundos, a freqüência cardíaca vai aumentando gradativamente até atingir um patamar de estabilidade após 20 a 30 segundos. Dessa forma, índices baseados na medida dos intervalos RR individualmente, como SDNN e SDANN, representam a variabilidade global e refletem a atividade de ambos, parassimpático e simpático.

Demonstraremos a seguir (Figuras 1 a 5) o modo simplificado do cálculo dos índices da VFC no domínio do tempo. 


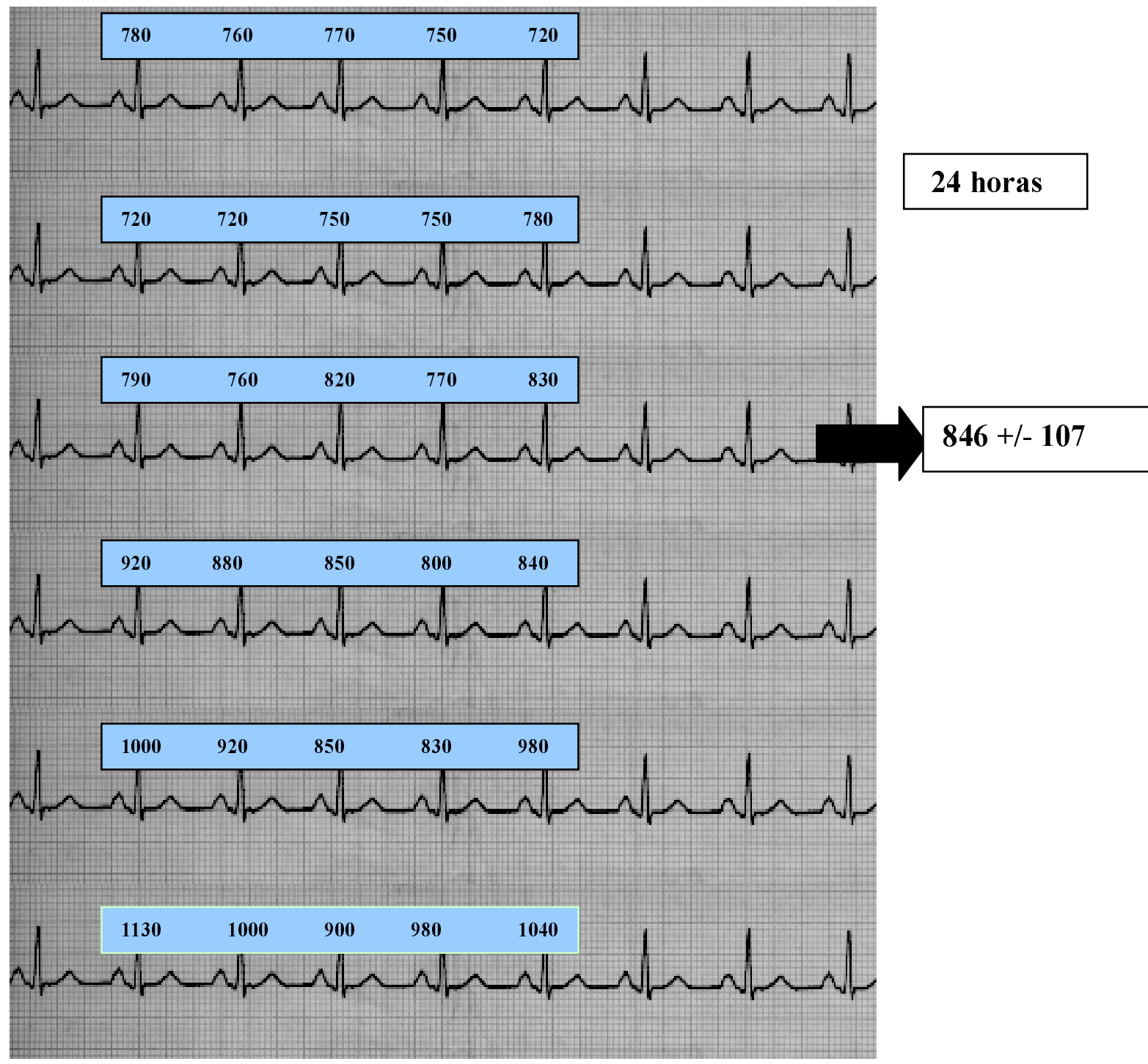

Figura 1. SDNN: desvio-padrão da média de todos os intervalos RR normais, em gravação de 24 horas, expresso em milissegundos (ms). Neste exemplo simbólico e abreviado, a média equivale a $846 \mathrm{~ms}$ e o desviopadrão (ou SDNN) a $107 \mathrm{~ms}$. Em termos simples, desvio-padrão é um modo de representar a dispersão dos valores ao redor da média. Para distribuições Gaussianas, permite inferir que aproximadamente $68 \%$ dos valores situamse entre menos um e mais um desvios-padrão (entre 739 e $953 \mathrm{~s}$, no caso acima), $95 \%$ entre dois desvios-padrão e $99 \%$ entre três desvios-padrão. 


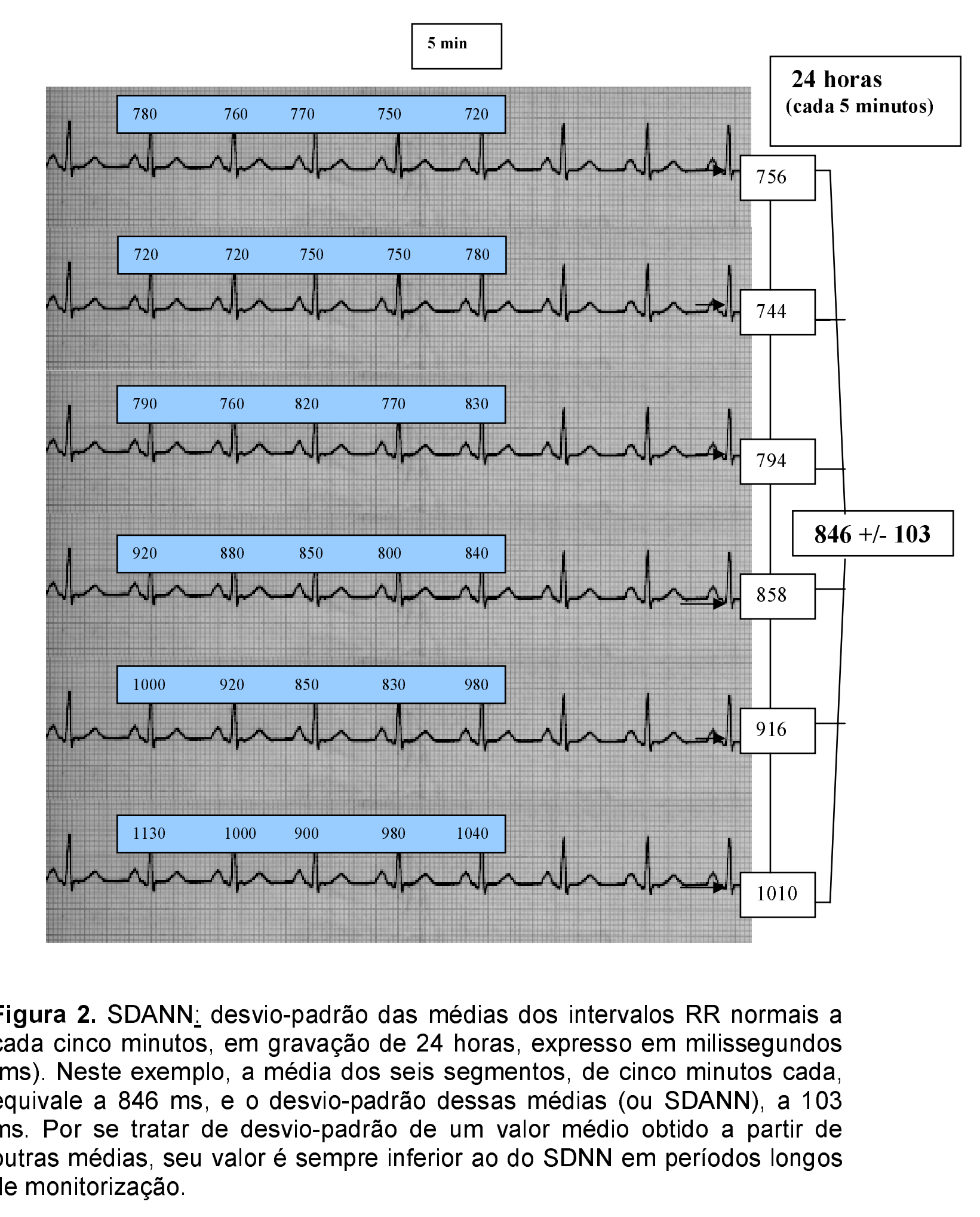


24 horas

(cada 5 minutos)

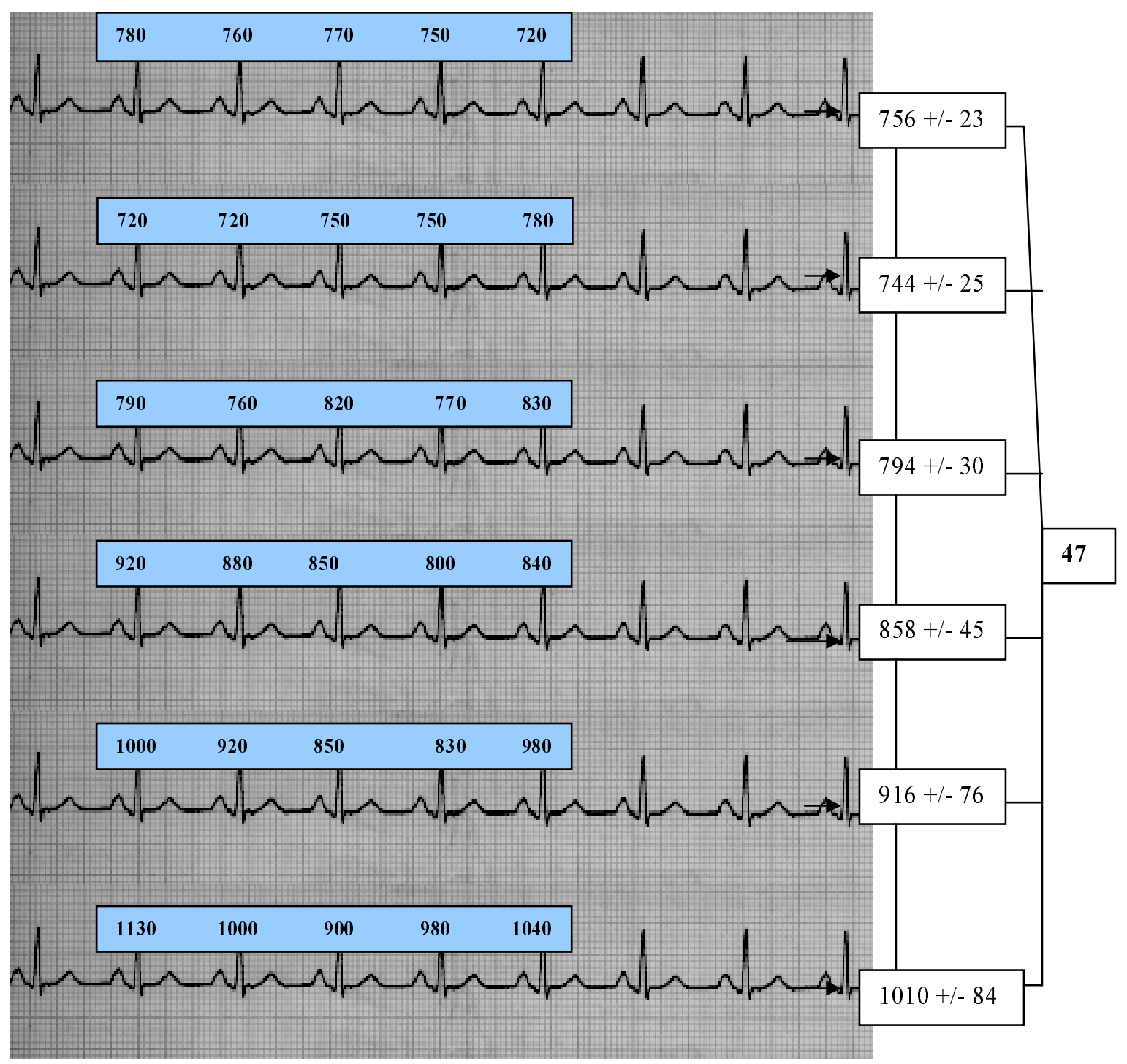

Figura 3. SDNN index: média dos desvios-padrão dos intervalos RR normais a cada cinco minutos, expressa em milissegundos (ms). Neste exemplo, equivale a $47 \mathrm{~ms}$. Seu valor geralmente é inferior ao do SDNN e SDANN. 


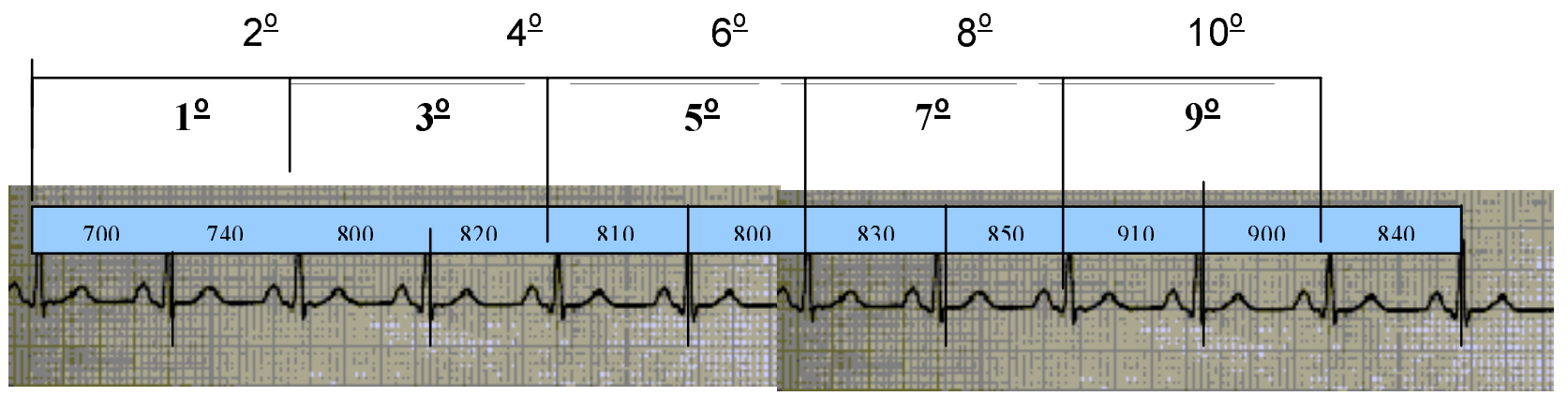

Figura 4. pNN50: percentagem de intervalos RR adjacentes com diferença de duração maior que 50 milissegundos (ms). Neste exemplo equivale a $30 \%$, ou seja, dos 10 intervalos RR adjacentes, apenas três (o $2^{\circ}$, o $8^{\circ}$ e 0 $10^{\circ}$ ) apresentam diferença de duração superior a $50 \mathrm{~ms}$.

$\sqrt{\frac{\left(40^{2}\right)+\left(60^{2}\right)+\left(20^{2}\right)+\left(-10^{2}\right)+(-102)+\left(30^{2}\right)+\left(20^{2}\right)+\left(60^{2}\right)+\left(-10^{2}\right)+\left(-60^{2}\right)}{10}}=\sqrt{1440}=37,94$

Figura 5. rMSSD: raiz quadrada da média do quadrado das diferenças entre intervalos RR normais adjacentes, expressa em milissegundos (ms). Neste exemplo simplificado, é calculada por meio desta fórmula específica ${ }^{1,2}$. 


\subsection{Análise da variabilidade da freqüência cardíaca no domínio do tempo por meio de índices geométricos}

A grande dificuldade para o emprego de métodos estatísticos (SDNN, SDANN, rMSSD etc.), é a obtenção de registros eletrocardiográficos de boa qualidade para a análise dos intervalos RR normais. Como em períodos prolongados de monitorização eletrocardiográfica, esses registros dificilmente são obtidos, os sistemas comerciais de monitorização eletrocardiográfica, dispõem de mecanismos de filtragem que excluem os intervalos RR normais com duração maior ou menor que $20-30 \%$ em relação aos intervalos vizinhos, diminuindo assim a possibilidade de inclusão de artefatos ou de intervalos erroneamente classificados na analise estatística. Contorna-se este problema também pelo emprego de métodos geométricos que utilizam a seqüência de intervalos RR normais para construir uma forma geométrica, habitualmente através do histograma de densidade ou de um mapa de coordenadas cartesianas, deles extraindo os índices de análise da VFC.

O índice geométrico mais utilizado é o índice triangular, calculado a partir da construção do histograma dos intervalos RR normais, o qual mostra no eixo horizontal todos os possíveis valores dos intervalos RR, obtidos geralmente com uma freqüência de amostragem de $128 \mathrm{~Hz}$ - equivalente a uma diferença de aproximadamente $8 \mathrm{~ms}(1 / 128)$ entre os valores medidos —e, no eixo vertical, a freqüência com que cada um deles ocorreu. 
Considerando-se que a união dos pontos das colunas do histograma forma uma figura semelhante a um triângulo e que a largura da base desse triângulo expressa a variabilidade dos intervalos RR, um índice de VFC pode ser facilmente calculado a partir de regras geométricas simples, levando-se em conta a área e a altura do triângulo.

Apesar da sua utilidade, particularmente em relação a registros eletrocardiográficos imperfeitos, e da sua validação como importante preditor de morte súbita após o infarto do miocárdio (valores inferiores a 20-15), o índice triangular não é muito utilizado, pois são poucos os sistemas de monitorização eletrocardiográfica que oferecem o software para a sua análise.

A VFC pode também ser avaliada por meio da "plotagem" de Lorenz (plotagem de Poincaré ou mapa de retorno), que nada mais é do que um mapa de pontos em coordenadas cartesianas, onde cada ponto é representado, no eixo horizontal $X$ (abscissa), pelo intervalo RR normal precedente e, no eixo vertical $Y$ (ordenada), pelo intervalo RR seguinte.

A plotagem de um número suficiente de intervalos $R R$ em função do intervalo RR precedente, durante períodos longos de monitorização eletrocardiográfica, possibilita a criação de alguns padrões característicos, que são facilmente reconhecidos e que traduzem o comportamento da VFC. Variações fisiológicas do intervalo RR produzem uma plotagem de Lorenz ampla (largura e comprimento), em forma de cometa, ao passo que traçados com redução acentuada da VFC geram padrões mais compactos, semelhantes a um torpedo quanto à sua forma. Além disso, intervalos RR 
medidos de maneira incorreta podem ser facilmente identificados, pois localizam-se bem distantes do envelope central.

A limitação do método é que ele não traz nenhuma informação sobre a densidade da plotagem, o que significa dizer que o número de pares de intervalos RR correspondentes ao mesmo ponto no mapa de coordenadas cartesianas não é conhecido. Desta maneira, é possível que traçados com diferenças significativas na VFC apresentem padrões semelhantes de plotagem de Lorenz.

\subsection{Análise no domínio da freqüência}

A VFC também pode ser avaliada por meio de medidas no domínio da freqüência. Pelo fato de a freqüência cardíaca apresentar flutuações, que em grande parte são periódicas, o registro contínuo do eletrocardiograma durante períodos curtos ou prolongados $(24$ h) e a subseqüente representação gráfica dos intervalos $\mathrm{RR}$ normais em relação ao tempo (tacograma), dão origem a um fenômeno ondulatório complexo, que pode ser decomposto em ondas mais simples, por meio de algoritmos matemáticos, como a transformação rápida de Fourier $^{3}$ ou o modelo autoregressivo $0^{4,5}$ (Figura 6). 


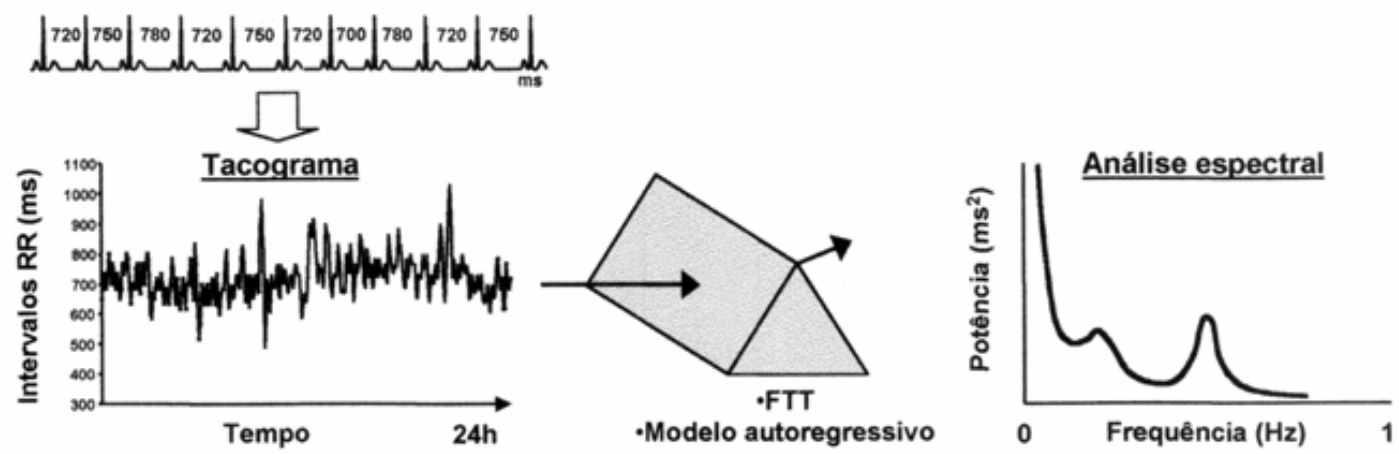

Figura 6. Análise da variabilidade da freqüência cardíaca (VFC) no domínio da freqüência: após a representação gráfica dos intervalos $R R$ em relação ao tempo (tacograma), o sinal eletrocardiográfico é decomposto em componentes de freqüência através da transformação rápida de Fourier $^{3}$ (modelo autoregressivo).

Esse processo, denominado análise espectral, permite decompor 0 sinal eletrocardiográfico oriundo da série temporal (tacograma) em seus diferentes componentes de freqüência, ou seja, nas chamadas bandas de freqüências. Vale ressaltar que freqüência refere-se ao número de vezes que um determinado fenômeno (por exemplo, onda sonora, corrente elétrica ou qualquer forma de onda cíclica) ocorre em relação ao tempo. Habitualmente, a unidade de freqüência utilizada é o Hertz $(\mathrm{Hz})$, que equivale a um ciclo por segundo. As Figuras 7, 8 e 9 representam uma análise hipotética no domínio da freqüência ${ }^{5}$.

No exemplo simplificado, a variabilidade total resulta de três fenômenos ondulatórios distintos: um componente de alta freqüência, equivalente a 0,25 $\mathrm{Hz}(15$ ciclos $/$ minuto $=15$ ciclos $/ 60$ segundos $=0,25$ ciclos $/$ segundo $=0,25$ $\mathrm{Hz}$ ), um componente de baixa freqüência, equivalente a $0,1 \mathrm{~Hz}(6$ ciclos/minuto) e um componente de muito baixa freqüência, de $0,016 \mathrm{~Hz}(1$ ciclo/minuto). 


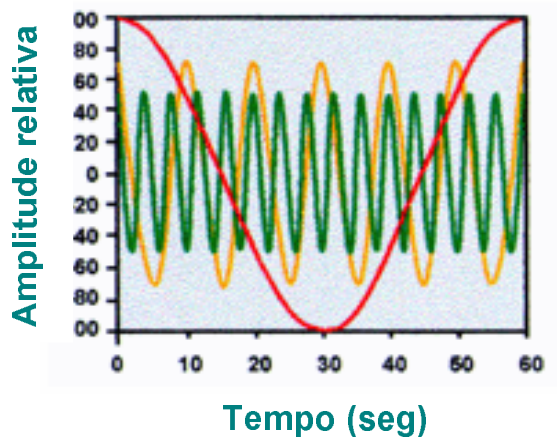

Figura 7. Três ritmos distintos: alta freqüência, em verde (15 ciclos/minuto ou $0,25 \mathrm{~Hz}$ ); baixa freqüência, em laranja (6 ciclos/minuto ou $0,1 \mathrm{~Hz}$ ) e muito baixa freqüência, em vermelho (1 ciclo/minuto ou $0,016 \mathrm{~Hz})$.

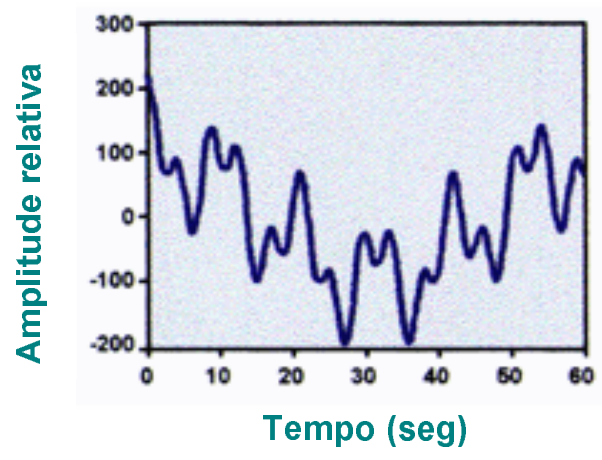

Figura 8. Sinal complexo resultante da combinação dos três fenômenos ondulatórios representados na Figura 7 (equivalente ao tacograma de RR).

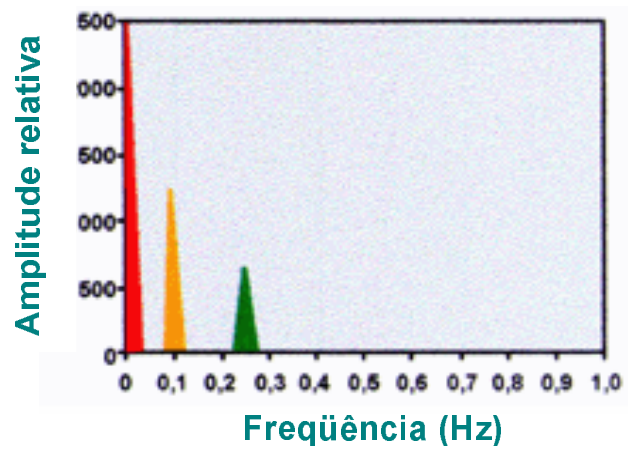

Figura 9. Resultado da análise espectral realizada no sinal representado na Figura 8, com identificação das três faixas de freqüência $(0,016,0,1$ e $0,25 \mathrm{~Hz}$ ) 
A combinação das três ondas senoidais (Figura 8) gera um sinal ondulatório complexo que pode muito bem ser comparado ao sinal que se obtém quando a freqüência cardíaca é expressa em um gráfico temporal (tacograma). A Figura 9 mostra o resultado da análise espectral realizada no sinal representado na Figura 8, ou seja, como uma eventual série temporal determinada por ciclos cardíacos sucessivos pode ser decomposta em seus componentes periódicos e como cada uma das freqüências que compõem a análise espectral pode ser quantificada em sua amplitude (magnitude).

Ademais, o cálculo da área compreendida por cada faixa de freqüência (que é proporcional ao quadrado da amplitude do sinal original e, portanto, neste caso, expresso em milissegundos ao quadrado, ou $\mathrm{ms}^{2}$ ), permite separar a quantidade de variância (potência) atribuída a cada freqüência.

Desta maneira, a participação individual de cada uma das divisões do sistema nervoso autônomo (simpático e parassimpático) em diferentes situações, fisiológicas e patológicas, assim como sua relação com os principais sistemas que interferem com a VFC (sistemas respiratório, vasomotor, termorregulador, da renina-angiotensina e sistema nervoso central), podem ser melhor estudadas. Essa é, por sinal, a principal diferença da análise espectral em relação à análise no domínio do tempo: esta última não consegue, de modo geral, diferenciar quais os ritmos ou oscilações dominantes que conferem à freqüência cardíaca sua variabilidade. 
Em registros longos (24 horas), a potência total se decompõe em quatro bandas distintas:

1) banda de alta freqüência ( $\mathrm{AF}$ ou $\mathrm{HF}$ ), oscilando à freqüência de 0,15 a $0,40 \mathrm{~Hz}$, ou seja, 9-24 ciclos/minuto, e correspondendo às variações da freqüência cardíaca relacionadas com o ciclo respiratório (arritmia sinusal respiratória). São tipicamente moduladas pelo parassimpático ${ }^{6,7}$.

2) banda de baixa freqüência (BF ou LF), 0,04 a $0,15 \mathrm{~Hz}$ ou 2,4 a 9 ciclos/minuto, modulada tanto pelo simpático quanto pelo parassimpático, com predominância simpática em algumas situações específicas, e que reflete as oscilações do sistema barorreceptor ${ }^{8,9}$.

3) banda de muito baixa freqüência (MBF ou VLF), 0,003 a $0,04 \mathrm{~Hz}$ ou 0,2 a 2,4 ciclos/minuto, dependente dos mecanismos termorreguladores e do sistema renina-angiotensina, cuja regulação também é efetuada pelo simpático e parassimpático $0^{8,9}$.

4) banda de ultra-baixa freqüência (UBF ou ULF) $<0,003 \mathrm{~Hz}$ ou $<0,2$ ciclos/minuto, que corresponde à maior parte da variância total, mas cujo significado fisiológico ainda não está bem definido. Essa banda sofre a influência do parassimpático e simpático e, obviamente, não está presente nos registros de curta duração. Parece estar relacionada com o sistema neuroendócrino e ritmos circadianos, dentre outros.

A medida dos componentes espectrais (Figura 10) habitualmente é feita em valores absolutos de potência $\left(\mathrm{ms}^{2}\right)$. Entretanto, os valores de AF e BF podem também ser expressos em unidades normalizadas (nu), representando o valor de cada um destes componentes em relação à 
potência total (PT) menos o componente de MBF. São calculados por meio das seguintes fórmulas: $\mathrm{AF}(\mathrm{nu})=\mathrm{AF} /(\mathrm{PT}-\mathrm{MBF}) \times 100$ e $\mathrm{BF}(\mathrm{nu})=\mathrm{BF} /(\mathrm{PT}-$ MBF) $\times 100$. Com isto, os efeitos das alterações na faixa de MBF sobre as outras duas de freqüências mais rápidas (BF e AF) são minimizados.

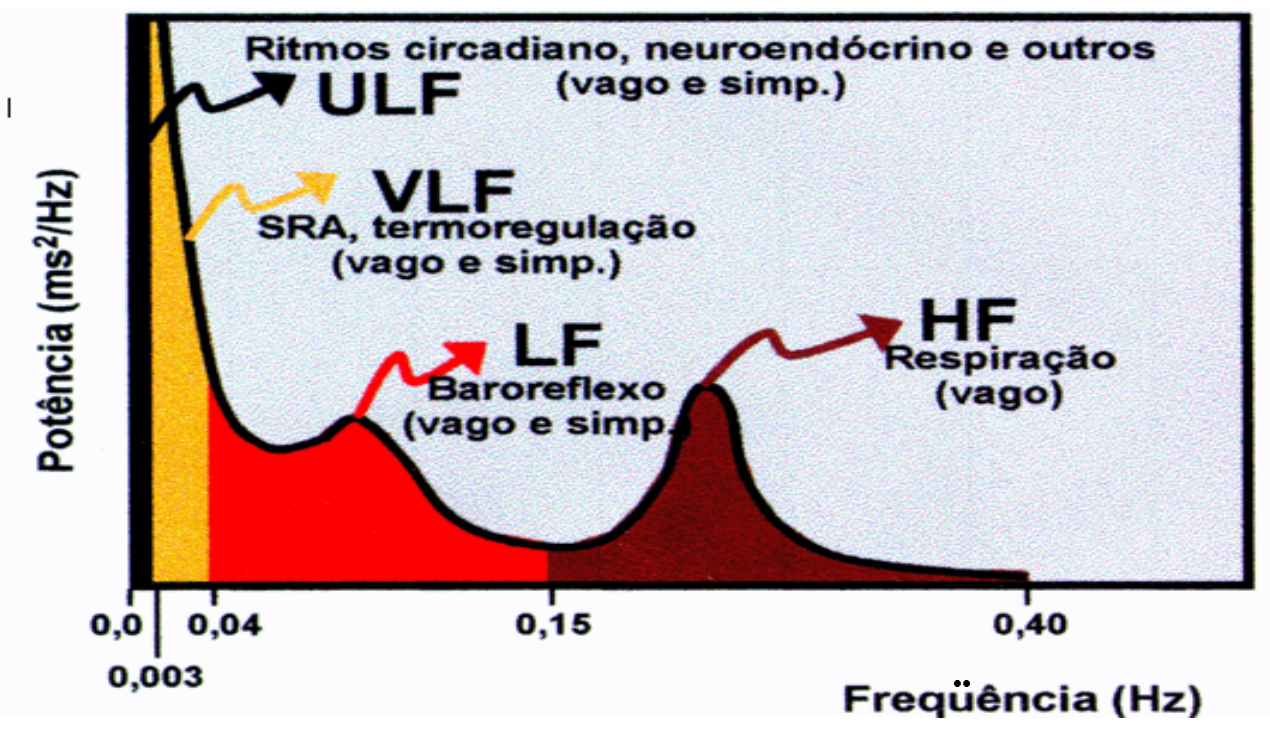

Figura 10. Componentes espectrais do tacograma (bandas de freqüências, nervos eferentes e moduladores fisiológicos)

Outra medida muito utilizada é a relação $\mathrm{LF} / \mathrm{HF}$ ou $\mathrm{BF} / \mathrm{AF}$, a qual pode fornecer informações úteis sobre balanço entre os sistemas simpático e parassimpático. Ressalta-se ainda que, em virtude de os valores absolutos em $\mathrm{ms}^{2}$ apresentarem grande variabilidade e assimetria de distribuição, a sua transformação logarítmica geralmente se faz necessária.

Como as medidas de VFC nos dois domínios são expressões do mesmo fenômeno, algumas correlações entre índices do domínio do tempo e de freqüência têm sido demonstradas. Assim, o SDNN e o índice triangular, ao avaliarem a variabilidade total, apresentam boa correlação com 
a potência total da análise espectral. Por outro lado, o pNN50 e o rMSSD, por considerarem diferenças entre intervalos RR adjacentes, quantificando variações rápidas da freqüência cardíaca, correlacionam-se com 0 componente de alta freqüência do espectro de potência. SDANN com ULF e SDNN index com ambos MBF e BF são outros exemplos de correlações significativas $(r>0,90)$. A Tabela 1 representa os valores normais dos índices de variabilidade da freqüência cardíaca.

Tabela 1. Valores normais dos índices de variabilidade da freqüência cardíaca (VFC).

\begin{tabular}{cccc}
\hline Variável & unidade & $\begin{array}{c}\text { população normal } \\
\text { (média +/- desvio-padrão) }\end{array}$ & $\begin{array}{c}\text { risco de } \\
\text { morte súbita }\end{array}$ \\
SDNN & $\mathrm{ms}$ & $141+/-39$ & $<50$ \\
SDANN & $\mathrm{ms}$ & $127+/-35$ & $<40$ \\
SDNNi & $\mathrm{ms}$ & $54+/-15$ & $<20$ \\
PNN50 & $\mathrm{ms}$ & $9+/-7$ & $<0,75$ \\
RMSSD & $\%$ & $27+/-12$ & $<15$ \\
Poder total & $\mathrm{ms}^{2}$ & $3466+/-1018$ & \\
BF & $\mathrm{ms}^{2}$ & $1.170+/-416$ & \\
AF & $\mathrm{ms}^{2}$ & $975+/-203$ & \\
B/A & & $1,5-2,0$ & \\
\hline
\end{tabular}

\subsection{Referências bibliográficas do Apêndice}

1. Illes RW, Silverman NA, Krukenkamp IB, del Nido PJ, Levitsky S. Amelioration of postischemic stunning by deferoxamine-blood cardioplegia. Circulation. 1989;80(5 Pt 2):III30-5.

2. Huikuri HV, Makikallio TH. Heart rate variability in ischemic heart disease. Auton Neurosci. 2001;90(1-2):95-101.

3. Pichot V, Gaspoz JM, Molliex S, Antoniadis A, Busso T, Roche F, et al. Wavelet transform to quantify heart rate variability and to assess its instantaneous changes. J Appl Physiol. 1999;86(3):1081-91.

4. Kusuoka H, Koretsune $\mathrm{Y}$, Chacko VP, Weisfeldt ML, Marban E. Excitationcontraction coupling in postischemic myocardium. Does failure of 
activator Ca2+ transients underlie stunning? Circ Res. 1990;66(5):126876.

5. Pincus SM. Assessing serial irregularity and its implications for health. Ann N Y Acad Sci. 2001;954:145-67.

6. Braunwald E, Kloner RA. The stunned myocardium: prolonged, postischemic ventricular dysfunction. Circulation. 1982;66(6):1146-9.

7. Pomeranz B, Macaulay RJ, Caudill MA, Kutz I, Adam D, Gordon D, et al. Assessment of autonomic function in humans by heart rate spectral analysis. Am J Physiol. 1985;248(1 Pt 2):H151-3.

8. Ambrosio G, Jacobus WE, Bergman CA, Weisman HF, Becker LC. Preserved high energy phosphate metabolic reserve in globally "stunned" hearts despite reduction of basal ATP content and contractility. J Mol Cell Cardiol. 1987;19(10):953-64. 